Laser Doppler Velocimeter Studies of the Pipeflow Produced by a Generic Header

T. T. Yeh and G. E. Mattingly

QC 
he National Institute of Standards and Technology was established in 1988 by Congress to "assist industry in

the development of technology ... needed to improve product quality, to modernize manufacturing processes, to ensure product reliability ... and to facilitate rapid commercialization ... of products based on new scientific discoveries."

NIST, originally founded as the National Bureau of Standards in 1901, works to strengthen U.S. industry's competitiveness; advance science and engineering; and improve public health, safety, and the environment. One of the agency's basic functions is to develop, maintain, and retain custody of the national standards of measurement, and provide the means and methods for comparing standards used in science, engineening, manufacturing, commerce, industry, and education with the standards adopted or recognized by the Federal Government.

As an agency of the U.S. Commerce Department's Technology Administration, NIST conducts basic and applied research in the physical sciences and engineering, and develops measurement techniques, test methods, standards, and related services. The Institute does generic and precompetitive work on new and advanced technologies. NIST's research facilities are located at Gaithersburg, MD 20899, and at Boulder, CO 80303 . Major technical operating units and their principal activities are listed below. For more information contact the Public Inquiries Desk, 301-975-3058.

\section{Office of the Director}

- Advanced Technology Program

- Quality Programs

- International and Academic Affairs

\section{Technology Services}

- Manufacturing Extension Partnership

- Standards Services

- Technology Commercialization

- Measurement Services

- Technology Evaluation and Assessment

- Information Services

\section{Materials Science and Engineering Laboratory \\ - Intelligent Processing of Materials \\ - Ceramics \\ - Materials Reliability \\ - Polymers \\ - Metallurgy \\ - Reactor Radiation}

Chemical Science and Technology Laboratory

- Biotechnology

- Chemical Kinetics and Thermodynamics

- Analytical Chemical Research

- Process Measurements ${ }^{2}$

- Surface and Microanalysis Science

- Thermophysics ${ }^{2}$

\section{Physics Laboratory}

- Electron and Optical Physics

- Atomic Physics

- Molecular Physics

- Radiometric Physics

- Quantum Metrology

- Ionizing Radiation

- Time and Frequency'

- Quantum Physics'
Manufacturing Engineering Laboratory

- Precision Engineering

- Automated Production Technology

- Intelligent Systems

- Manufacturing Systems Integration

- Fabrication Technology

Electronics and Electrical Engineering Laboratory

- Microelectronics

- Law Enforcement Standards

- Electricity

- Semiconductor Electronics

- Electromagnetic Fields'

- Electromagnetic Technology'

- Optoelectronics ${ }^{1}$

Building and Fire Research Laboratory

- Structures

- Building Materials

- Building Environment

- Fire Safety

- Fire Science

Computer Systems Laboratory

- Office of Enterprise Integration

- Information Systems Engineering

- Systems and Software Technology

- Computer Security

- Systems and Network Architecture

- Advanced Systems

Computing and Applied Mathematics Laboratory

- Applied and Computational Mathematics ${ }^{2}$

- Statistical Engineering ${ }^{2}$

- Scientific Computing Environments ${ }^{2}$

- Computer Services

- Computer Systems and Communications ${ }^{2}$

- Information Systems 


\section{NIST Technical Note 1409}

\section{Laser Doppler Velocimeter Studies of the Pipeflow Produced by a Generic Header}

T. T. Yeh and G. E. Mattingly

Chemical Science and Technology Laboratory National Institute of Standards and Technology

Gaithersburg, MD 20899-0001

April 1995

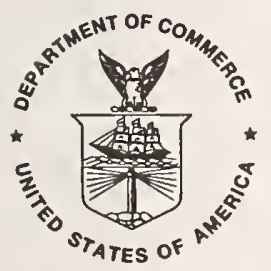

U.S. Department of Commerce Ronald H. Brown, Secretary

Technology Administration

Mary L. Good, Under Secretary for Technology

National Institute of Standards and Technology Arati Prabhakar, Director 
National Institute of Standards and Technology

Technical Note 1409

Natl. Inst. Stand. Technol.

Tech. Note 1409

79 pages (April 1995)

CODEN: NTNOEF
U.S. Government Printing Office

Washington: 1995
For sale by the Superintendent of Documents

U.S. Government Printing Office Washington, DC 20402 


\section{PREFACE}

The research results reported in this document were produced with the support of a National Institute of Standards and Technology (NIST) initiated industrygovernment consortium. This is an established cooperative research effort on generic technical issues to produce industry-needed flow metering improvements. In this mode of operation, there is a high degree of interaction between the representatives of the consortium member companies and the NIST researchers. These interactions include: (1) the planning of the specific focus of the NIST research efforts, (2) the discussions and analyses of the results obtained, and (3) the conclusions drawn for the particular phase of the work. For this reason, it is pertinent to acknowledge both the support given to this phase of the research program and the technical contributions made by the representatives of the consortium members.

The current consortium as of October 1993 is, alphabetically:

1. British Columbia Hydro \& Power Auth. (Canada)

2. Chevron Oil

3. Consolidated Edison

4. Controlotron

5. Dow Chemical Co.

6. E.I. Dupont de Nemours

7. Fisher Precision Systems, Inc.

8. Ford Motor Co.

9. Gas Unie (The Netherlands)

10. Inst. of Paper Science \& Tech.

11. Instrument Testing Assoc.

12. Ketema-McCrometer

13. Ketema-Schutte and Koerting

14. Kimmon Mfg. Ltd. (Japan)

15. NRTC (NOVACOR Res. Tech. Corp.)

16. Pacific Gas \& Electric Co.

17. Rosemount 


\section{TABLE OF CONTENTS}

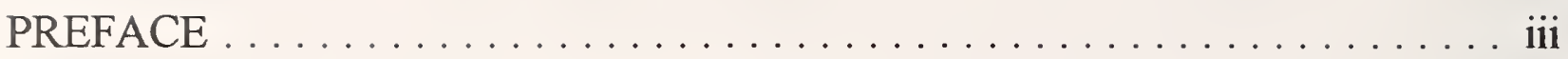

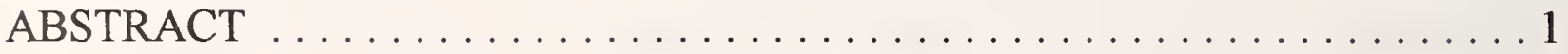

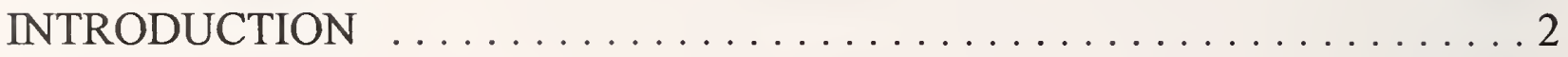

TEST CONFIGURATION: A Generic Header . . . . . . . . . . . . . . . 4

EXPERIMENTAL RESULTS $\ldots \ldots \ldots \ldots \ldots \ldots \ldots \ldots \ldots$

A) LDV Velocity Measurements $\ldots \ldots \ldots \ldots \ldots \ldots \ldots \ldots \ldots \ldots$

1. Downstream of the Header ........................ 6

2. Velocity Comparisons Among Different Configurations .......... 8

3. Velocity Downstream of the Header and 19-Tube Tube Bundle ..... 9

B) Characteristics of the Mean Velocity Profile $\ldots \ldots \ldots \ldots \ldots \ldots 11$

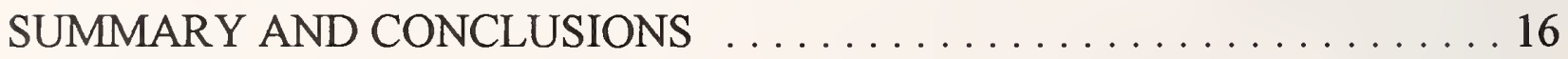

REFERENCES ................................ 17

FIGURES . . . . . . . . . . . . . . . . . . . . . . . 19-49

APPENDIX A .............................. A1-A12

APPENDIX B ............................... B1-B12 


\title{
Laser Doppler Velocimeter Studies of the Pipeflow Produced by A Generic Header
}

\author{
T.T. Yeh \\ G.E. Mattingly \\ Fluid Flow Group \\ Process Measurements Division \\ Chemical Science and Technology Laboratory \\ National Institute of Standards and Technology \\ Gaithersburg, Maryland 20899
}

\section{$\underline{\text { ABSTRACT }}$}

This report presents recent results obtained in a consortium-sponsored research program on flowmeter installation effects being conducted at NIST. The piping element tested and reported here is a generic header which has a specific arrangement of one inlet and two outlets. Laser Doppler velocimetry (LDV) velocity measurements are reported for the pipeflows produced downstream of the header with and without a conventional 19-tube concentric tube bundle flow conditioner.

The results indicate that the secondary flow produced by the generic header is very similar to that produced by the closely coupled double elbows out-of-plane piping configuration. The axial velocities are slower than the ideal flow near the pipe center and higher near the walls. Transverse velocity distributions show a very strong swirl eddy flow pattern produced by this header. This swirl eddy is relatively stable and organized and its dissipation is slower than that observed for the double elbows out-ofplane. The 19-tube tube bundle is quite effective in reducing the transverse velocities associated with the energetic, swirl flow from this header.

Several profile indexes are presented to characterize the swirl intensity of the header flow and the shape of the velocity profiles. These indexes can also be used to develop criteria for improving flow meter performance in the outlet piping from this header. 


\section{INTRODUCTION}

In many cases, flowmeters are being retrofitted into fluid systems that were not designed for them. This invariably means the meters are being inserted into "nonideal" installation conditions where the upstream piping conditions produce pipeflow distributions that differ from those ideal installation conditions used to design the meter. "Ideal" installation conditions are where the meter location is preceded by sufficiently long, straight lengths of constant diameter piping that the meter's performance is not affected when the meter is installed further downstream.

The prevalent concern in the flow measurement community is for increased metering accuracy levels. These levels are desired for existing meter systems - either by upgrading the flow conditions at meter's entrance or by replacing the device's auxiliary components so that accuracy levels are increased. Various flow conditioning devices are frequently recommended for improving flowmeter performance where installation conditions are not ideal. However, the pipeflows generated by these devices have to be considered with respect to the type and design of flowmeter installed downstream of the specific piping configuration. It has been shown previously[1-7] $]^{1}$ that certain flow conditioner installations can produce serious deviations from the performance of specific meters in ideal installation conditions.

The NIST industry-government consortium research program on flowmeter installation effects is designed to help to improve fluid metering performance when installation conditions are not ideal. This program has the main objective of producing a basic understanding of the flow phenomena that are produced in prevalently encountered, nonideal installation conditions and to quantify these phenomena relative to the pipe flow in ideal installation conditions. The experimental program is based upon the measurements of pipe flows from selected piping configurations using laser Doppler velocimetry (LDV). The program uses basic experimental research tools available to the fluid dynamicist to measure, understand, and parameterize the salient features of the pipeflow phenomena. The successive phase of the program is to evaluate quantitatively how these phenomena influence selected types of fluid meters and how to use these evaluations to produce satisfactory flow measurements.

Square bracketed integers refer to references given in the reference section on page 17. 
This research effort has also included experimental studies of the flow into and out of several tube bundle flow conditioners. These results have produced detailed descriptions of the effects these devices have on different pipe flows. The performances of both orifice and turbine flowmeters have also been determined for different installation locations downstream of selected pipeline elements, both without and with tube bundle flow conditioners. The results show that while the conventional 19-tube tube bundle successfully removes swirl from these pipeflows it apparently produces other effects in the streamwise velocity profiles that cause several different types of perturbations both on orifice and turbine meters performance [1].

Previous phases of this research program have produced LDV measurements for a single elbow, double elbows-out-of-plane, the tee-used-as-an-elbow, the concentric reducer, and the $45^{\circ}$ elbow. Conventional, long-radius elbows are used in all of these studies; the radius of the centerline through these elbows is 1.5 pipe diameters. Detailed results of these studies can be found in [1-5]; summary descriptions of these studies are given in [6-8].

In all these studies, the working fluid is water and the piping is $52.5 \mathrm{~mm}$ (2 in diameter), smooth, stainless steel. Water temperature is controlled using a heat exchanger to maintain a set temperature of $21 \pm 0.5{ }^{\circ} \mathrm{C}$. The pertinent parameters considered important in the experiments are Reynolds number, and pipe relative roughness. The relative roughness of this pipe has been measured with a profilometer to indicate a value of $0.006 \%$ based on interior pipe diameter. The diametral Reynolds number in the test section was $10^{5}$ using bulk average velocity.

This report presents the recent results obtained in the flowmeter installation effects program. The primary piping element tested and reported is a generic header configuration. Header or manifold configurations are commonly found in various, industrial plants. One of the most common reasons to use header configurations is to improve the overall rangeability of flow rate measurements by using headers with multi-outlet meter stations. Other purposes of header configurations in multi-run meter pipings are to reduce capital costs in making flow rate measurements. Headers or flow manifolds are also used to rearrange the flow loop direction or to serve as a settling chamber in designing flow loops. Despite the wide spread industrial use of headers, there is very little information available regarding the flow patterns emerging from headers or the effects of these flows on meter performance. Recently, flow 
disturbances caused by special headers and their effects on metering performance have been the subjects of various investigations $[9,10]$. However, many of the configurations used in these investigations are the combinations of the specific header and various upstream piping elements such as single elbow, reducer, riser, etc. It seems evident that the flow upstream entering a pipe element such as an elbow, reducer, etc. or a header may greatly influence the flow pattern exiting the element or header. Rather than test the combination of a header with some complicated or unknown upstream/downstream piping elements, the objective of the present study is to study the flow pattern produced solely by the generic header. To do this, the piping configuration upstream of the header was installed to insure that the entering pipe flow is an otherwise, fully developed, equilibrated one.

\section{TEST CONFIGURATION: A Generic Header}

Figure 1 shows a sketch of the generic header geometry, that is denoted H342. This generic header consists of one inlet and two outlets having the same pipe size. The direction of the inlet pipe is normal both to the header and to the outlet pipes. The diameters of the inlet, the header, and outlet pipes are $77 \mathrm{~mm}$ (3 in), $103 \mathrm{~mm}$ (4 in), and $52 \mathrm{~mm}$ ( $2 \mathrm{in}$ ), respectively. H342 denotes the relative diameter ratios of $3: 4: 2$. In the test, the header is installed vertically and the upper outlet (the one near the inlet) is outlet \#1 and the lower outlet (the one far from the inlet) is outlet \#2. Other parameters needed to be specified for this header test are the flow rates in each outlet and the outlet selected for the velocity measurement. To identify a specific test and flow condition, the complete designation will be H342-F1/F2-n. Where F1/F2 gives the ratio of the flow rates flowing through the outlet \#1 and outlet \#2. The last digit " $n$ " is used to denote the outlet for the test. In the test described in this report, F1/F2=100/0 and $n=1$. That is, all flow is going through outlet $\# 1$ and no flow exits outlet $\# 2$ and tests are performed at the outlet \#1. The test results include flow measurements with and without the conventional 19-tube concentric tube bundle flow conditioner. Although other flow divisions can be arranged, it was thought that, in this condition, the effect of the header on the flow downstream will be most significant, i.e., the worst case for downstream meter performance, due to the largest possible flow rate in the outlet pipe. Tests for other flow divisions are in progress.

Figure 2 shows the piping arrangement and the coordinate system used in the test. A right handed coordinate system is used which has the origin (i.e., $\mathrm{X}=\mathrm{Y}=\mathrm{Z}=0$ ) in the 
entrance plane of the outlet pipe (the exit plane of the header at the header tank diameter) and at the pipe centerline. The positive $\mathrm{Z}$ direction is downstream; the positive $\mathrm{Y}$ direction is upward; the $\mathrm{X}$ direction is, therefore, to the right looking upstream. The mean velocities in the $X, Y$, and $Z$ directions are $U, V$, and $W$, respectively; and the corresponding turbulence velocities are $u^{\prime}, v^{\prime}$, and w', respectively. In this study, only two velocity components, the axial velocity, $W$ and the vertical velocity, $\mathrm{V}$ are measured. The horizontal component, $\mathrm{U}$ is not measured. In what follows, nondimensionalized quantities will be used to describe and to plot results. Lengths and velocities are normalized using the pipe diameter, D and average-bulk velocity, $W_{b}$, respectively.

To study the flow effects produced by the generic header configuration, efforts have been made to ensure a fully developed pipe flow that is free from other disturbances enters the header configuration. The upstream piping was arranged so that over 45 pipe diameters of straight, constant diameter piping preceded the header. This inlet pipe section was a single piece of standard piping to assure a concentric constant diameter along the entire section without any misalignment that could result from joints. Upstream of this straight length of piping, the inlet flow was arranged to have a special, radial inlet so that no axial vorticity was produced by this entrance condition. Although the pipeflow entering the header was not directly measured, all LDV measurements from previous phases of our program made downstream from a single elbow showed that the effects of the elbow were negligibly small after about 30 pipe diameters for Reynolds number $10^{5}$. Since in this $75 \mathrm{~mm}$ (3 in) diameter pipe, the Reynolds number was 66000 (corresponding to $10^{5}$ in the $52 \mathrm{~mm}$ pipe), the pipeflow entering the header was assumed to be fully developed. With these reference profiles entering the header, the exiting pipeflows can be interpreted, for this conventional piping configuration, to be due solely to this generic header.

A conventional, 19 tube, concentric tube bundle flow conditioner was also tested with the generic header. The results for the combined configuration are presented below. In this report only velocity measurement results will be presented. The results for the flowmeter performance downstream of this generic header configuration will be presented separately [11]. 


\section{EXPERIMENTAL RESULTS}

\section{A) LDV Velocity Measurements}

\section{Downstream of the Header}

The LDV results obtained downstream from the generic header piping configuration are presented in tabular format in Appendix A, Mean and Turbulence Velocity Profiles for Header H342-100/0-1.

Figure 3 shows LDV measurements of the mean axial velocity profiles, $W / W_{b}$, versus horizontal radial position, $X / D$, at successive downstream locations, $Z / D$, from the header for $\mathrm{Re}=10^{5}$. The solid curve is the fully developed, equilibrated pipeflow distribution put forth by Bogue and Metzner [12]. The data clearly indicate that the header significantly modifies the axial velocity profile as the fluid passes through the header. These axial velocity profiles are symmetric about the pipe centerline along the horizontal diameter. In the region near the pipe center, the flow is slower than the fully developed pipe flow, while near the pipe walls the flow velocities exceed the fully developed pipe flow. The centerline deviation from the ideal profile at the most upstream location of $Z / D=3.35$ is about $22 \%$ of the bulk velocity. Near the wall the deviations are about $15 \%$ of the bulk velocity in excess of ideal profile values. These deviations decrease with downstream distance. However, even for the measured location of $Z / D=30$, the profile is still very uniform over about $80 \%$ of the center core of the pipeflow. At this location, the centerline velocity is about $12 \%$ of the bulk velocity below the ideal velocity.

Figure 4 presents the mean axial velocity profile, $W / W_{b}$, versus the vertical radial position, $\mathrm{Y} / \mathrm{D}$, at successive downstream locations, $\mathrm{Z} / \mathrm{D}$, from the header for $\operatorname{Re}=10^{5}$. Again, the solid curve is the fully developed, equilibrated pipeflow distribution of Bogue and Metzner. These axial velocity profiles are also symmetric about the pipe centerline along the vertical diameter. With downstream distance, these deviations decrease so that at $Z / D=30$, the central core flow is only about $10 \%$ of the bulk velocity below the ideal values. At this location, the profile is considerably more smoothly varying than the fully developed distribution. Both figures 3 and 4 indicate that, for these conditions, these axial mean velocity profiles do not conform well to the fully developed distribution even 30 diameters from the header. 
Figure 5 presents vertical mean velocity profiles, $\mathrm{V} / \mathrm{W}_{\mathrm{b}}$, versus horizontal radial position, $\mathrm{X} / \mathrm{D}$ at successive downstream positions from the header for $\mathrm{Re}=10^{5}$. Here, the ideal, fully developed pipeflow is zero as shown by the solid line. The velocity profiles indicate that this pipe flow has a severe, clock-wise swirl. These data indicate that the swirl distribution is essentially that of a rigid body rotation. The peaks in the vertical velocity component are located near the pipe walls. Due to the nonslip condition, the velocity at the walls is zero. However, the velocity at or near the wall was not measured. It has been deemed not worthwhile to make the LDV measurements in the sub-layers of the flow near the wall owing both to the difficulty and to the nature of this flow. Inside the sub-layer, the tangential velocity gradient should be very large for this highly swirled flow field. At the location nearest the header, $Z / D=3.35$, the upward and downward vertical velocities near the pipe walls are about $22 \%$ and $-35 \%$ of the bulk velocity, respectively. With downstream distance these deviations diminish slightly so that at $Z / D=30.0$, the most distant location measured, the peak vertical velocity is about $20 \%$ of the bulk velocity upward near the - $x$ side wall and is about $-18 \%$ downward near the wall at the $+x$ axis. This single eddy flow is very similar to that from the closely-coupled double elbows out-of-plane configuration $[3,4,9]$. The major difference between these flows and those from the double elbows out-of-plane is that there is little rotation present in the exiting flow at the center of the pipe for the double elbows out-of-plane, while the header flow shows essentially solid body rotation even at the nearest measured location. With increased downstream distance, the swirl produced by the double elbows out-of-plane approaches solid body rotation except near the pipe walls where the usual wall boundary condition appears. The decay of the swirl from the header seems to be slower than that observed from the double elbows out-ofplane configuration.

Figure 6 shows the vertical mean velocity profiles versus the vertical radial position at successive downstream locations from the header for $\mathrm{Re}=10^{5}$. Again, the solid line shows that the ideal flow distribution is zero everywhere. These profiles indicate that all vertical velocities are small, being slightly downward nearer the header at $Z / D=3.35$ and slightly upward further from the header at $Z / D=30.0$.

Figures 7 and 8 present, respectively, the distributions for the root-mean-square (r.m.s.) values of the axial component of the turbulent velocity, $w^{\prime} / W_{b}$, versus the horizontal and vertical radial positions from the pipe centerline for $\mathrm{Re}=10^{\mathrm{s}}$. Figures 9 and 10 present profiles of the r.m.s. values of the vertical component of the turbulent velocity, $v^{\prime} / W_{b}$ 
for $\operatorname{Re}=10^{5}$. These measurements for different downstream distances from the header are plotted with the results measured by Laufer as shown via the solid curve for $\operatorname{Re}=41000$ (see [13]).

These results indicate that the turbulent intensity profiles are all higher than the ideal values (Laufer's results) and are symmetric about the pipe centerline, along either horizontal or vertical diameters. The distributions of the axial turbulence intensities are fairly smoothly varying across the pipe cross section, while there are high levels of turbulence in the vertical component of the turbulent velocity at the pipe centerline. Close to the header exit, at $Z / D=3.35$, the axial component of the turbulent velocity is about $13 \%$ of the bulk velocity across most of the pipe cross section, as shown in figures 7 and 8 , and the vertical component of the turbulent velocity is about $14 \%$ of the bulk velocity at pipe centerline as shown in figures 9 and 10 . With downstream distance, these turbulence levels decrease and approach the ideal values of Laufer. However, even at $\mathrm{Z} / \mathrm{D}=30.0$ all the turbulence intensities are still larger than, and the profiles are more uniform than, Laufer's data. Both the mean and turbulence velocity profiles indicate that the pipe flow in this outlet pipe is still in developing stages $30 \mathrm{D}$ downstream from the header.

\section{Velocity Comparisons Among Different Configurations}

Since the header arrangement and test conditions are very similar to the double elbow configuration studied previously, it is interesting to compare the respective exiting velocity profiles. In this section the velocity profiles, produced by the generic header, denoted according to the convention described above as H342-100/0-1 are compared with those from two double elbows out-of-plane configurations: a) the closely coupled double elbows, denoted by $2 \mathrm{~L} 0$, and $\mathrm{b}$ ) an arrangement having $2.4 \mathrm{D}$ of straight pipe between the elbows denoted 2L2.4. The data are compared at similar locations; one near the outlet at $Z / D=3$ and the other further downstream at about $Z / D=30$.

Figure 11 shows comparisons of the axial velocity profiles along the horizontal diameter at two axial locations downstream from the different piping configurations for $\mathrm{Re}=10^{5}$. Figure 12 shows a similar comparison along the vertical diameter. In both figures, the upper figure is for $Z / D=3$, approximately, and the lower figure is essentially for $Z / D=30$. The solid curve is the fully developed, equilibrated pipeflow by Bogue and Metzner [12]. At the near location, all three flows are very different 
from the ideal velocity profile with the header flow more uniform across the entire cross section of the pipe and the double elbow flows having maxima flows nearer the wall. These seem to indicate that the header configuration has provided more time for the swirl to be established in the header and thus the swirl is more completely established as it leaves the header, while the time for the fluid to pass through the double elbows is relatively short and thus the exiting flows are still developing. Although there are some differences in the quantitative details of the profiles, all three configurations basically produce slower axial mean velocities near the pipe center. Further downstream as shown in the lower figures, the header flow at $Z / D=30 \mathrm{D}$ is still very different from the ideal profile while the flow for the $2.4 \mathrm{D}$ spaced double elbows is fairly close to the ideal profile. This seems to indicate that the header flow swirl is more coherent and stable and thus its decay is much slower.

Figures 13 and 14 show comparisons of the vertical velocity profiles at two axial locations downstream from the three piping configurations for $\mathrm{Re}=10^{5}$. In figure 13 the results along the diameter parallel to $X$, the direction of the inlet flow, are presented, while in figure 14 the measurements along Y, the diameter normal to the inlet flow direction are shown. Also, the upper plot in these figures is for locations near $\mathrm{Z} / \mathrm{D}=3$ while the bottom figure is for $\mathrm{Z} / \mathrm{D}$ near 30 . Here, the fully developed pipeflow is zero as indicated by the solid line. The data indicate again that the three configurations produce qualitatively similar vertical velocity profiles. The radial velocities, as shown in figure 14 , are very small for all three cases. The swirl velocities, as shown in figure 13 , are significant for all three cases. The header flow seems to produce the most energetic, stable swirl among the three configurations. Near the header exit, the flow is essentially solid body rotation, while the two double elbows out-of-plane configurations produce very little swirl near the center of the pipe. Further downstream, as shown on the lower figure, all three flows exhibit essentially solid body rotation and the intensity of the swirl for the header flow is the strongest among the three cases.

\section{Velocity Downstream of the Header and 19-Tube Tube Bundle}

In this section, the results of the velocity measurement obtained in the pipe downstream of the header and the 19-tube tube bundle are presented. The LDV results for the generic header configuration with a 19-tube tube bundle downstream of the header are presented, in detail, in tabular format in Appendix B, Mean and Turbulence Velocity 
Profiles for Header H342-100/0-1 and a 19-Tube Tube Bundle.

Figure 15 shows the sketch of the header configuration and the tube bundle installation location. The tube bundle is installed at a fixed location relative to the header. The upstream and downstream ends of the tube bundle are at $Z=4.26 \mathrm{D}$ and $6.2 \mathrm{D}$, respectively. The distance downstream from the exit plane of the tube bundle flow conditioner is denoted by the length, $\mathrm{C}$, in diameters. The arrangement of the tube bundle is also shown in the figure 15. The tube bundle used is the conventional 19 tube concentric design. The unit is a geometrically scaled version of the prevalent unit used in large pipe sizes according to orifice meter technology (see [14]). It is comprised of tubes having a diameter of $9.5 \mathrm{~mm}$, wall thickness of $0.4 \mathrm{~mm}$, and tube length of 101.6 $\mathrm{mm}$ (approximately 2D length).

Figures 16 and 17 present, respectively, profiles of the time-averaged, streamwise velocity components along the horizontal radial positions for $\mathrm{Re}=10^{5}$. The solid curve is the fully developed, equilibrated pipeflow distribution put forth by Bogue and Metzner [12]. The 19-tube tube bundle is installed as shown in figure 15 at the fixed position of $Z-C=6.2 \mathrm{D}$ and the velocity profiles are measured at several axial distances, $C$, downstream of this tube bundle. These results show, just downstream from the 19tube tube bundle at $C / D=2.0$, the jetting effects of the flows from the individual tubes. These jetting effects diminish very quickly so they cannot be seen at $C / D=6.0$ These results show that, even the tube bundle does not alter significantly the axial mean velocity profile near the tube bundle ( e.g., at $C / D=6$ ), the tube bundle does enhance the process of changing the axial mean velocity to the ideal fully developed profile. At $C / D=22$, the axial mean velocity is fairly close to the profile of Boque and Metzner.

Figures 18 and 19 present measurement results for the vertical component of the timeaveraged velocity profile along the $\mathrm{X}$ and $\mathrm{Y}$ diameters downstream of the header and 19-tube tube bundle for $\operatorname{Re}=10^{\mathrm{s}}$. At all stations measured, the mean vertical velocities are very small and below $2 \%$. These show that the 19-tube tube bundle is very effective in reducing the transverse velocities. Particularly, figure 18 shows that the energetic, single eddy flow generated by the header and clearly visible via the vertical velocity component along the $\mathrm{X}$ axis as shown in figure 5 is reduced by this tube bundle to $2 \%$ or less just downstream of the tube bundle exit. Further downstream, the vertical velocities are below $1 \%$ of the bulk velocity, except at a small region near the wall at negative $\mathrm{X}$. 
Figures 20-23 present r.m.s. distributions of the streamwise and vertical components of the turbulent velocity measured downstream of the header and 19-tube tube bundle along the $\mathrm{X}$ and $\mathrm{Y}$ diameters. The profiles measured nearest the tube bundle exit show, via the peaks in these distributions, the effects of the interactions between the jetting flows from the individual tubes. The ideal distributions from Laufer's work at $\mathrm{Re}=41000$ are shown via the solid lines. The decay of the turbulence is so rapid that only the value at the first measured location is larger than those of the Laufer data. At all other measured stations, the turbulence intensity is lower than the Laufer data. Also, these measured profiles are more uniform across the pipe cross-section. These data indicate the turbulence distribution is still dominated by the effects of the multi-jet mixing flows and the pipeflow is still developing downstream of the 19-tube tube bundle even at $C / D=22$. These results indicate that these pipeflows are still decaying at these locations downstream of the tube bundle, apparently due to the multi-jet turbulence. The viscous effects of the pipe wall boundary layer have not completely traversed the entire pipe cross section and equilibrated these flows. Thus, it is concluded that these pipeflows are still evolving toward fully developed distributions.

\section{B) Characteristics of the Mean Velocity Profile}

The results presented above include both the mean and turbulence velocity profiles downstream of the selected header. The next effort is to characterize and understand these velocity profiles in order to find some criteria for improving the meter performance prediction prospects in these nonideal conditions.

Different piping configurations produce different velocity profiles. These velocity profiles change the pipe flow characteristics from those of the fully developed distributions of ideal flow and these in turn can significantly affect flowmeter performance. Based on the measured velocities, important flow field parameters can be defined and quantified. Depending on the particular piping configuration some parameters may be more important than the others in affecting meter performance. Previous research results have shown that swirling flows produced by several different pipe configurations can have very strong effects on the meter performance of selected meters $[1,6,7]$.

Various parameters can be used to characterize the degree of the swirl flow. The swirl angle at a point in the flow, defined by the vertical inclination angle of the velocity 
vector as $\phi=\arctan (\mathrm{V} / \mathrm{W})$, is good example. It is a measure of the flow vector's deviation from the ideal streamline direction. Figure 24 shows the profiles of the point swirl angle $\phi$ vs. horizontal radial position at different downstream locations from the header. The swirl produced by the header configuration is quite similar to that from the closely-coupled double elbows out-of-plane configuration. At the upstream location of $Z=3.35 \mathrm{D}$, the swirl angle approximates $+16^{\circ}$ near one side of the pipe wall and $-20^{\circ}$ near the other side. These swirl angles change as the distance downstream increases. In the absence of flow conditioners, this swirl is still very strong $\left( \pm 12^{\circ}\right)$ at the $30 \mathrm{D}$ distance downstream. Figure 25 shows point swirl angle distributions at different downstream locations from the header and the 19-tube tube bundle. Except near the exit of the tube bundle, the point swirl angles are all very small and less than $1^{\circ}$. These data show again that the tube bundle flow conditioner is very effective in removing swirl from pipe flow.

It is noted that there is only one large swirl eddy produced in this header configuration. To characterize the decay of the swirl flow, a mean swirl angle, $S_{a}$, is defined as

$$
\mathrm{S}_{\AA}=(\phi+\infty) / 2
$$

where $\phi_{+}$and $\phi_{-}$are, respectively, the maximum magnitudes of the point swirl angles in the positive and negative $\mathrm{X}$ directions along the horizontal diameter at a given axial location Z.

Figure 26 shows the comparisons of the decays of the mean swirl angles downstream from different piping configurations. Data are shown for five piping configurations: header H342-100/0-1; double elbows out-of-plane(closely coupled, 2.42D spaced, and 5.32D spaced); and header with tube bundle. These data show the header produces the most energetic swirl and has the slowest decay rate among the five cases. At axial position, $Z / D=30$, the mean swirl angles are about $12^{\circ}, 7^{\circ}$, and $2^{\circ}$ for the header, closed coupled double elbows out-of-plane, and 2.42D spaced double elbows out-of-plane, respectively. The mean swirl angles for the other two cases are negligibly small. This is further testimony to the severity of the swirl produced by this header piping configuration. The large initial mean swirl angle for the double elbows out-of-plane is due to the large point swirl angle near the wall. These large swirl eddies decay very rapidly due to the wall boundary condition as well as the diffusion of the vorticity to the pipe center as they move downstream. The initial diffusion of the swirl for the 
double elbows out-of-plane is enhanced due to the fact that the initial axial vorticity is small in the pipe center for the double elbows out-of-plane configuration. The decay of swirl flows can also be quantified by a pipe swirl number defined as follows:

$$
S_{1}=4 \int_{-0.5}^{+0.5} \frac{W V X|X|}{W_{b}^{2} \mathbb{D}^{2}} \mathbb{( X / D )}
$$

The swirl number, $\mathrm{S}_{1}$, corresponds to an integral of the angular momentum over the entire pipe cross-section. Figure 27 shows the streamwise distributions of the swirl numbers for $\mathrm{Re}=10^{5}$ for the same five piping configurations (H342-100/0-1, L+X-Ys with three different spacings, $\mathrm{s}=0,2.42$ and 5.32D, and H342-100/0-1 with tube bundle). These data indicate that the header piping produces very energetic, longlasting, single-eddy, swirled flows. As noted for the mean swirl angle, the swirl number, $S_{1}$ for the header is the largest and shows the slowest decay with downstream distance among the five configurations. The $S_{1}$ values for closely coupled $(s=0)$ double elbows-out-of-plane are much smaller than those for the header. The values of $S_{1}$ for spaced ( $\mathrm{s}=2.4$ and 5.3 diameters) double elbows-out-of-plane and for the header with the tube bundle are all negligibly small.

Another useful quantity regarding the pipe flow profile is the degree of the flatness or peakness of the mean velocity profile. To quantify the peakness of the velocity profiles produced by the piping configurations, a number of peakness parameters are introduced (see [15]). These include:

$$
\begin{aligned}
& P_{1}=W_{c} / W_{b}-1 \\
& P_{2}=W_{c}^{2} / W_{b}^{2}-1 \\
& P_{3}=1-W_{b} / W_{c} \\
& P_{4}=W_{c} / W_{w}
\end{aligned}
$$




$$
\begin{aligned}
& \mathbb{P}_{5}=\int_{-0.5}^{0.5}\left(\mathrm{~W}_{\mathrm{c}}-\mathrm{W}\right) \mathbb{Q}(\mathrm{r} / \mathbb{D}) / \mathrm{W}_{\mathrm{b}} \\
& \mathbb{P}_{6}=\int_{-0.5}^{0.5}\left(\mathrm{~W}_{\mathrm{c}}{ }^{2}-\mathrm{W}^{2}\right) \mathbb{d}(\mathrm{r} / \mathbb{D}) / \mathrm{W}_{\mathrm{b}}^{2} \\
& \mathbb{P}_{7}=\int_{-0.5}^{0.05} \mathrm{~W}\left(\mathrm{~W}_{\mathrm{c}}-\mathrm{W}\right) \mathbb{d}(\mathrm{r} / \mathbb{D}) / \mathrm{W}_{\mathrm{b}}^{2}
\end{aligned}
$$

where $\mathrm{W}_{\mathrm{c}}$ is the velocity at the pipe centerline location and $\mathrm{W}_{\mathrm{w}}$ is the velocity at a point near the wall, defined as $\mathrm{r}=0.475 \mathrm{D}$. All the parameters have similar meaning for characterizing the velocity profile peakness. A larger peakness index will mean high flow velocities near the pipecenter, i.e., a more "peaky" profile near the center core. Both $\mathrm{P}_{1}$ and $\mathrm{P}_{3}$ show the overshoot of the centerline velocity from the average bulk velocity, except $P_{1}$ is normalized by the averaged bulk velocity while $P_{3}$ is normalized by the centerline velocity. $\mathrm{P}_{2}$ quantifies the excess of the centerline dynamic pressure over the dynamic pressure based on the averaged velocity. $\mathrm{P}_{4}$ is the ratio between the centerline velocity and the velocity near the pipe wall (at $2.5 \%$ diameter from the wall). The parameters $\mathrm{P}_{1}, \mathrm{P}_{2}$, and $\mathrm{P}_{3}$ are obtained only by the single point velocity at the pipe centerline. $\mathrm{P}_{4}$ is determined by two local velocities, while $\mathrm{P}_{5}, \mathrm{P}_{6}$ and $\mathrm{P}_{7}$ are determined from integrations of velocities over the pipe diameter. These integrated quantities are similar to the displacement thickness and momentum thickness parameters commonly used in studying boundary layer flows.

Other investigators have introduced some of these parameters in their studies. For example, Klein $[16,17]$ called $\mathrm{P}_{3}$ a blocking factor in studying turbulent, developing pipe flow and the effects of inlet conditions on conical-diffuser performance. In studying the effect of flow profiles on orifice meter performance Ghazi [18] has introduced the parameters $F_{1}$ and $F_{2}$ which are closely related to the peakness parameters, $\mathrm{P}_{3}$ and $\mathrm{P}_{4}$, respectively; in which $\mathrm{F}_{1}=1-\mathrm{P}_{3}$ and $\mathrm{F}_{2}=1 / \mathrm{P}_{4}$.

Besides these peakness parameters, other parameters that quantify how the flow is displaced from the center of the pipe can also be used. A more peaky flow means that 
the flow is faster at and near the pipe center with slower flow further from the pipe centerline. A displacement parameter is introduced to quantify the average flow displacement from the pipe centerline for a selected quantity as follows:

$$
\mathbb{D}_{\min }=\frac{\int_{-D / 2}^{+D / 2} \mathrm{WW}^{\mathrm{m}_{\mathrm{r}} \mathrm{n}} d \mathrm{r}}{\mathbb{D} \int_{-D / 2}^{+D / 2} \mathrm{~W}^{\mathrm{m}^{\mathrm{n}}} d \mathrm{r}}
$$

In this report, the results for only two flow displacement parameters will be presented. $\mathrm{D}_{20}$ is for the dynamic pressure, $\mathrm{W}^{2}$, and $\mathrm{D}_{21}$ is for the first radial moment of the dynamic pressure, $\mathrm{W}^{2} \mathrm{r}$. Likewise, only two peakness parameters, $\mathrm{P}_{2}$ and $\mathrm{P}_{6}$, are presented here.

These profile peakness and flow displacement parameters are determined as functions of the axial distance downstream from different piping configurations for $\operatorname{Re}=10^{5}$. Figure 28 shows the evolution of the profile peakness, $\mathrm{P}_{2}$ downstream from different piping configurations. In the figure the change of the peakness from the ideal flow condition is plotted. Figure 29 shows the evolution of the profile peakness, $\mathrm{P}_{6}$ for the flow from five piping configurations as noted. Figures 30 and 31 show the evolutions of the profile displacements $\mathrm{D}_{20}$ and $\mathrm{D}_{21}$, respectively, for the same five configurations. Again, all these flow profile indexes presented are given by the values that differ significantly from the ideal condition. Thus, if a profile is flatter than the ideal profile the change of the peakness relative to the ideal will be negative. In this case, the flow field is displaced from the centerline and the change of the displacement relative to the ideal should be positive. On the other hand, if the change of the peakness is positive, or the relative change of the displacement is negative, the axial mean velocity profile is more peaked at the pipe center.

These data show that, for small values of $Z / D$, the changes in the peakness, parameter are negative and the changes in the displacement are positive. With downstream distance, the values tend to approach the ideal values. They also show that the header flow with no flow conditioning has profile indexes that deviate more from the ideal values than most of other configurations. 


\section{SUMMARY AND CONCLUSIONS}

Experimental measurements have been made, using laser Doppler velocimetry in the pipe flows produced by a generic header. With a limited set of measurements of fluid velocity, the profile characteristics of the mean velocity downstream of a header are described both qualitatively and quantitatively. Several profile indexes are introduced to characterize the profile swirl, peaknesses, and flow displacements. These indexes could be used to develop criteria for improving flow meter performance in nonideal installation conditions. The velocity data indicate that the header produces, initially, a velocity profile that is highly swirled and more smoothly varying than the fully developed distribution that is pertinent to the Reynolds number and relative roughness conditions.

The secondary flow produced by the header is very similar to that for the closelycoupled double elbows out-of-plane configurations. As compared to fully developed pipe profile, the header flow velocities near the pipe center are much slower, and those near the pipe walls are faster. At the location, 30D downstream from the header, the profile is fairly flat across most of the center core of the pipe, and it is symmetric. A strong single eddy swirl distribution is generated by the turning action of this header configuration. Results indicate that the single eddy produced by the header is relatively stable and organized and its dissipation is slower than the swirl from previously studied double elbows out-of-plane cases. Additionally, these flows are accompanied by levels of turbulence that are slightly lower than those for the double elbows out-of-plane. The net results are that the flow effects from the header dissipate more slowly than those from the double elbows out-of-plane. Data for the conditions tested show that the single-eddy swirl pattern produced by the header persist to well beyond 30D from the exit of the header. The extent to which this swirl propagates down the pipe has not yet been completed. The flow also has smoothly varying turbulence distributions across the pipe even at $Z=30 \mathrm{D}$ and the flow is still developing toward a fully developed pipeflow condition.

The results obtained when a tube bundle is installed in the outlet piping show that, just downstream of the 19 tube bundle, the pipeflow is dominated by the effects of the multi-jets from the individual tubes. The axial velocity profiles exhibit very smoothly varying velocity distributions in which the major portion of the center core of the pipeflow is quite slow in comparison with the fully developed distributions. The 19tube bundle is quite effective in reducing transverse velocities. At 22D downstream of 
the tube bundle, the effect of the pipe wall boundary layer has not yet completely propagated over the entire pipe cross section and thus the pipeflow is still in the process of evolving toward the fully developed distribution.

\section{REFERENCES}

[1] Mattingly, G.E. and Yeh, T.T., NIST's Industry-Government Consortium Research Program on Flowmeter Installation Effects: Report of Results for the Research Period Nov. - May 1989, NISTIR 4310, Apr. 1990.

[2] Mattingly, G.E. and Yeh, T.T., Summary Report of NIST's Industry-Government Consortium Research Program on Flowmeter Installation Effects With Emphasis on the Research Period January-September 1991: The Reducer, NISTIR 4779, December 1991.

[3] Mattingly, G.E. and Yeh, T.T., NIST's Industry-Government Consortium Research Program on Flowmeter Installation Effects: Report of Results for the Research Period July - December 1987. NISTIR-88-3898, May 1988.

[4] Mattingly, G.E. and Yeh, T.T., Effects of Pipe Elbows and Tube Bundles on Selected Types of Flowmeters, Journal of Flow Measurements and Instrumentation, Vol. 2, pp. 4-13, January, 1991.

[5] Yeh, T.T. and Mattingly, G.E., Summary Report of NIST's Industry-Government Consortium Research Program on Flowmeter Installation Effects: The $45^{\circ}$ Elbow, NIST Technical Note 1408, October, 1994.

[6] Mattingly, G.E. and Yeh, T.T., Flowmeter Installation Effects Due to Several Elbow Configurations, Proceedings of the 2nd International Symposium on Fluid Flow Measurement, pp. 271-283, June, 1990.

[7] Mattingly, G.E. and Yeh, T.T., Robertson, B. and Kothari, K., NBS Research on In-Situ Flowmeter Installations, Procs, AGA Distribution and Transmission Confr. Las Vegas, NV, May 1987.

[8] Yeh, T.T. and Mattingly, G.E., Mixing Motions Produced by Pipe Elbows, NISTIR 89-4029 January 1989. 
[9] Harbrink, B., Zirnig, W., Hassenpflug, H., Kerber, W. and Zimmermann, H.; The Disturbance of Flow Through an Orifice Plate Meter Run by the Upstream Header, 5th International IMEKO=Conference on Flow Measurement FLOMEKO, Dusseldorf(FRG), pp. 75-90, October, 1989.

[10] Williamson, I.D., Botros, K.K. and Price, G.R.; Flow Characteristics and Orifice Meter Error Caused by Upstream Headers in Multi-Run Meter Stations. ASME Fluid Measurements and Instrumentation Forum, FED-Vol.161, 1993.

[11] Yeh, T.T. and Mattingly, G.E., Flowmeter Installation Effects due to a Generic Header. (To appear as NIST Technical Note)

[12] Bogue, D.C. and Metzner, A.B., Velocity Profiles in Turbulent Pipe Flow, I\&EC Fundamentals Vol. 2, No. 2, May 1963, pp. 143-9.

[13] Laufer, J., The Structure of Turbulence in Fully Developed Pipe Flow, NBS Rept. 1974, Sept. 1952.

[14] Orifice Metering of Natural Gas and Other Related Hydrocarbon Fluids, Part 2, Specification and Installation Requirements, AGA Report No.3, API 14.3, GPA 8185-90, 3rd Ed., February 1991.

[15] Yeh, T.T. and Mattingly, G.E., Pipeflow Downstream of a Reducer and Its Effects on Flowmeters. ASME Fluid Measurement and Instrumentation Forum, FED-Vol.161, 1993, pp. 21-28.

[16] Klein, A. Review:Turbulent Developing Pipe Flow. J. of Fluids Engineering, June 1981, Vol.103, pp. 243-249.

[17] Klein,A. Review:Effects of Inlet conditions on Conical-Diffuser Performance. J. of Fluid Engineering, June 1981, Vol. 103, p. 250

[18] Ghazi, H.S. A Pressure Index for Predicting the effect of Flow Profiles on Orifice Meter Performance. J. of Basic Engineering, March 1966, pp. 93-100 


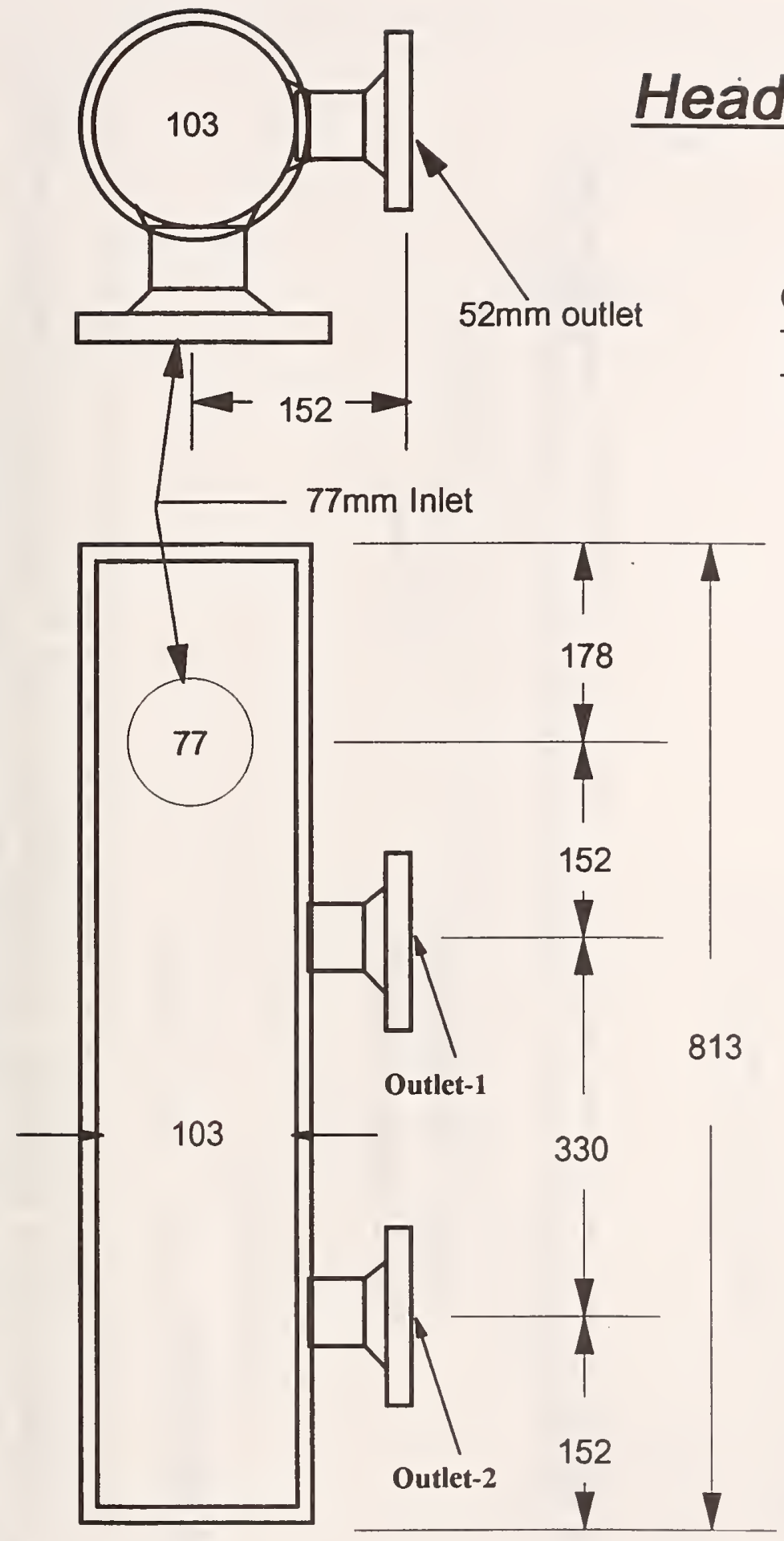

One Inlet: $\quad 77 \mathrm{~mm}$ Dia.

Two Outlets: $52 \mathrm{~mm}$ Dia.

Tank Body: 103 mm Dia.

All dimensions are

nominal and in $\mathrm{mm}$

Figure 1 The Generic Header Geometry, H342 Consisting One Inlet and Two Outlets. 

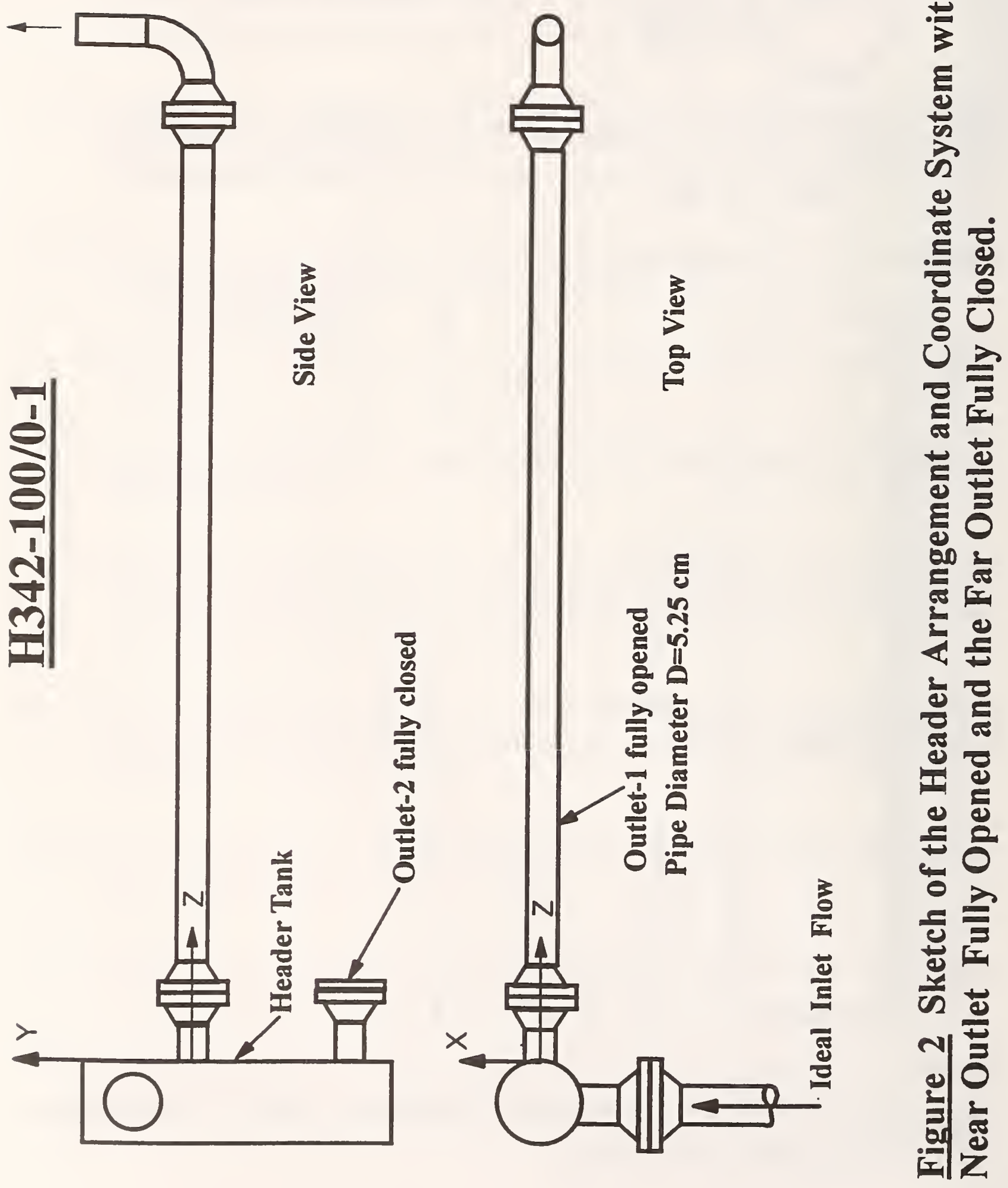


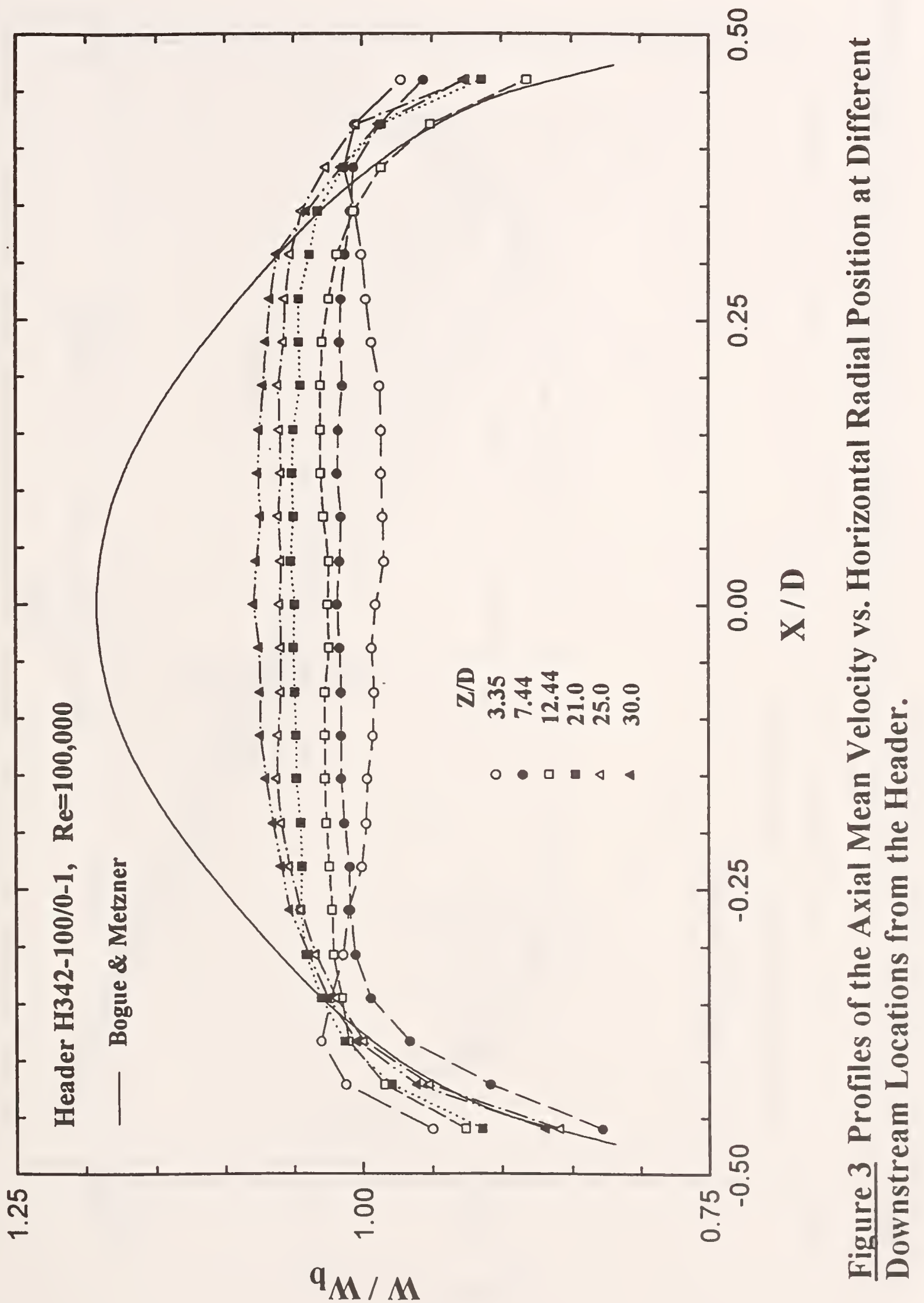




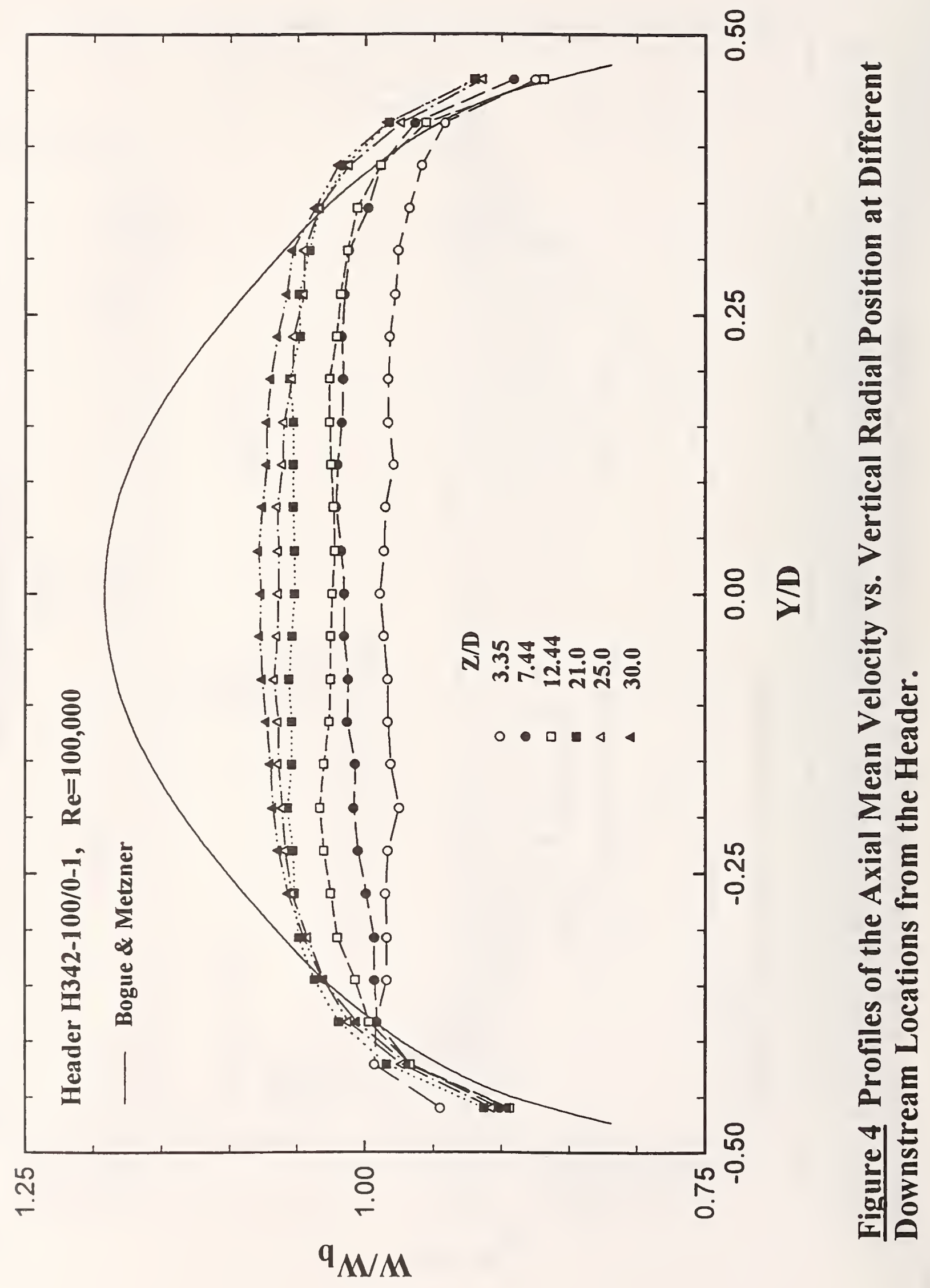




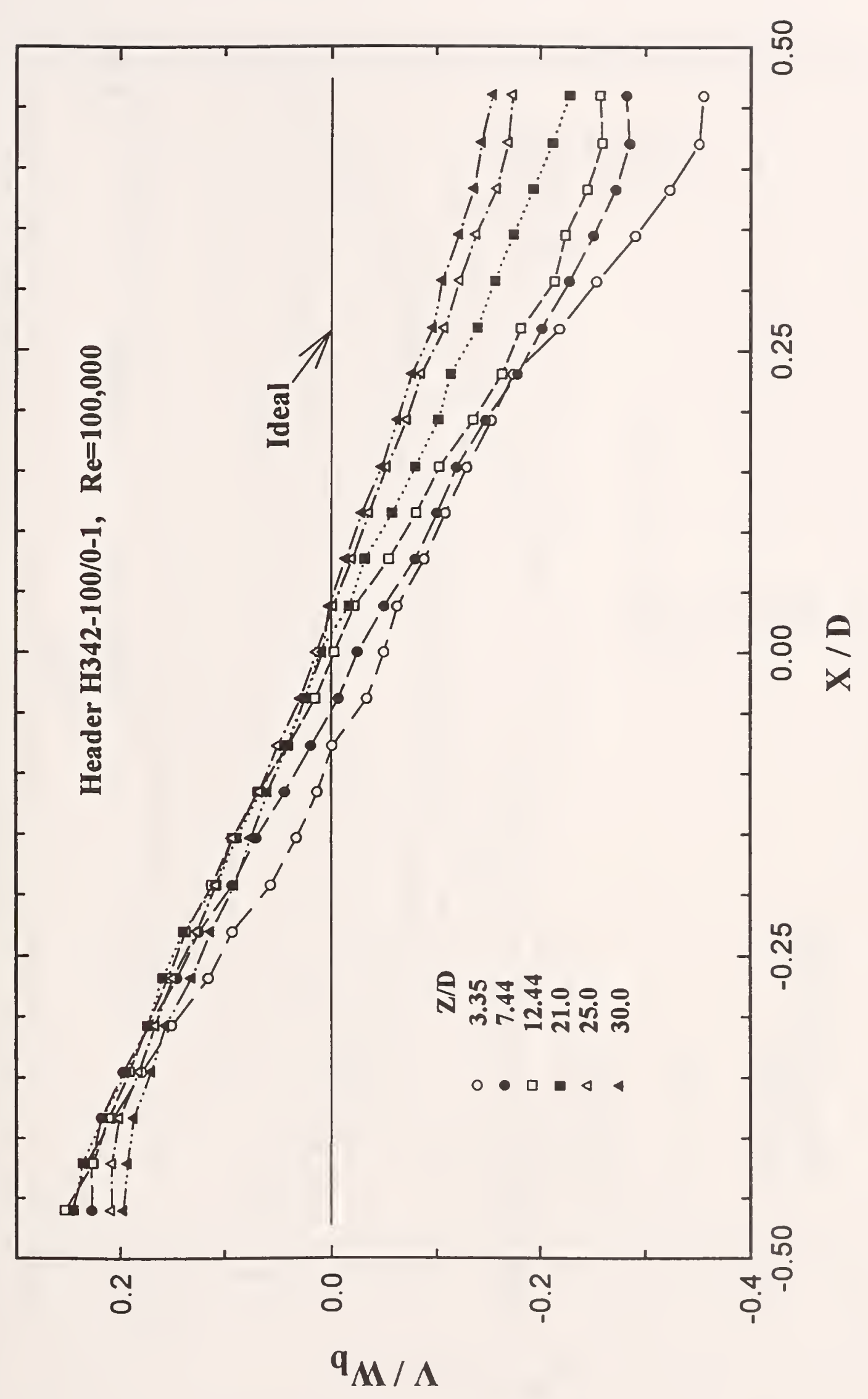

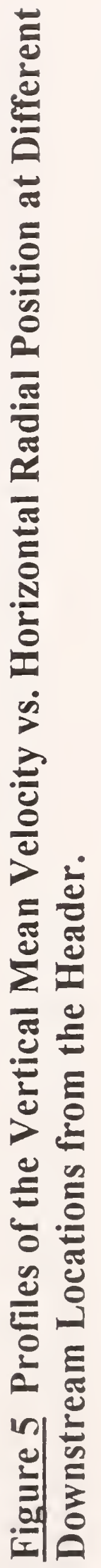

善 


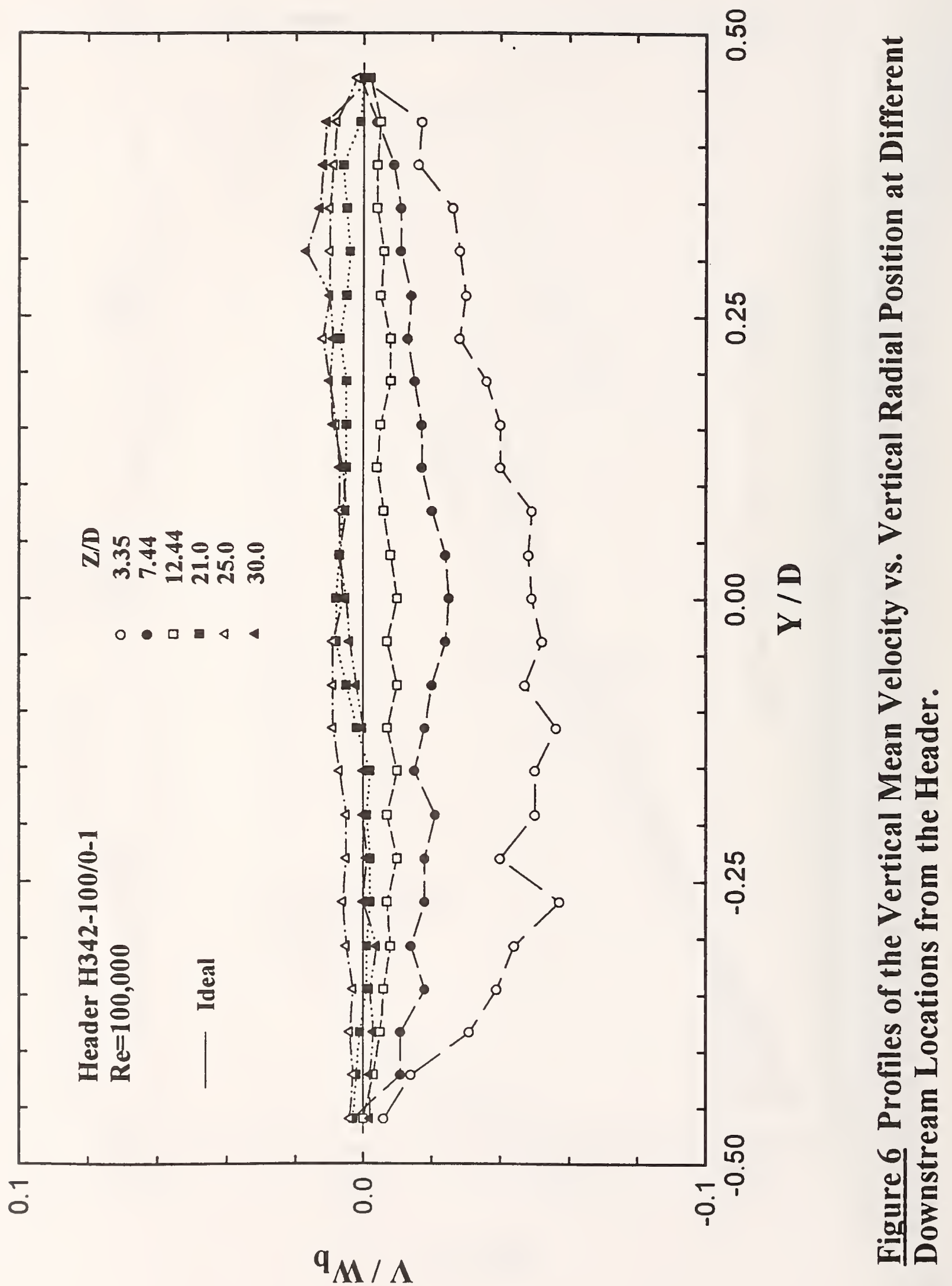




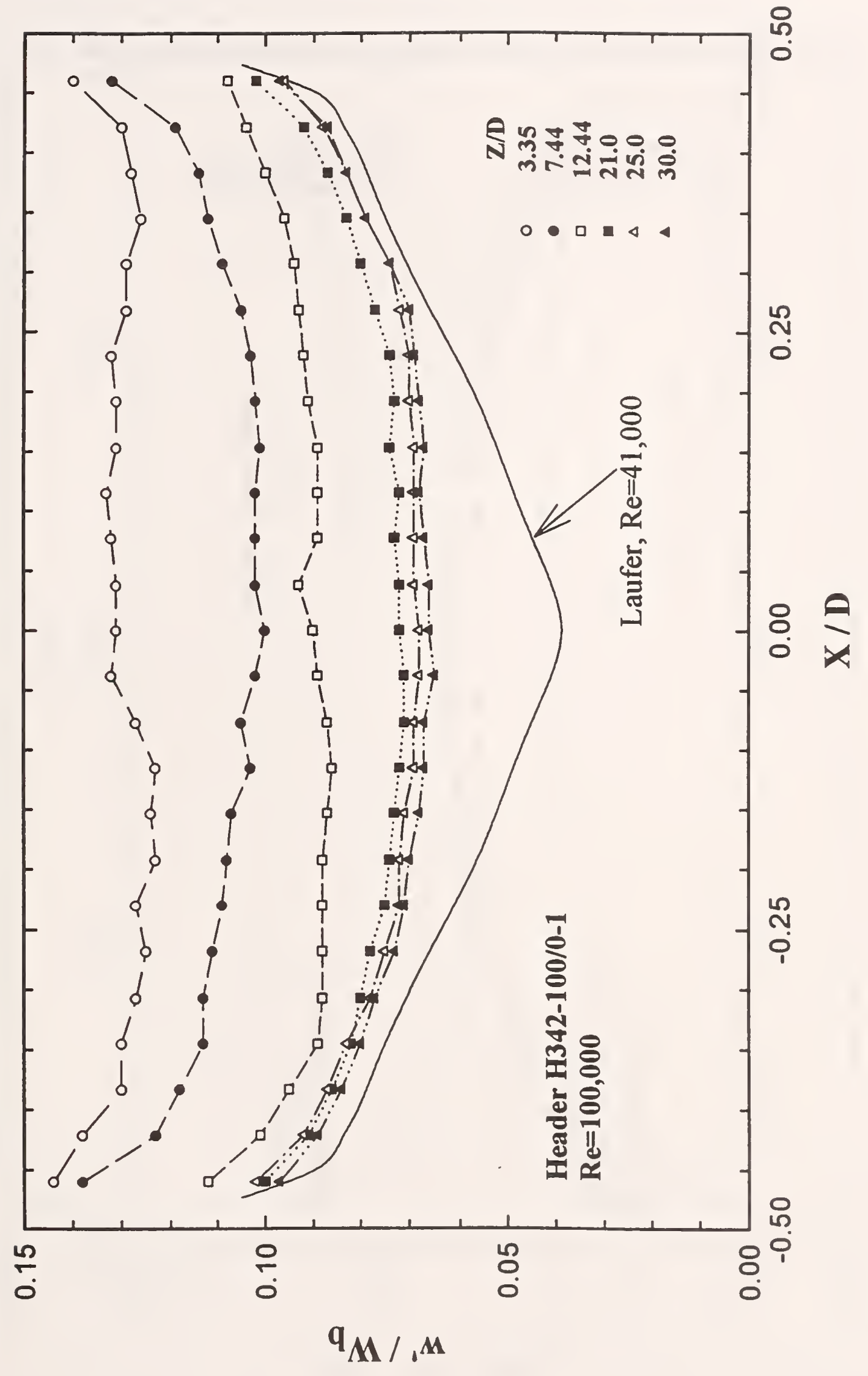

$\frac{x}{3}$

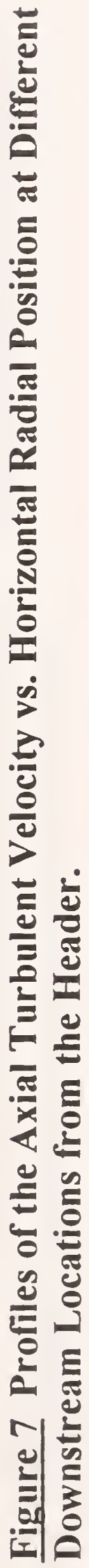




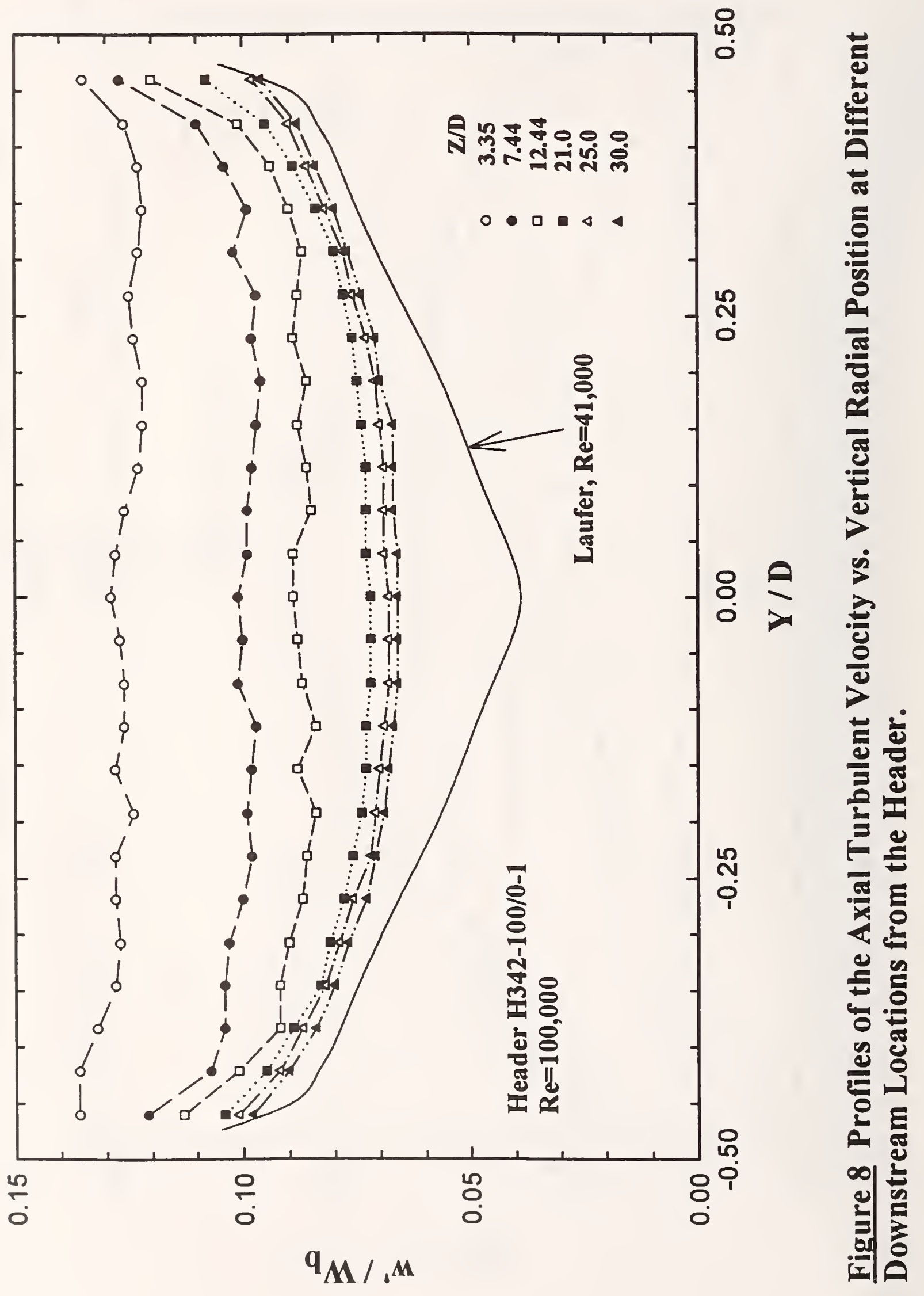




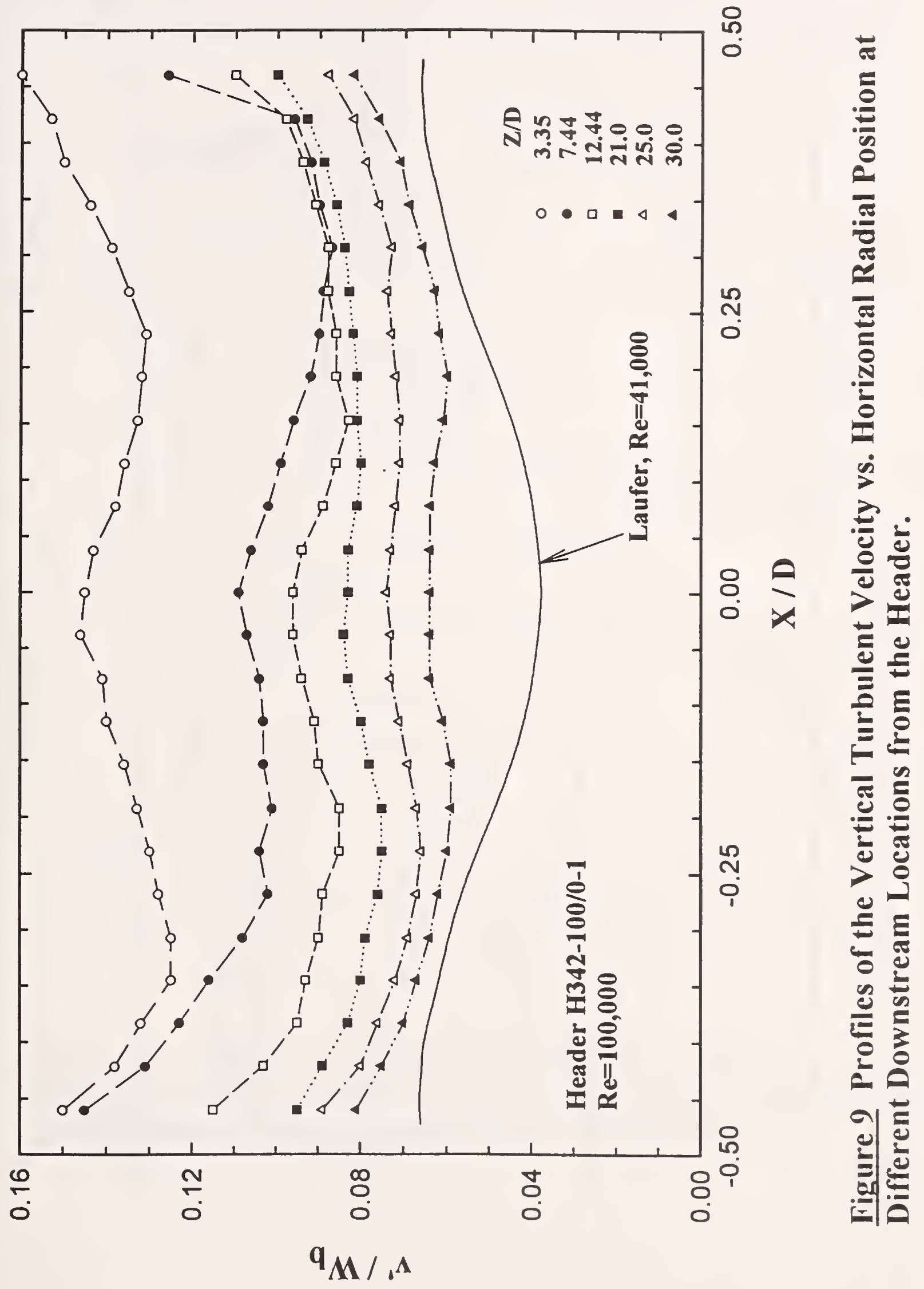

希 


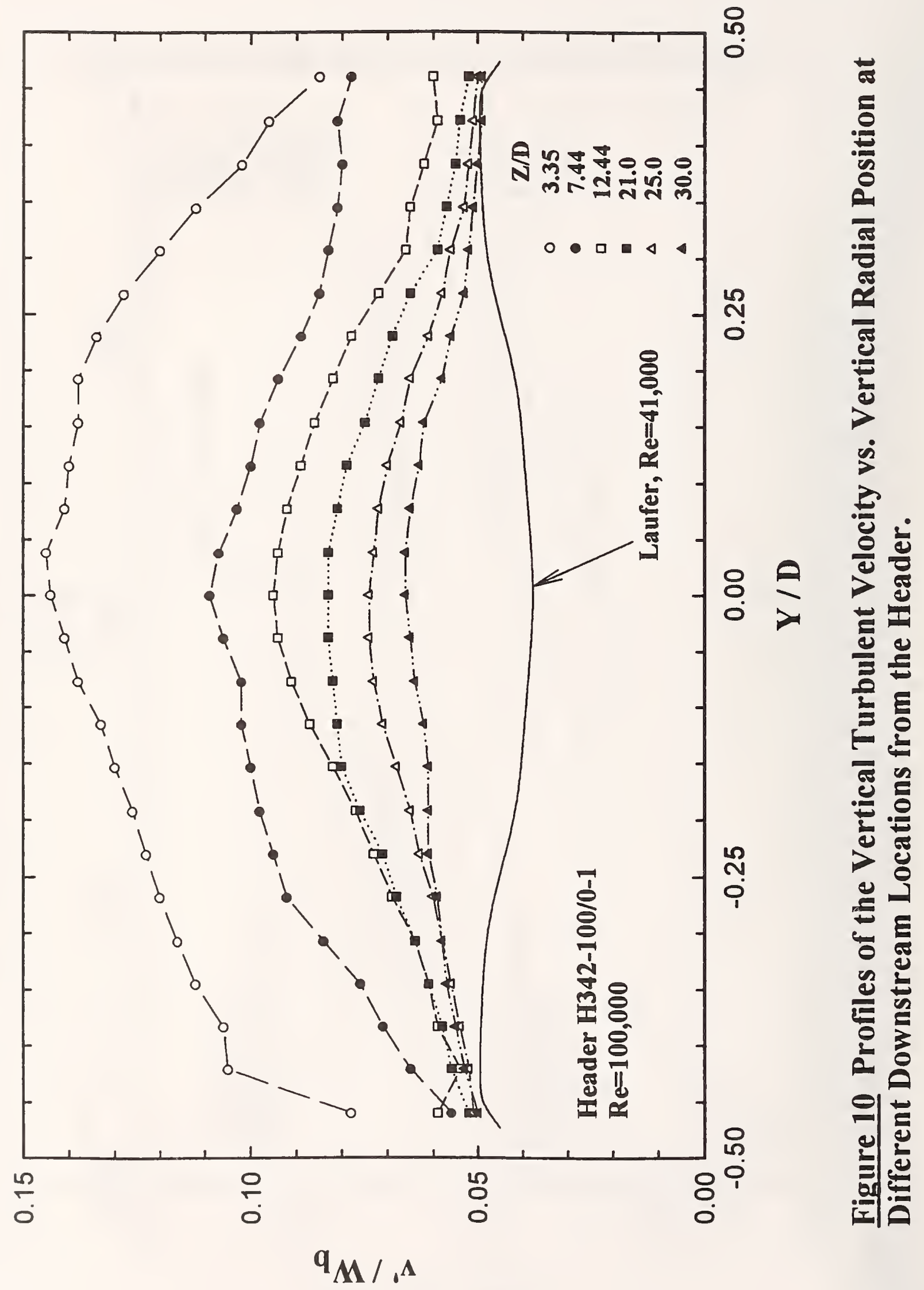




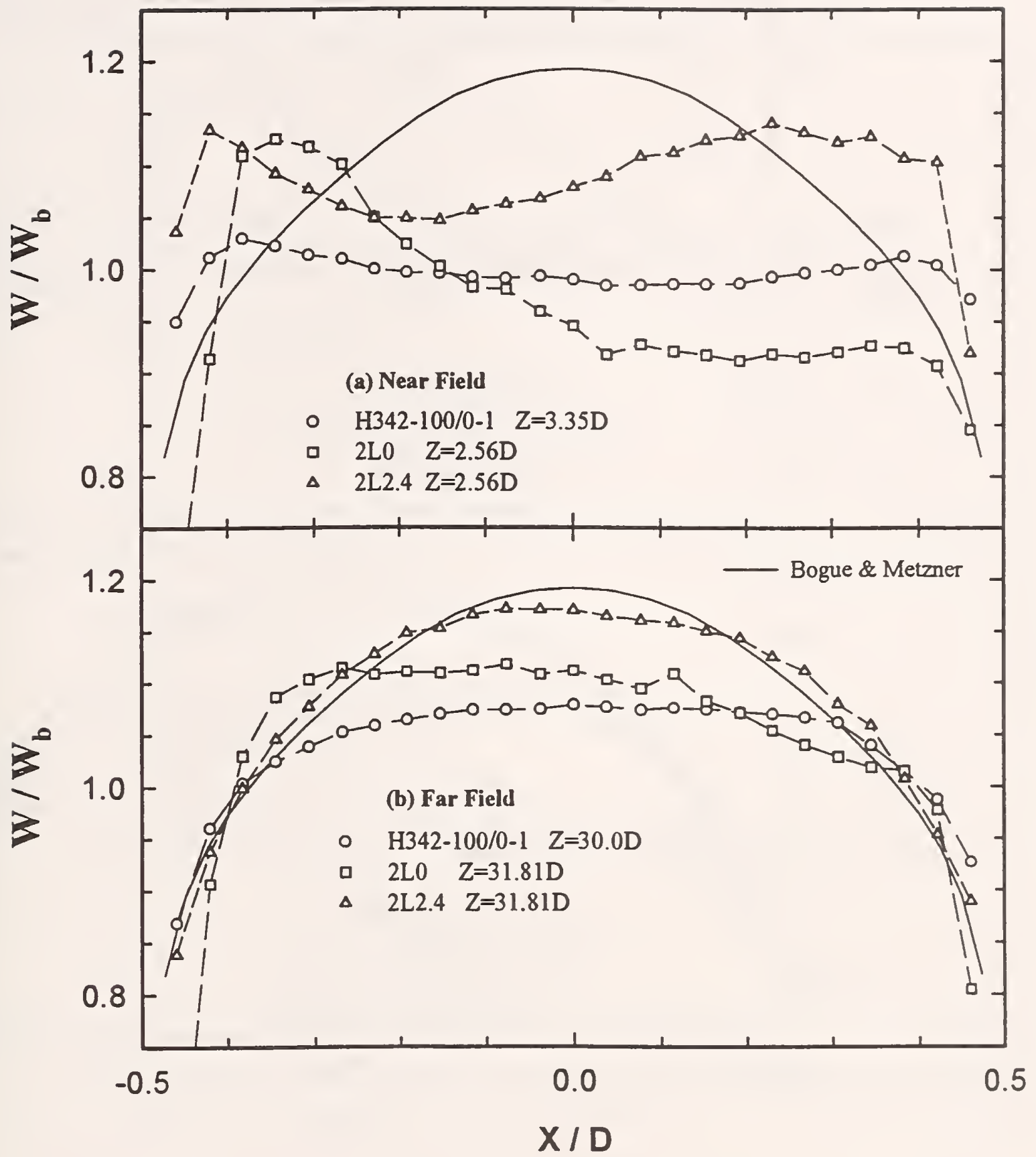

Figure 11 Comparison of the Axial Velocity Profile vs.

Horizontal Radial Position at Two Axial Locations Downstream from Different Piping Configurations. $R e=100,000$. 


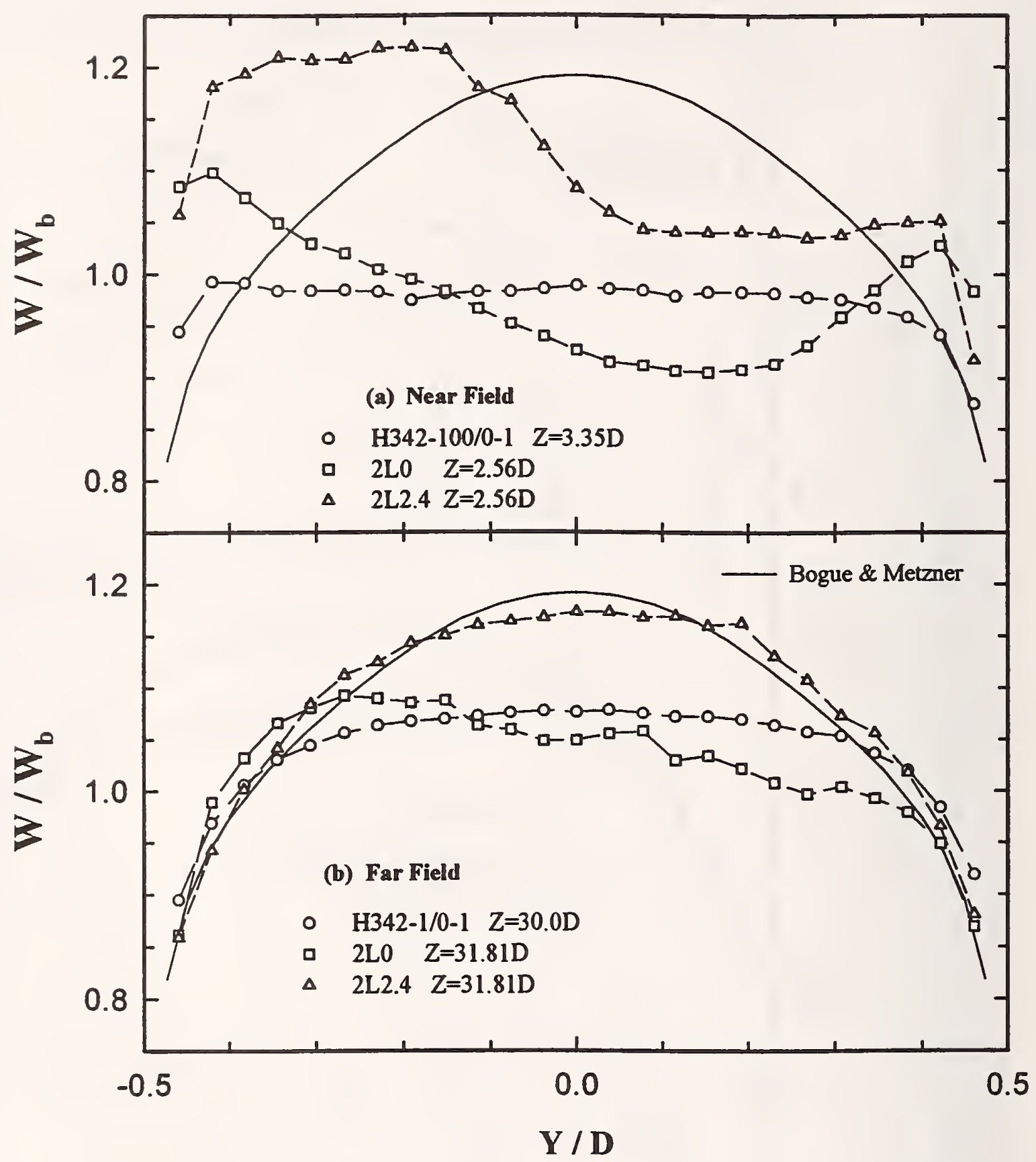

Figure 12 Comparison of the Axial Velocity Profile vs. Vertical Radial Position at Two Axial Locations Downstream from Different Piping Configurations. $\mathbf{R e}=\mathbf{1 0 0 , 0 0 0}$. 


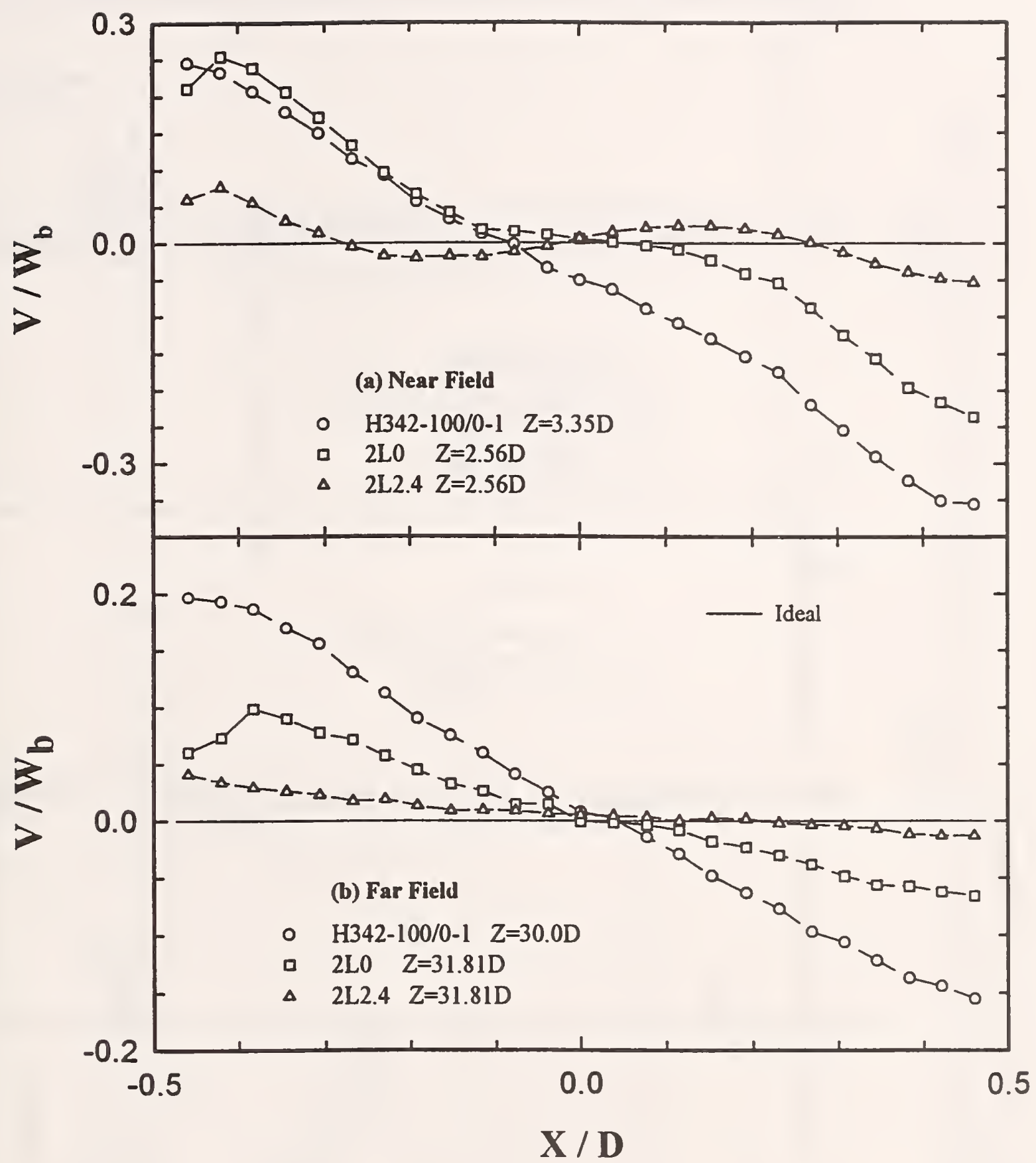

Figure 13 Comparison of the Vertical Velocity Profile vs. Horizontal Radial Position at Two Axial Locations Downstream from Different Piping Configurations. $R e=100,000$. 


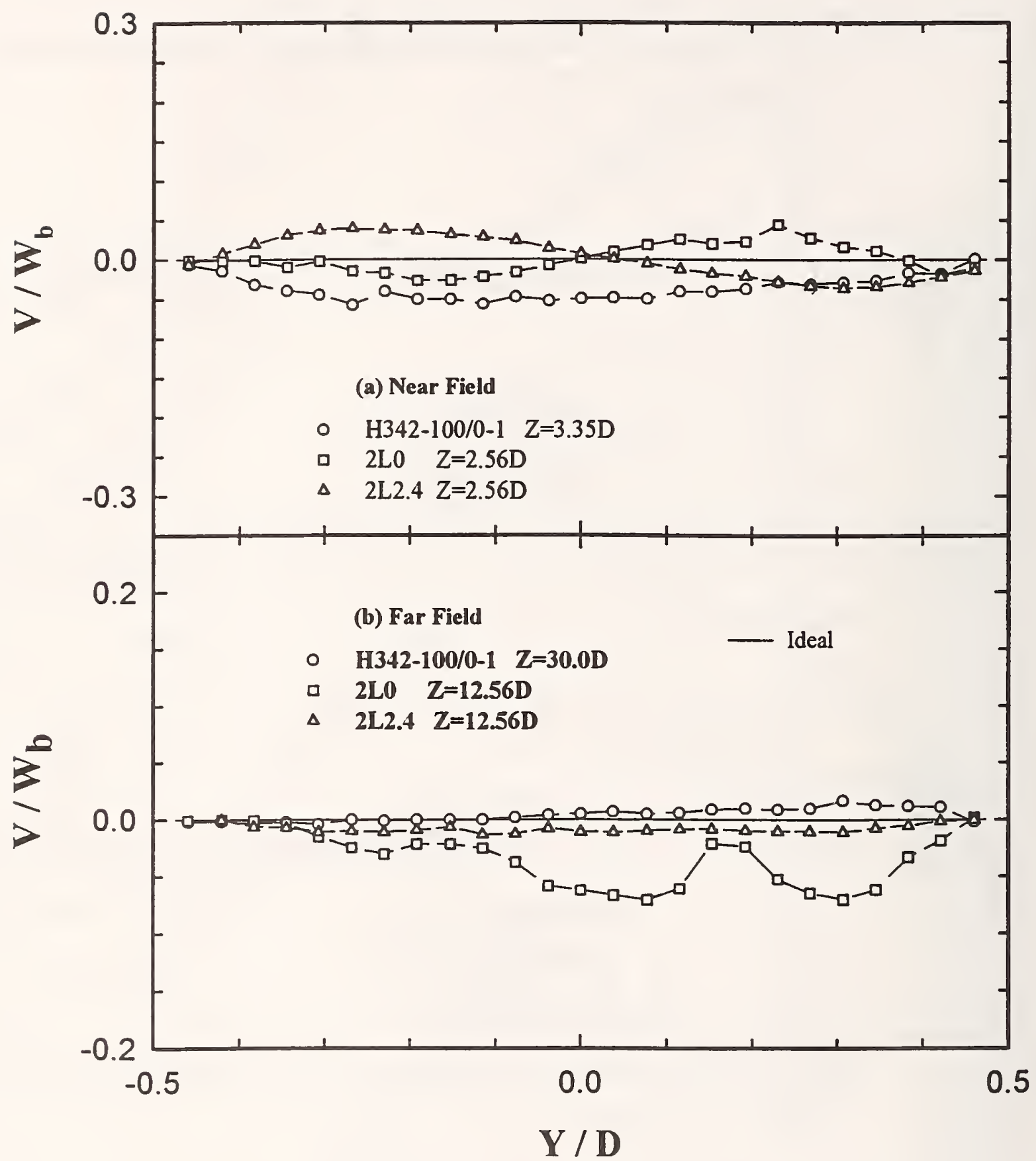

Figure 14 Comparison of the Vertical Velocity Profile vs. Vertical Radial Position at Two Axial Locations Downstream from Different Piping Configurations. $\mathrm{Re}=\mathbf{1 0 0 , 0 0 0}$. 


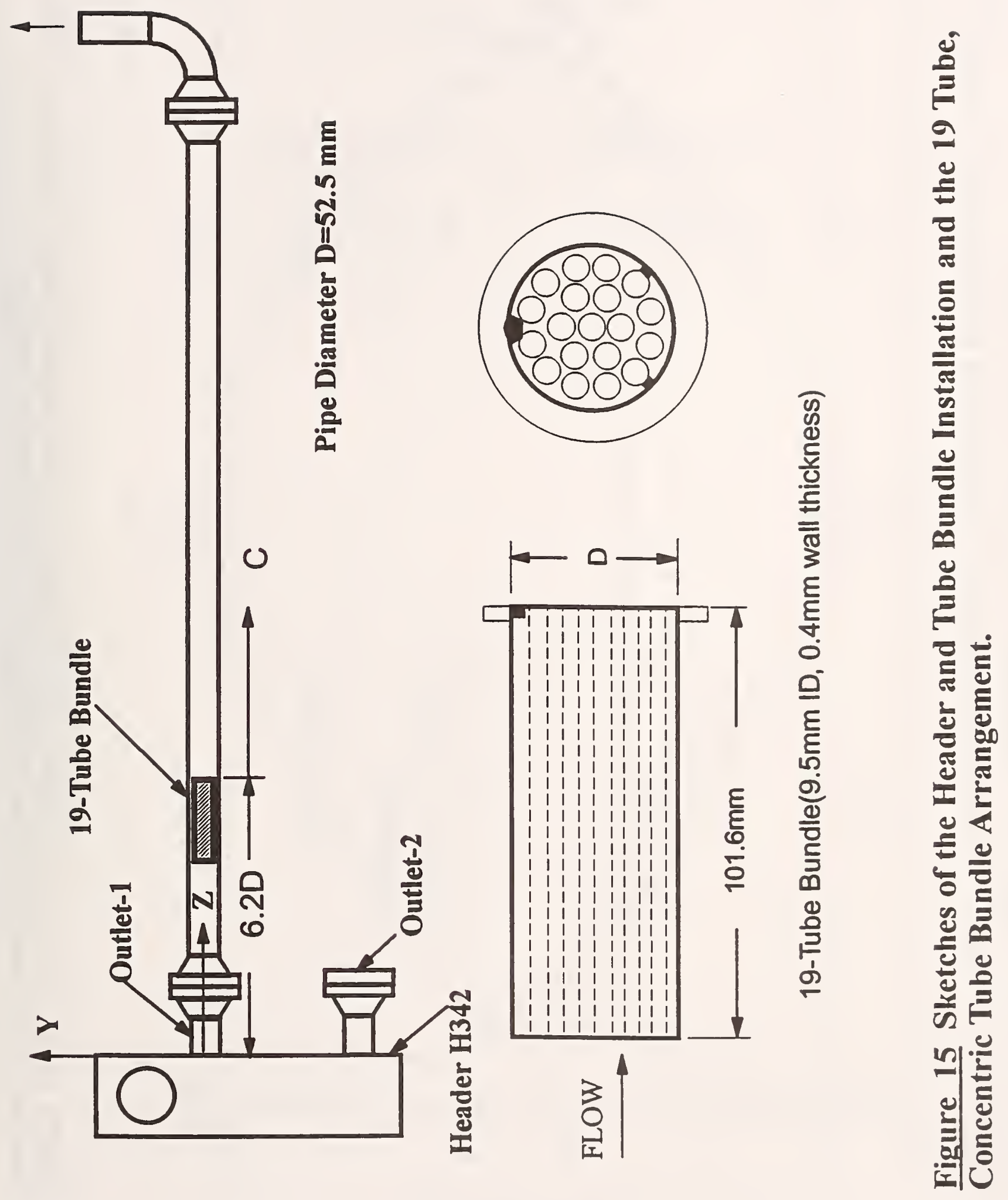




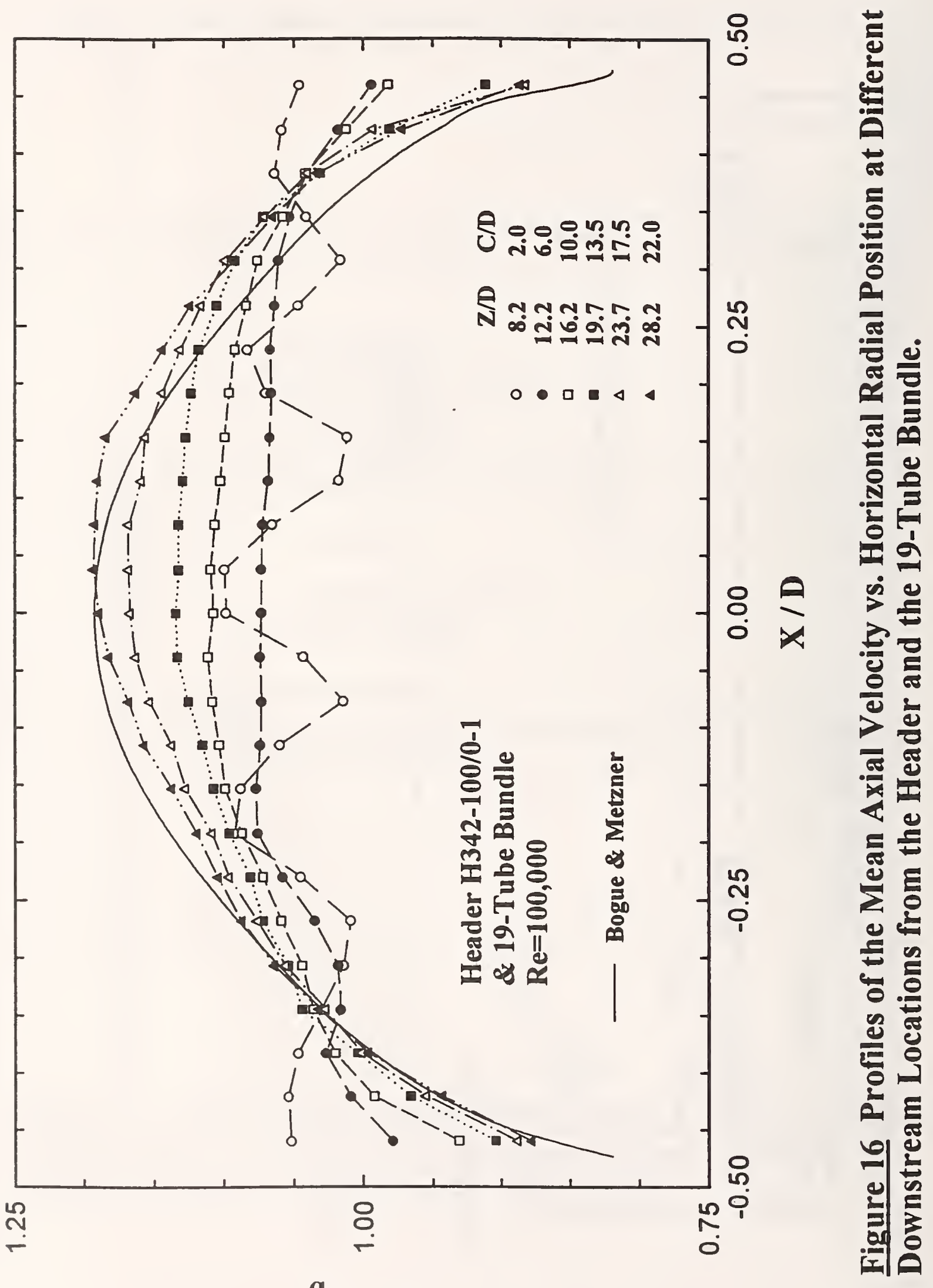




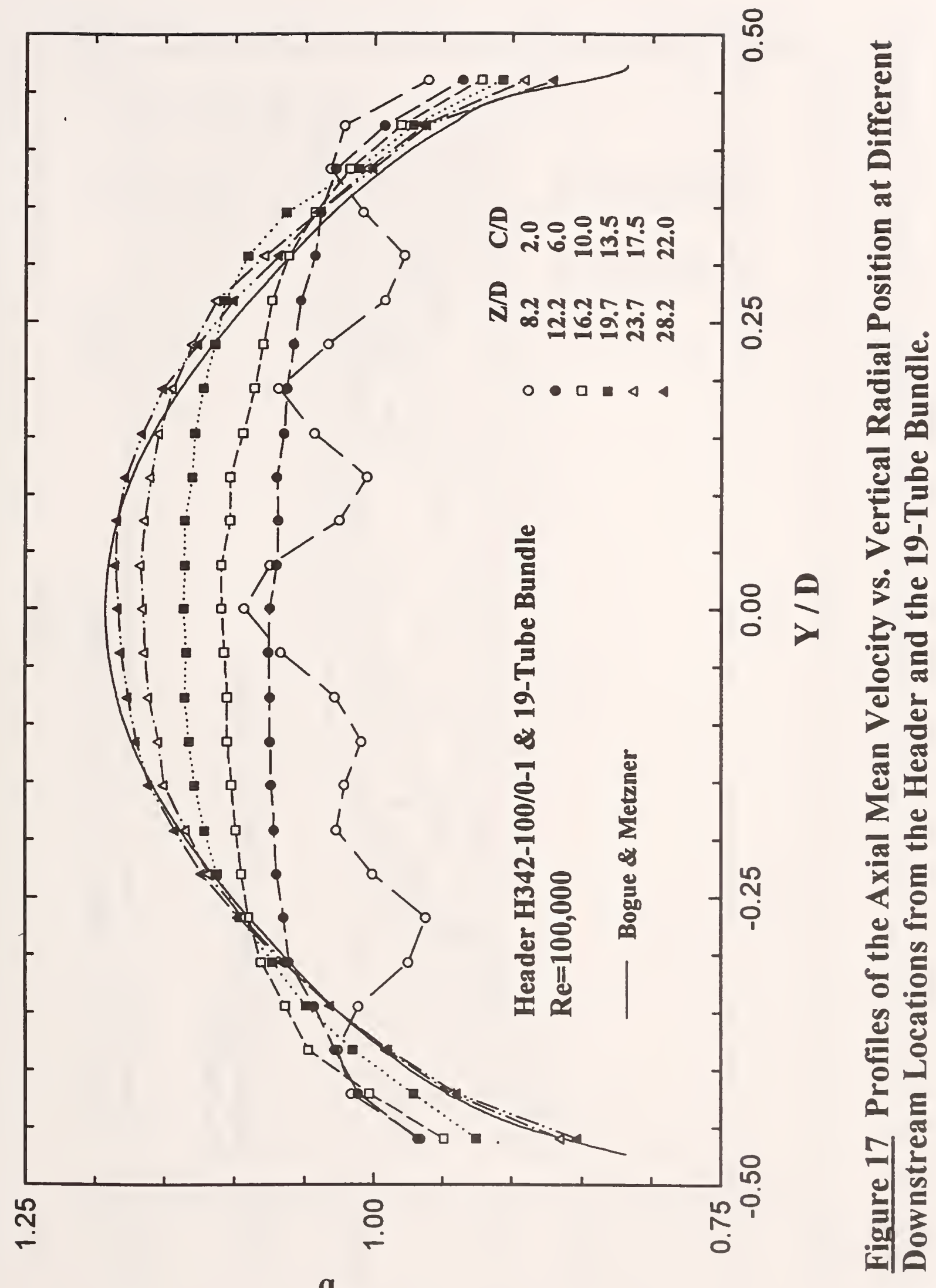




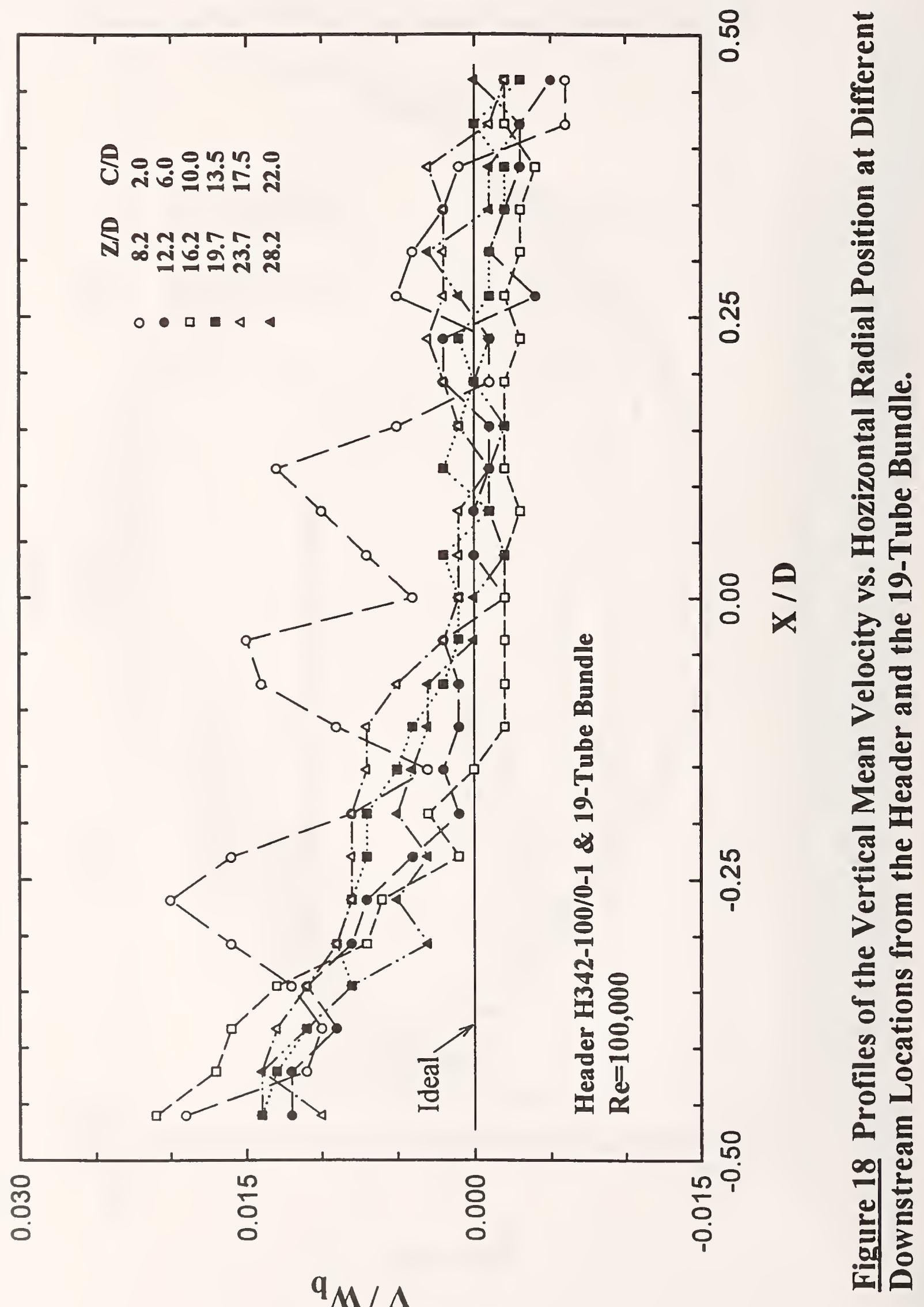




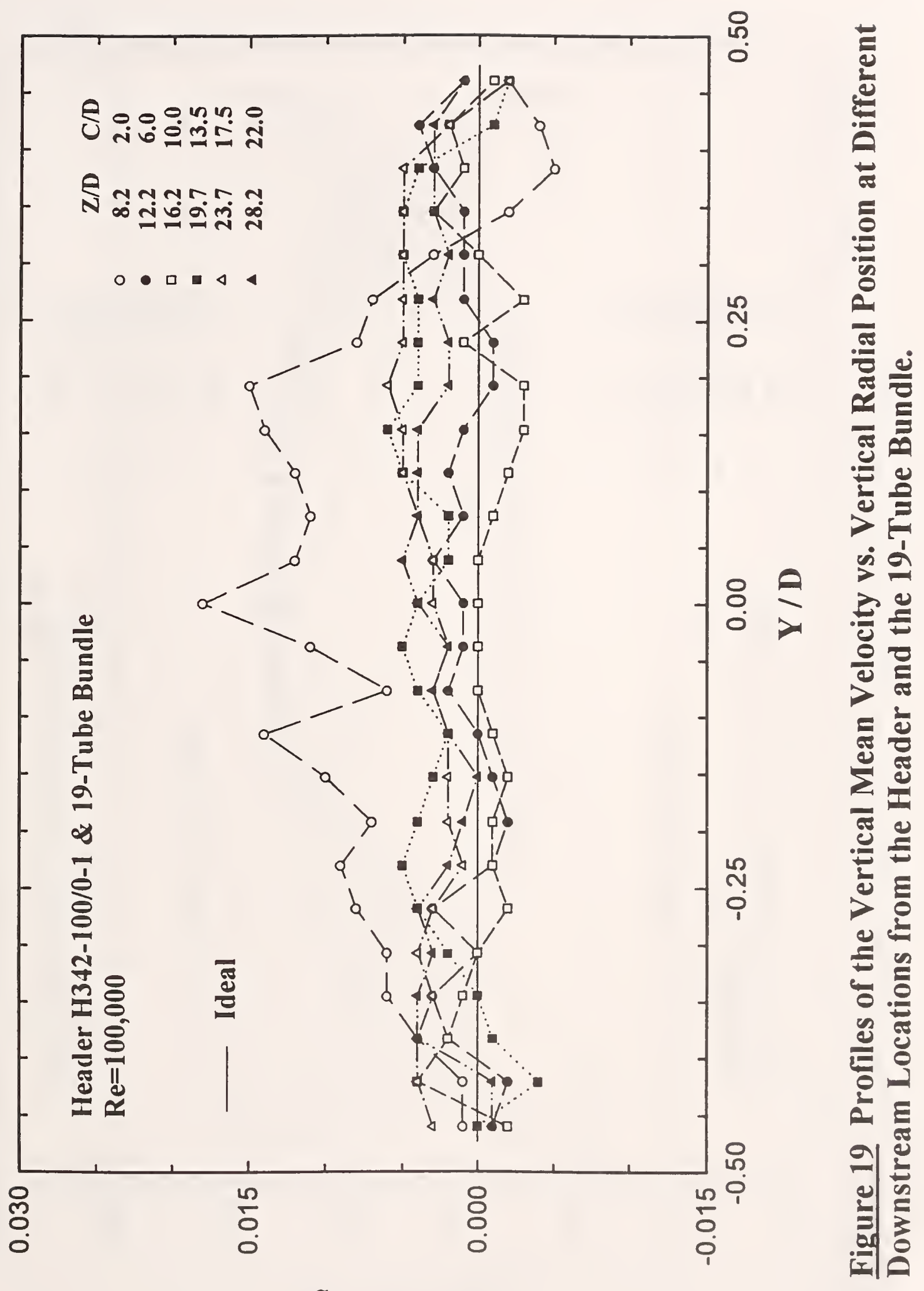

$\sum_{\substack{n \\ j}}^{0}$ 


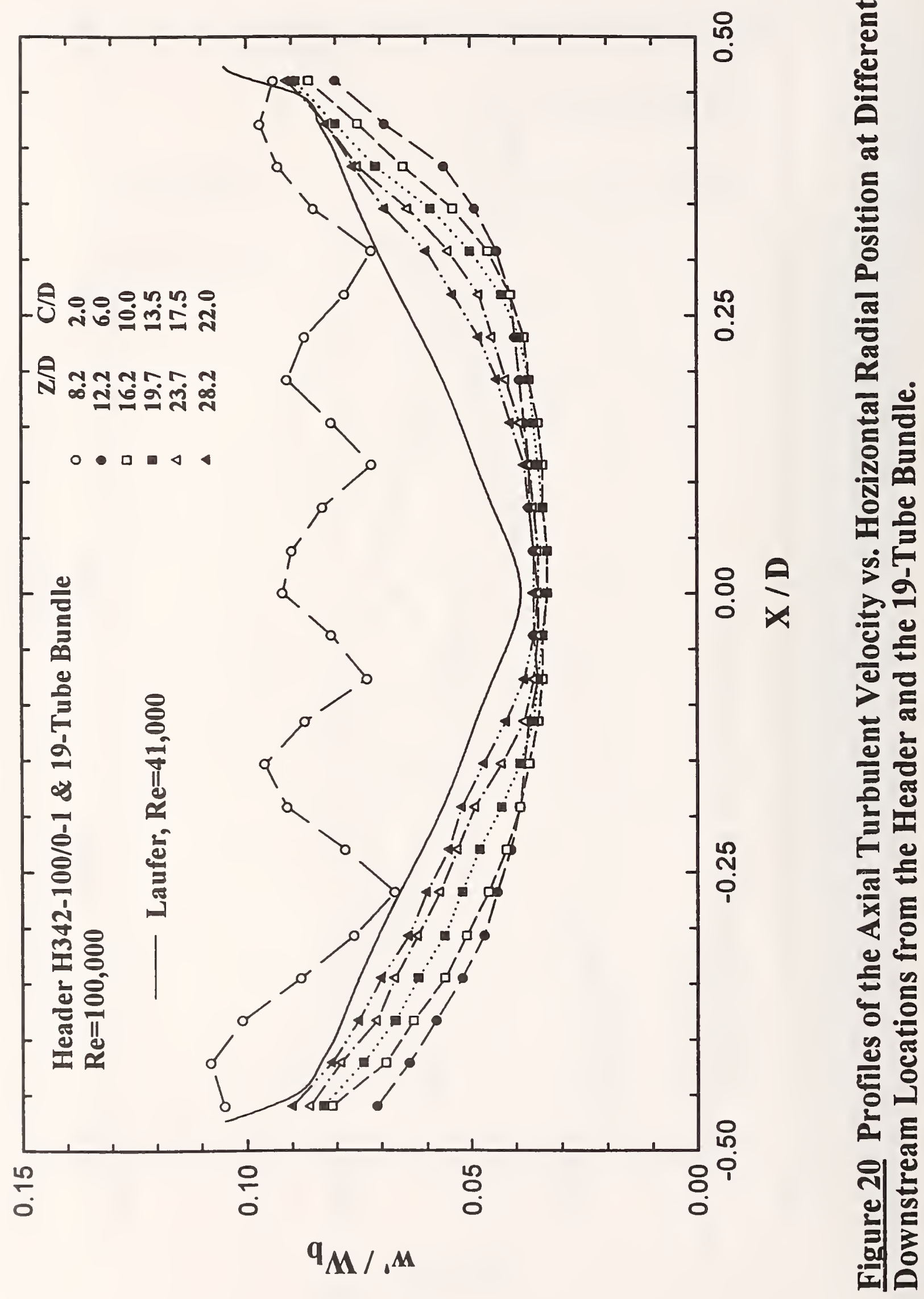




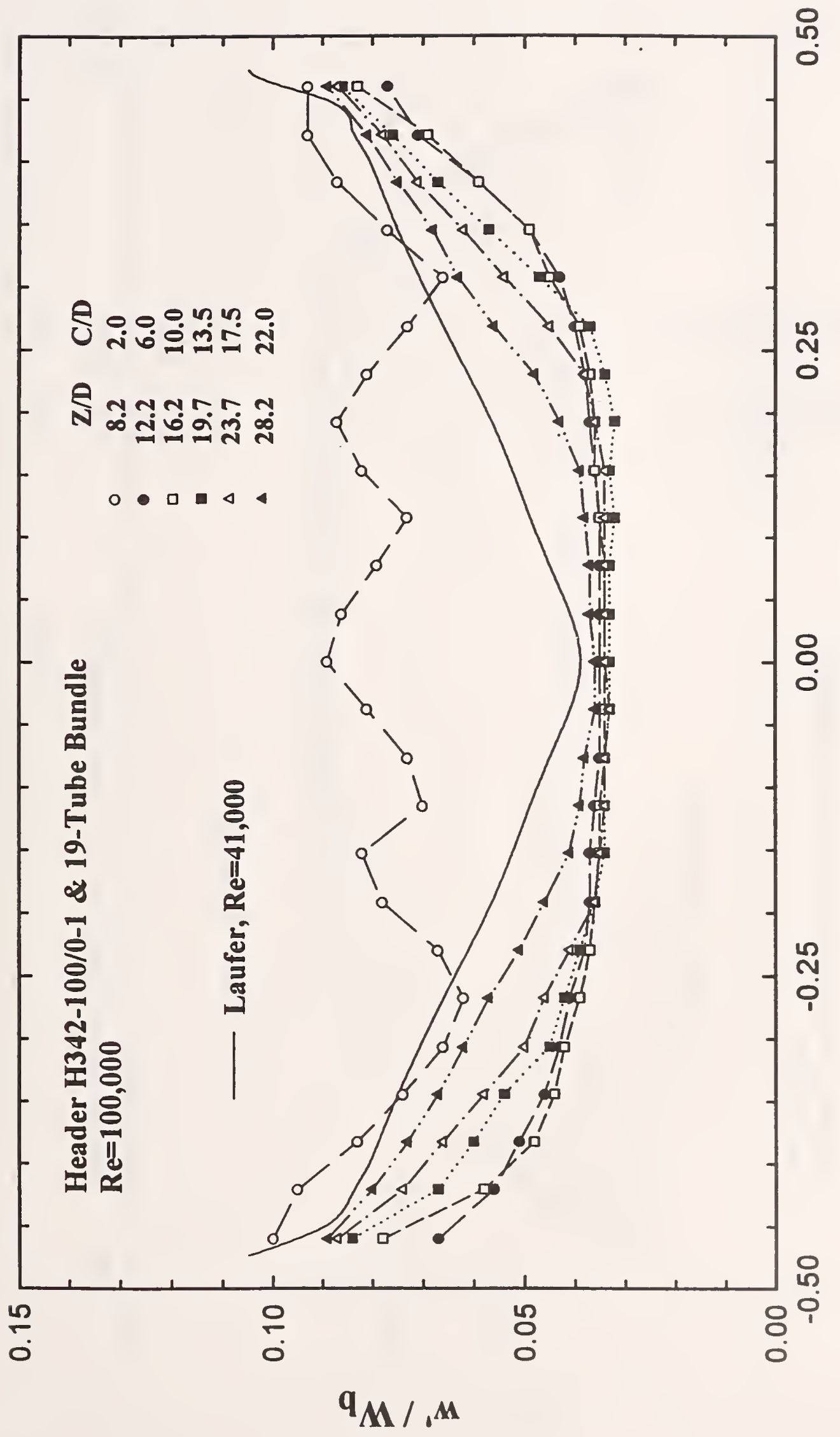

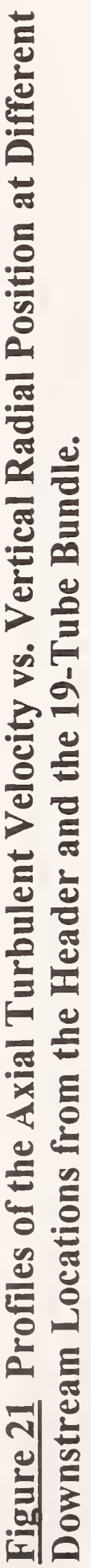




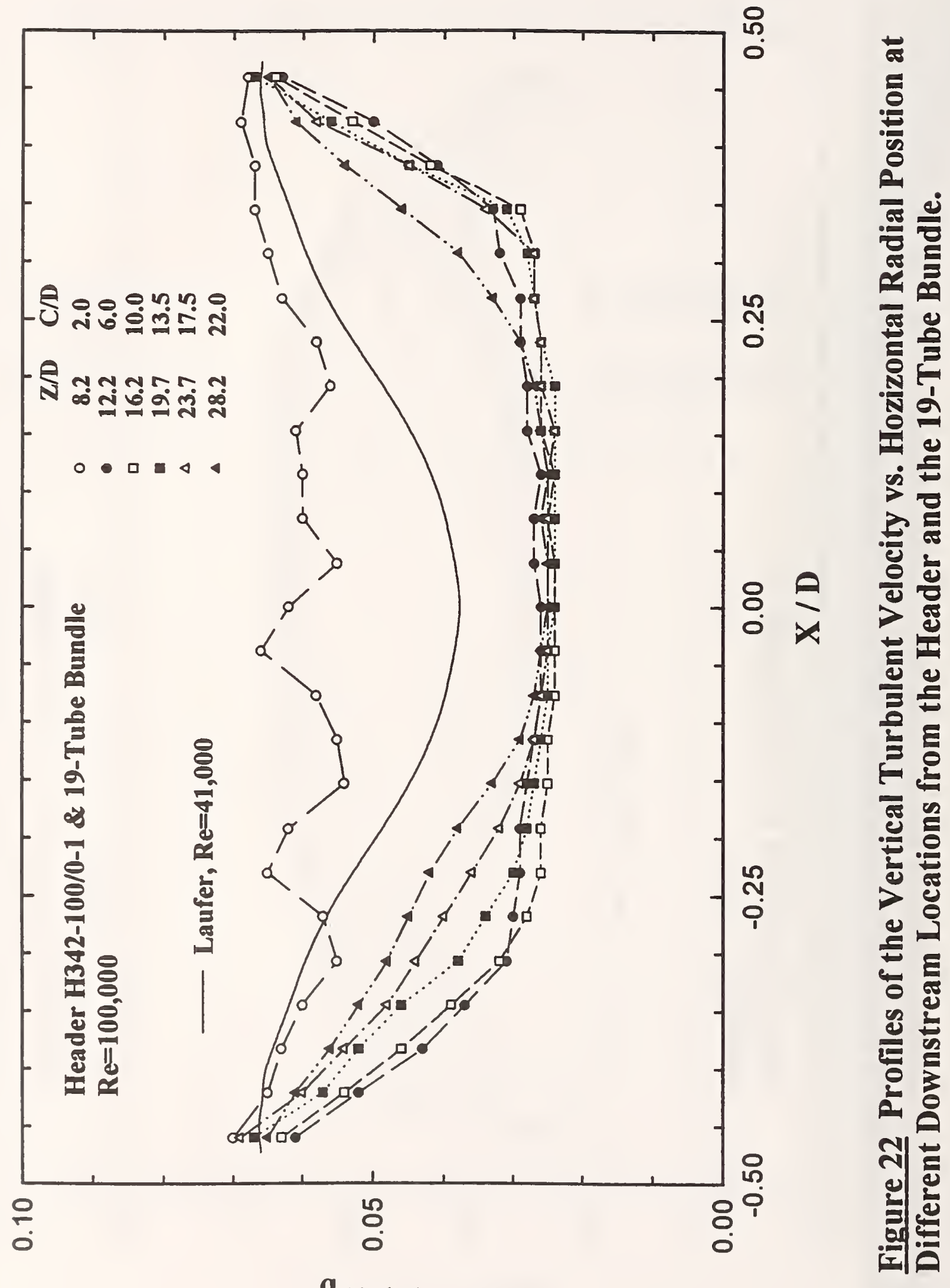




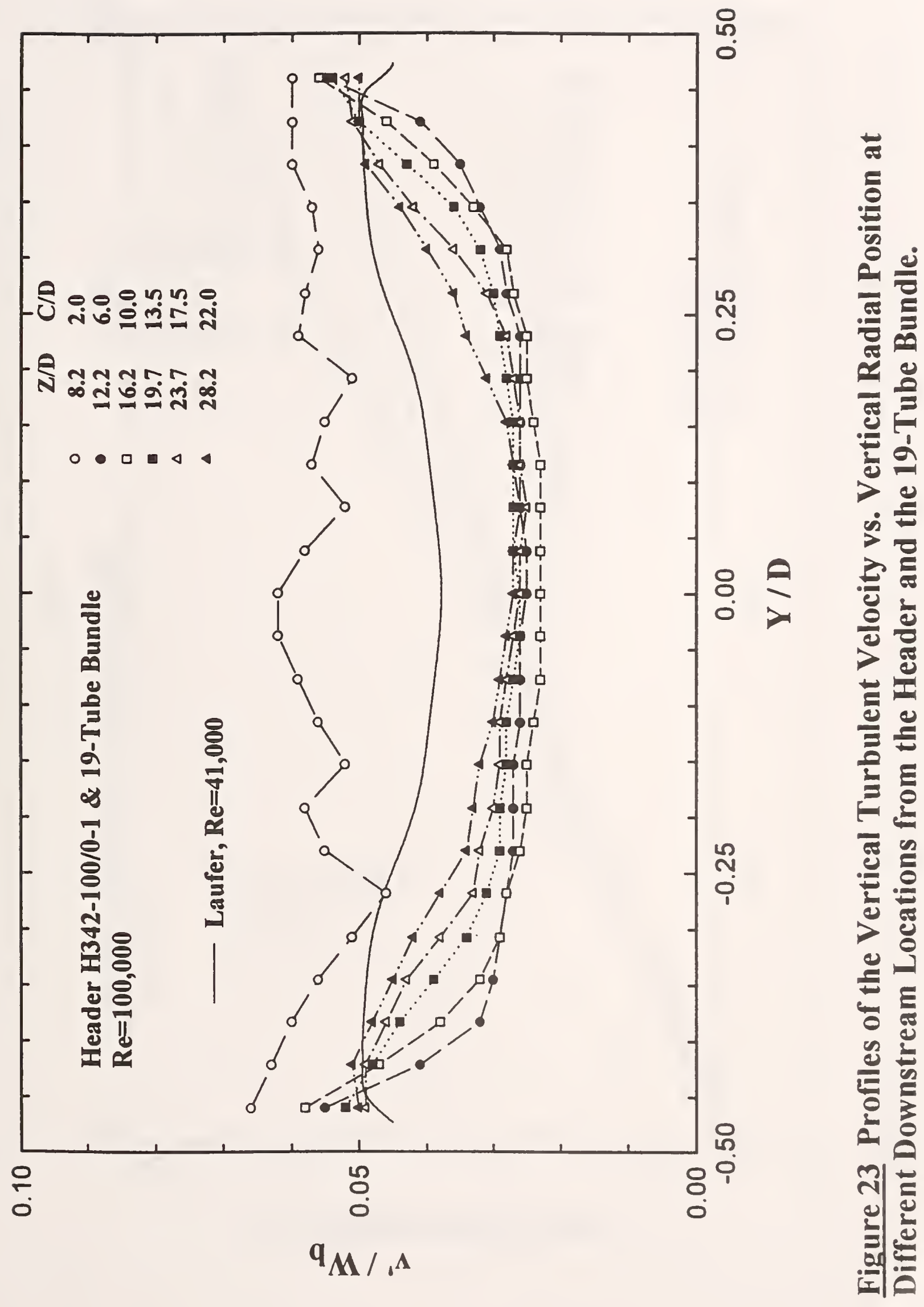

$\frac{0}{5}$ 


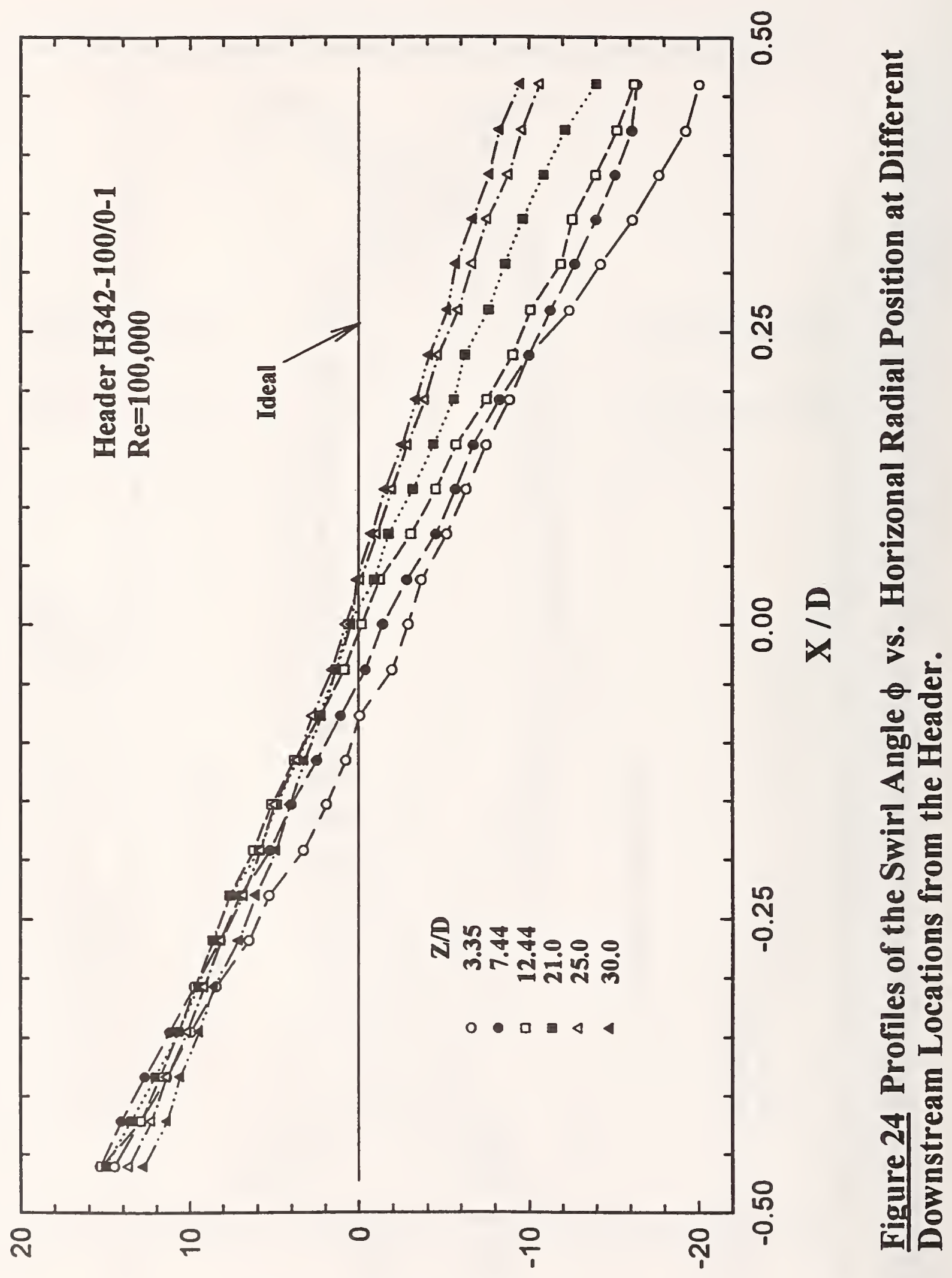

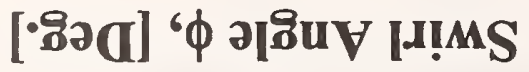




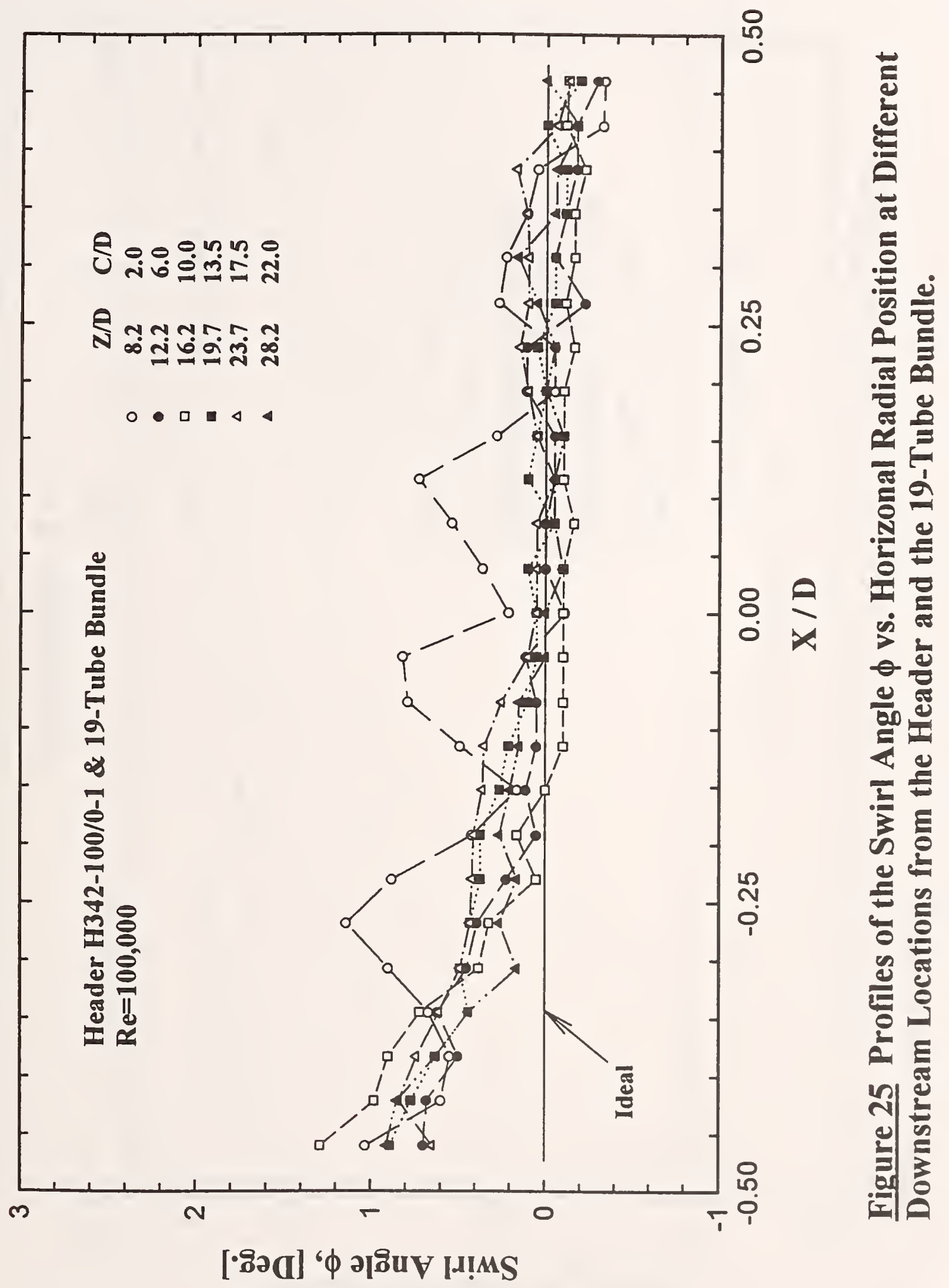

$\frac{y}{x}$ 


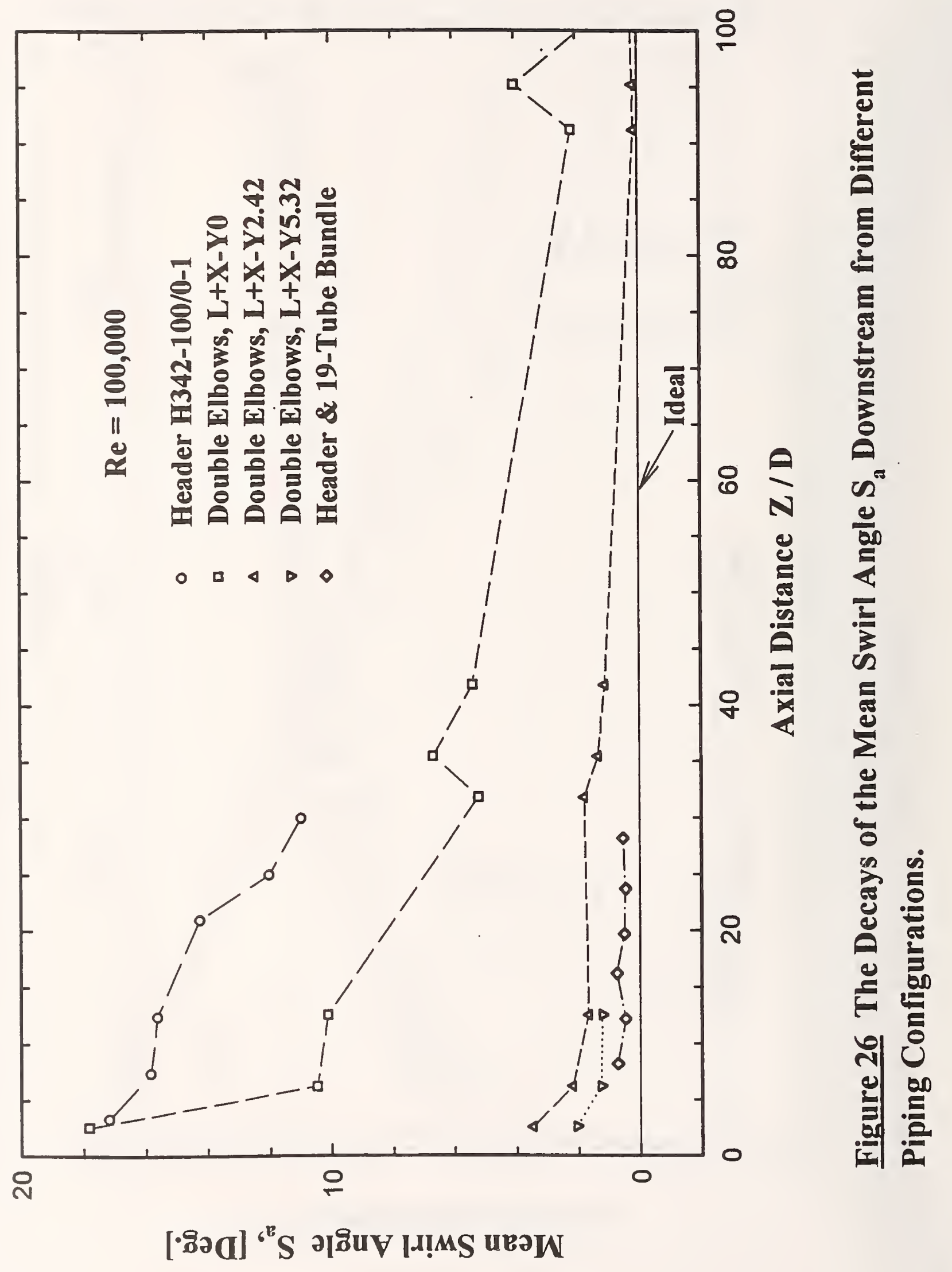




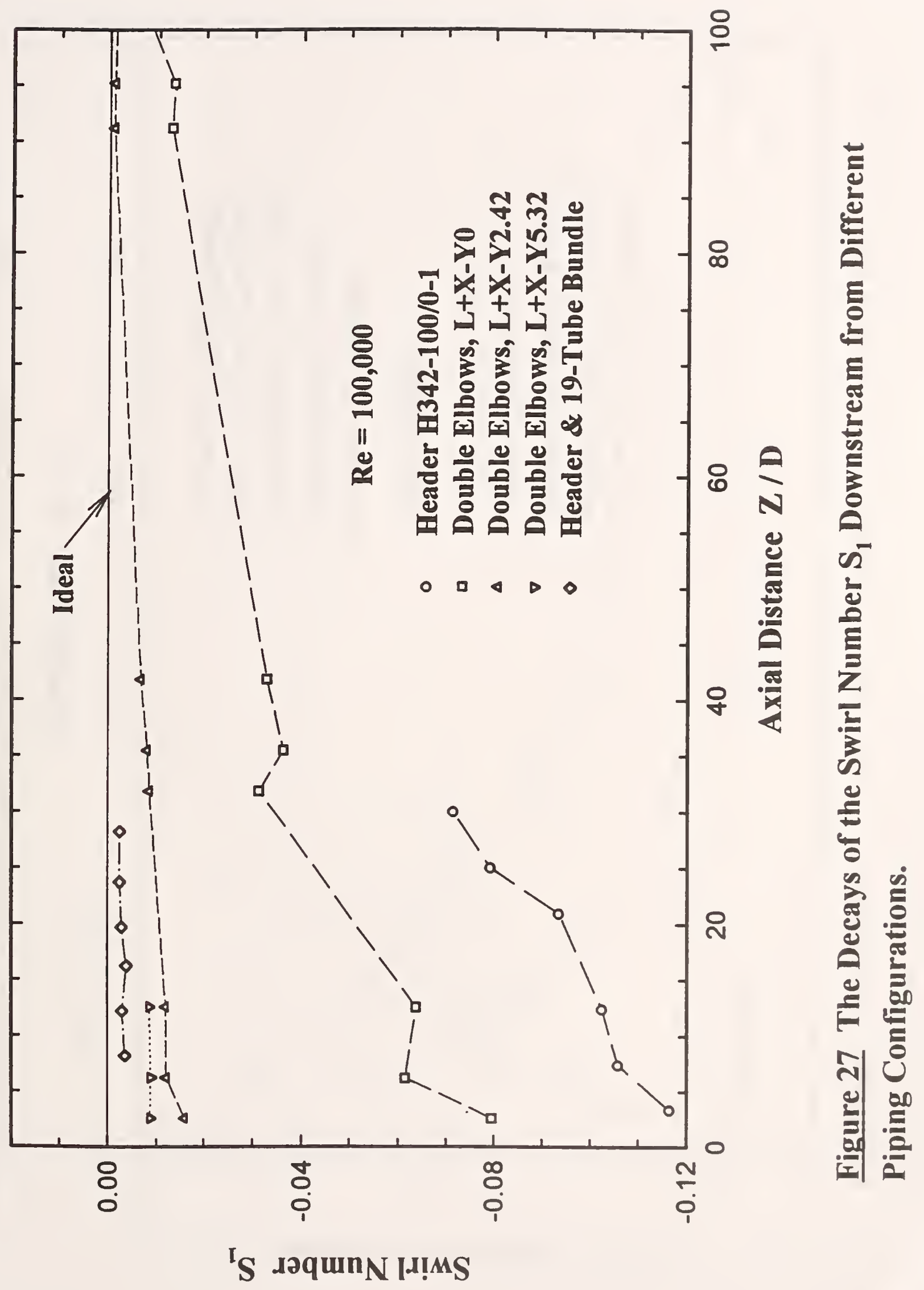




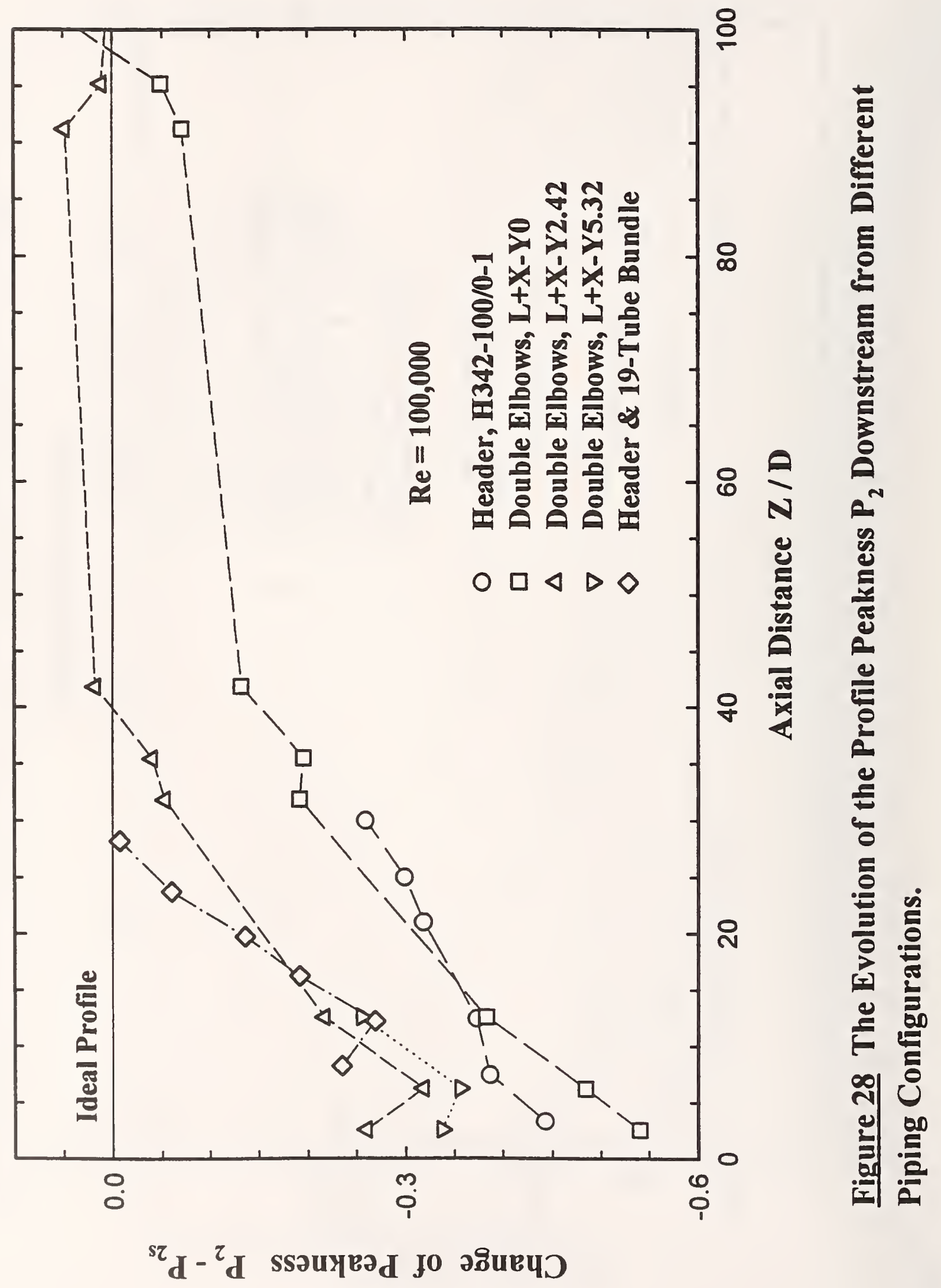




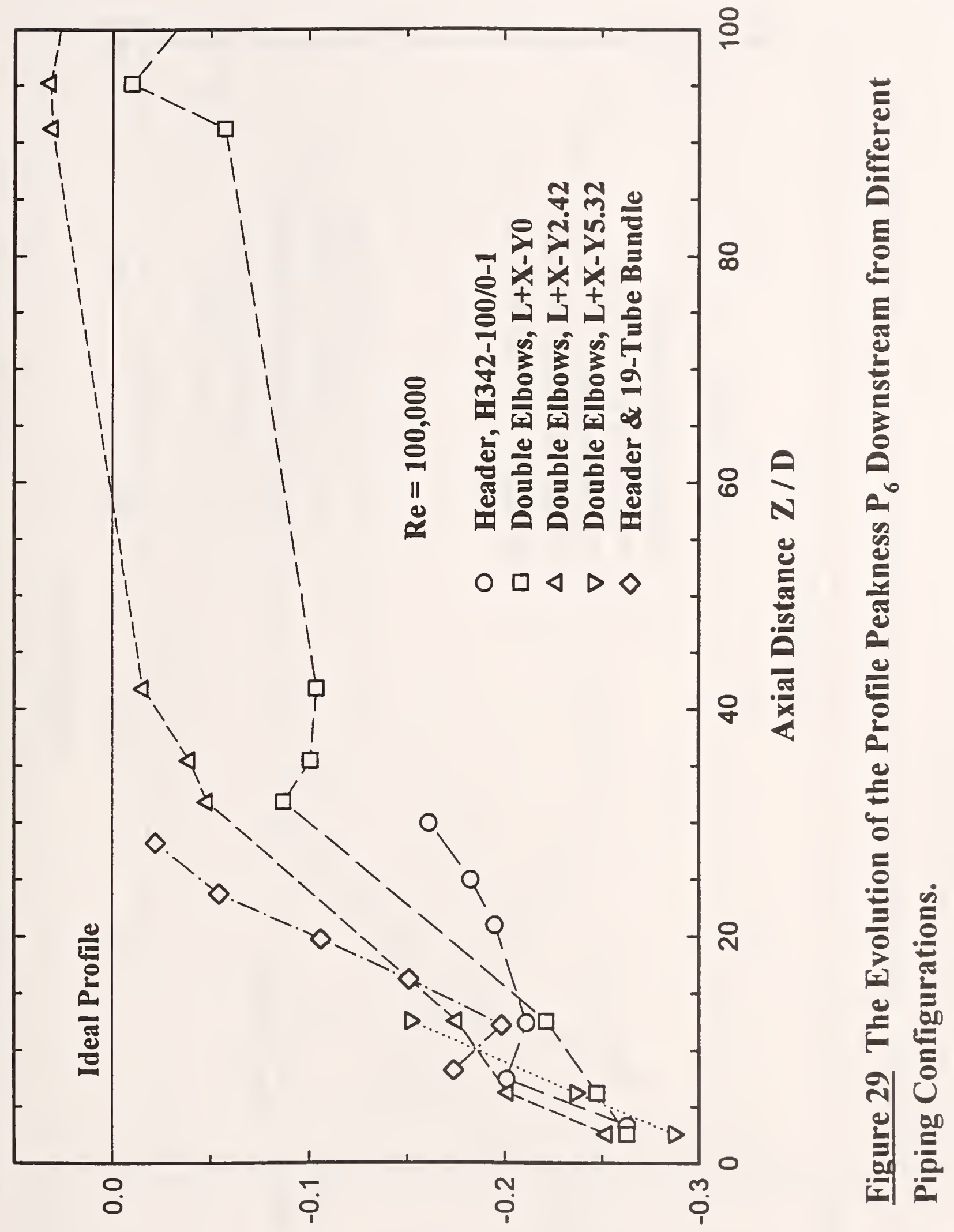

䓂

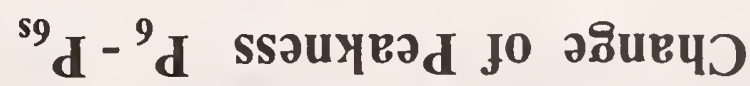




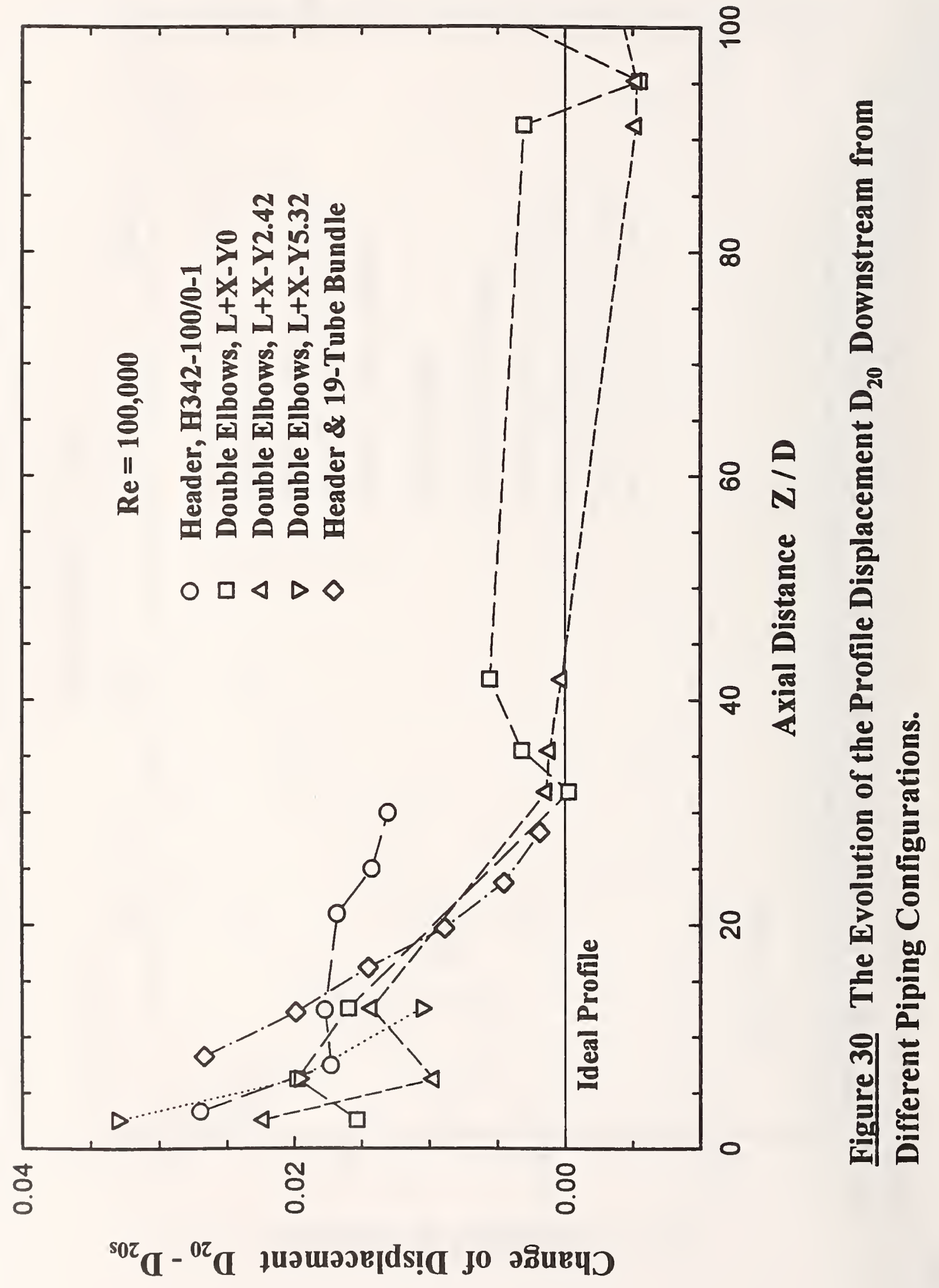




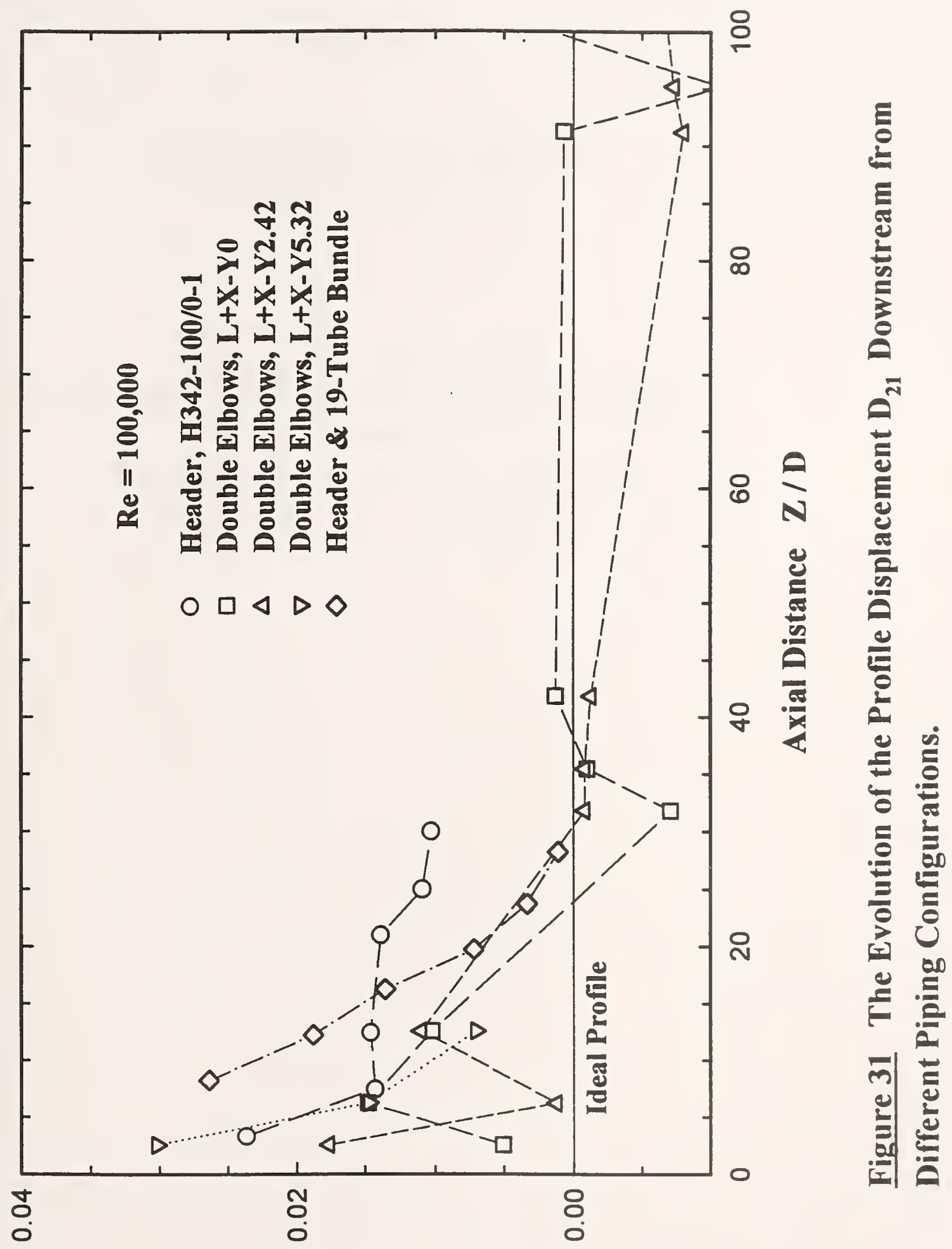

气ิ๊

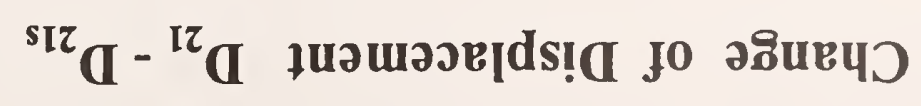





\title{
APPENDIX A
}

\section{Mean and Turbulence Velocity Profiles \\ for Header H342-100/0-1}

\author{
Velocities in the Outlet Pipe \#1 \\ with Outlet \#1 Fully Opened and Outlet \#2 Fully Closed. \\ Water Temperature $=21.5^{\circ} \mathrm{C}$ \\ Water Kinematic Viscosity $=9.71958 * 10^{-7} \mathrm{~m}^{2} / \mathrm{s}$ \\ Pipe Diameter, $\mathrm{D}=5.25 \mathrm{~cm}$ (2.07 in) \\ Reynolds Number $\mathrm{Re}=100000$
}





\section{1) Velocity Profile at $Y=0$, and $Z=3.35 \mathrm{D}$}

I $\quad X / D \quad W / W_{b} \quad W^{\prime} / W_{b} \quad V / W_{b} \quad v^{\prime} / W_{b} \quad \phi$, Deg.

$\begin{array}{lllllll}1 & -0.460 & 0.950 & 0.144 & 0.246 & 0.150 & 14.52\end{array}$

$\begin{array}{lllllll}2 & -0.421 & 1.012 & 0.138 & 0.233 & 0.138 & 12.97\end{array}$

$\begin{array}{lllllll}3 & -0.383 & 1.030 & 0.130 & 0.207 & 0.132 & 11.36\end{array}$

$\begin{array}{lllllll}4 & -0.345 & 1.023 & 0.130 & 0.179 & 0.125 & 9.92\end{array}$

$\begin{array}{lllllll}5 & -0.307 & 1.014 & 0.127 & 0.150 & 0.125 & 8.41\end{array}$

$\begin{array}{lllllll}6 & -0.268 & 1.010 & 0.125 & 0.115 & 0.128 & 6.50\end{array}$

$\begin{array}{lllllll}7 & -0.230 & 1.000 & 0.127 & 0.093 & 0.130 & 5.31\end{array}$

$\begin{array}{lllllll}8 & -0.192 & 0.997 & 0.123 & 0.057 & 0.133 & 3.27\end{array}$

$\begin{array}{lllllll}9 & -0.153 & 0.996 & 0.124 & 0.033 & 0.136 & 1.90\end{array}$

$\begin{array}{rrrrrrr}10 & -0.115 & 0.992 & 0.123 & 0.013 & 0.140 & 0.75\end{array}$

$\begin{array}{lllllll}11 & -0.077 & 0.991 & 0.127 & -0.001 & 0.141 & -0.06\end{array}$

$\begin{array}{lllllll}12 & -0.038 & 0.993 & 0.132 & -0.034 & 0.146 & -1.96\end{array}$

$\begin{array}{lllllll}13 & 0.000 & 0.990 & 0.131 & -0.050 & 0.145 & -2.89\end{array}$

$\begin{array}{lllllll}14 & 0.038 & 0.984 & 0.131 & -0.063 & 0.143 & -3.66\end{array}$

$\begin{array}{lllllll}15 & 0.077 & 0.985 & 0.132 & -0.089 & 0.138 & -5.16\end{array}$

$\begin{array}{lllllll}16 & 0.115 & 0.986 & 0.133 & -0.109 & 0.136 & -6.31\end{array}$

$\begin{array}{lllllll}17 & 0.153 & 0.986 & 0.131 & -0.130 & 0.133 & -7.51\end{array}$

$\begin{array}{lllllll}18 & 0.192 & 0.987 & 0.131 & -0.154 & 0.132 & -8.87\end{array}$

$\begin{array}{lllllll}19 & 0.230 & 0.993 & 0.132 & -0.175 & 0.131 & -9.99\end{array}$

$\begin{array}{lllllll}20 & 0.268 & 0.997 & 0.129 & -0.219 & 0.135 & -12.39\end{array}$

$\begin{array}{lllllll}21 & 0.307 & 1.000 & 0.129 & -0.254 & 0.139 & -14.25\end{array}$

$\begin{array}{llllllll}22 & 0.345 & 1.005 & 0.126 & -0.291 & 0.144 & -16.15\end{array}$

$\begin{array}{llllllll}23 & 0.383 & 1.013 & 0.128 & -0.323 & 0.150 & -17.69\end{array}$

$\begin{array}{lllllll}24 & 0.421 & 1.005 & 0.130 & -0.351 & 0.153 & -19.25\end{array}$

$\begin{array}{lllllll}25 & 0.460 & 0.972 & 0.140 & -0.355 & 0.160 & -20.06\end{array}$ 


\section{2) Velocity Profile at $\mathrm{X}=0$, and $\mathrm{Z}=3.35 \mathrm{D}$}

I $\quad Y / D \quad W / W_{b} \quad W^{\prime} / W_{b} \quad V / W_{b} \quad v^{\prime} / W_{b} \quad \phi$, Deg.

$\begin{array}{rrrrrrr}1 & -0.460 & 0.945 & 0.136 & -0.006 & 0.078 & -0.36 \\ 2 & -0.421 & 0.993 & 0.136 & -0.014 & 0.105 & -0.81 \\ 3 & -0.383 & 0.992 & 0.132 & -0.031 & 0.106 & -1.79 \\ 4 & -0.345 & 0.984 & 0.128 & -0.039 & 0.112 & -2.27 \\ 5 & -0.307 & 0.984 & 0.127 & -0.044 & 0.116 & -2.56 \\ 6 & -0.268 & 0.985 & 0.128 & -0.057 & 0.120 & -3.31 \\ 7 & -0.230 & 0.983 & 0.128 & -0.040 & 0.123 & -2.33 \\ 8 & -0.192 & 0.975 & 0.124 & -0.050 & 0.126 & -2.94 \\ 9 & -0.153 & 0.981 & 0.128 & -0.050 & 0.130 & -2.92 \\ 10 & -0.115 & 0.983 & 0.126 & -0.056 & 0.133 & -3.26 \\ 11 & -0.077 & 0.983 & 0.126 & -0.047 & 0.138 & -2.74 \\ 12 & -0.038 & 0.986 & 0.127 & -0.052 & 0.141 & -3.02 \\ 13 & 0.000 & 0.989 & 0.129 & -0.049 & 0.144 & -2.84 \\ 14 & 0.038 & 0.986 & 0.128 & -0.048 & 0.145 & -2.79 \\ 15 & 0.077 & 0.985 & 0.126 & -0.049 & 0.141 & -2.85 \\ 16 & 0.115 & 0.979 & 0.123 & -0.040 & 0.140 & -2.34 \\ 17 & 0.153 & 0.983 & 0.122 & -0.040 & 0.138 & -2.33 \\ 18 & 0.192 & 0.983 & 0.122 & -0.036 & 0.138 & -2.10 \\ 19 & 0.230 & 0.982 & 0.124 & -0.028 & 0.134 & -1.63 \\ 20 & 0.268 & 0.978 & 0.125 & -0.030 & 0.128 & -1.76 \\ 21 & 0.307 & 0.976 & 0.123 & -0.028 & 0.120 & -1.64 \\ 22 & 0.345 & 0.968 & 0.122 & -0.026 & 0.112 & -1.54 \\ 23 & 0.383 & 0.959 & 0.123 & -0.016 & 0.102 & -0.96 \\ 24 & 0.421 & 0.942 & 0.126 & -0.017 & 0.096 & -1.03 \\ 25 & 0.460 & 0.875 & 0.135 & 0.001 & 0.085 & 0.07\end{array}$




\section{3) Velocity Profile at $\mathrm{Y}=0$, and $\mathrm{Z}=7.44 \mathrm{D}$}

I $\quad X / D \quad W / W_{b} \quad w^{\prime} / W_{b} \quad V / W_{b} \quad v^{\prime} / W_{b} \quad \phi$, Deg.

$\begin{array}{rrrrrrr}1 & -0.460 & 0.828 & 0.138 & 0.227 & 0.145 & 15.33 \\ 2 & -0.421 & 0.908 & 0.123 & 0.228 & 0.131 & 14.10 \\ 3 & -0.383 & 0.966 & 0.118 & 0.218 & 0.123 & 12.72 \\ 4 & -0.345 & 0.994 & 0.113 & 0.197 & 0.116 & 11.21 \\ 5 & -0.307 & 1.005 & 0.113 & 0.172 & 0.108 & 9.71 \\ 6 & -0.268 & 1.009 & 0.111 & 0.145 & 0.102 & 8.18 \\ 7 & -0.230 & 1.009 & 0.109 & 0.124 & 0.104 & 7.01 \\ 8 & -0.192 & 1.013 & 0.108 & 0.093 & 0.101 & 5.25 \\ 9 & -0.153 & 1.015 & 0.107 & 0.071 & 0.103 & 4.00 \\ 10 & -0.115 & 1.015 & 0.103 & 0.044 & 0.103 & 2.48 \\ 11 & -0.077 & 1.015 & 0.105 & 0.019 & 0.104 & 1.07 \\ 12 & -0.038 & 1.016 & 0.102 & -0.007 & 0.107 & -0.39 \\ 13 & 0.000 & 1.018 & 0.100 & -0.025 & 0.109 & -1.41 \\ 14 & 0.038 & 1.016 & 0.102 & -0.050 & 0.106 & -2.82 \\ 15 & 0.077 & 1.015 & 0.102 & -0.080 & 0.102 & -4.51 \\ 16 & 0.115 & 1.018 & 0.102 & -0.101 & 0.099 & -5.67 \\ 17 & 0.153 & 1.017 & 0.101 & -0.120 & 0.096 & -6.73 \\ 18 & 0.192 & 1.014 & 0.102 & -0.148 & 0.092 & -8.30 \\ 19 & 0.230 & 1.016 & 0.103 & -0.179 & 0.090 & -9.99 \\ 20 & 0.268 & 1.015 & 0.105 & -0.202 & 0.089 & -11.26 \\ 21 & 0.307 & 1.012 & 0.109 & -0.228 & 0.087 & -12.70 \\ 22 & 0.345 & 1.008 & 0.112 & -0.251 & 0.090 & -13.98 \\ 23 & 0.383 & 1.006 & 0.114 & -0.272 & 0.092 & -15.13 \\ 24 & 0.421 & 0.987 & 0.119 & -0.285 & 0.096 & -16.11 \\ 25 & 0.460 & 0.956 & 0.132 & -0.282 & 0.126 & -16.43\end{array}$




\section{4) Velocity Profile at $\mathrm{X}=0$, and $\mathrm{Z}=7.4 \mathrm{DD}$}

I $\quad Y / D \quad W / W_{b} \quad W^{\prime} / W_{b} \quad V / W_{b} \quad v^{\prime} / W_{b} \quad \phi$, Deg.

$\begin{array}{lllllll}1 & -0.460 & 0.901 & 0.121 & 0.003 & 0.056 & 0.19\end{array}$

$\begin{array}{lllllll}2 & -0.421 & 0.967 & 0.107 & -0.011 & 0.065 & -0.65\end{array}$

$\begin{array}{lllllll}3 & -0.383 & 0.991 & 0.104 & -0.011 & 0.071 & -0.64\end{array}$

$\begin{array}{lllllll}4 & -0.345 & 0.993 & 0.104 & -0.018 & 0.076 & -1.04\end{array}$

$\begin{array}{lllllll}5 & -0.307 & 0.993 & 0.103 & -0.014 & 0.084 & -0.81\end{array}$

$\begin{array}{lllllll}6 & -0.268 & 0.999 & 0.100 & -0.018 & 0.092 & -1.03\end{array}$

$\begin{array}{lllllll}7 & -0.230 & 1.005 & 0.098 & -0.018 & 0.095 & -1.03\end{array}$

$\begin{array}{lllllll}8 & -0.192 & 1.008 & 0.099 & -0.021 & 0.098 & -1.19\end{array}$

$\begin{array}{lllllll}9 & -0.153 & 1.007 & 0.098 & -0.015 & 0.100 & -0.85\end{array}$

$\begin{array}{lllllll}10 & -0.115 & 1.013 & 0.097 & -0.018 & 0.102 & -1.02\end{array}$

$\begin{array}{lllllll}11 & -0.077 & 1.012 & 0.101 & -0.020 & 0.102 & -1.13\end{array}$

$\begin{array}{lllllll}12 & -0.038 & 1.015 & 0.100 & -0.024 & 0.106 & -1.35\end{array}$

$\begin{array}{lllllll}13 & 0.000 & 1.015 & 0.101 & -0.025 & 0.109 & -1.41\end{array}$

$\begin{array}{lllllll}14 & 0.038 & 1.017 & 0.099 & -0.024 & 0.107 & -1.35\end{array}$

$\begin{array}{lllllll}15 & 0.077 & 1.021 & 0.099 & -0.020 & 0.103 & -1.12\end{array}$

$\begin{array}{llllllll}16 & 0.115 & 1.020 & 0.098 & -0.017 & 0.100 & -0.95\end{array}$

$\begin{array}{llllllll}17 & 0.153 & 1.017 & 0.097 & -0.017 & 0.098 & -0.96\end{array}$

$\begin{array}{lllllll}18 & 0.192 & 1.016 & 0.096 & -0.015 & 0.094 & -0.85\end{array}$

$\begin{array}{llllllll}19 & 0.230 & 1.017 & 0.098 & -0.013 & 0.089 & -0.73\end{array}$

$\begin{array}{lllllll}20 & 0.268 & 1.015 & 0.097 & -0.014 & 0.085 & -0.79\end{array}$

$\begin{array}{lllllll}21 & 0.307 & 1.012 & 0.102 & -0.011 & 0.083 & -0.62\end{array}$

$\begin{array}{lllllll}22 & 0.345 & 0.998 & 0.099 & -0.011 & 0.081 & -0.63\end{array}$

$\begin{array}{lllllll}23 & 0.383 & 0.989 & 0.104 & -0.009 & 0.080 & -0.52\end{array}$

$\begin{array}{lllllll}24 & 0.421 & 0.964 & 0.110 & -0.004 & 0.081 & -0.24\end{array}$

$\begin{array}{lllllll}25 & 0.460 & 0.891 & 0.127 & 0.001 & 0.078 & 0.06\end{array}$ 


\section{5) Velocity Profile at $Y=0$, and $\mathrm{Z}=12.44 \mathrm{D}$}

I $\quad z / D \quad W / W_{b} \quad w^{\prime} / W_{b} \quad V / W_{b} \quad v^{\prime} / W_{b} \quad \phi$, Deg.

$\begin{array}{rrrrrrr}1 & -0.460 & 0.926 & 0.112 & 0.253 & 0.115 & 15.28 \\ 2 & -0.421 & 0.984 & 0.101 & 0.226 & 0.103 & 12.94 \\ 3 & -0.383 & 1.010 & 0.095 & 0.211 & 0.095 & 11.80 \\ 4 & -0.345 & 1.015 & 0.089 & 0.191 & 0.093 & 10.66 \\ 5 & -0.307 & 1.021 & 0.088 & 0.174 & 0.090 & 9.67 \\ 6 & -0.268 & 1.022 & 0.088 & 0.154 & 0.089 & 8.57 \\ 7 & -0.230 & 1.024 & 0.088 & 0.137 & 0.085 & 7.62 \\ 8 & -0.192 & 1.026 & 0.088 & 0.112 & 0.085 & 6.23 \\ 9 & -0.153 & 1.027 & 0.087 & 0.093 & 0.090 & 5.17 \\ 10 & -0.115 & 1.027 & 0.086 & 0.069 & 0.091 & 3.84 \\ 11 & -0.077 & 1.027 & 0.087 & 0.041 & 0.094 & 2.29 \\ 12 & -0.038 & 1.024 & 0.089 & 0.015 & 0.096 & 0.84 \\ 13 & 0.000 & 1.025 & 0.090 & -0.003 & 0.096 & -0.17 \\ 14 & 0.038 & 1.024 & 0.093 & -0.022 & 0.094 & -1.23 \\ 15 & 0.077 & 1.028 & 0.089 & -0.055 & 0.089 & -3.06 \\ 16 & 0.115 & 1.030 & 0.089 & -0.081 & 0.086 & -4.50 \\ 17 & 0.153 & 1.030 & 0.089 & -0.103 & 0.083 & -5.71 \\ 18 & 0.192 & 1.030 & 0.091 & -0.136 & 0.086 & -7.52 \\ 19 & 0.230 & 1.029 & 0.092 & -0.164 & 0.086 & -9.06 \\ 20 & 0.268 & 1.024 & 0.093 & -0.182 & 0.088 & -10.08 \\ 21 & 0.307 & 1.018 & 0.094 & -0.214 & 0.088 & -11.87 \\ 22 & 0.345 & 1.006 & 0.096 & -0.224 & 0.091 & -12.55 \\ 23 & 0.383 & 0.986 & 0.100 & -0.245 & 0.094 & -13.95 \\ 24 & 0.421 & 0.951 & 0.104 & -0.259 & 0.098 & -15.23 \\ 25 & 0.460 & 0.882 & 0.108 & -0.257 & 0.110 & -16.25\end{array}$


6) Velocity Profile at $\mathrm{X}=0$, and $\mathrm{Z}=12.44 \mathrm{D}$

$I \quad Y / D \quad W / W_{b} \quad W^{1} / W_{b} \quad V / W_{b} \quad v^{\prime} / W_{b} \quad \phi$, Deg.

$\begin{array}{rrrrrrr}1 & -0.460 & 0.894 & 0.113 & 0.000 & 0.059 & 0.00 \\ 2 & -0.421 & 0.967 & 0.101 & -0.003 & 0.054 & -0.18 \\ 3 & -0.383 & 0.997 & 0.092 & -0.005 & 0.059 & -0.29 \\ 4 & -0.345 & 1.007 & 0.092 & -0.006 & 0.061 & -0.34 \\ 5 & -0.307 & 1.020 & 0.090 & -0.008 & 0.064 & -0.45 \\ 6 & -0.268 & 1.025 & 0.087 & -0.007 & 0.069 & -0.39 \\ 7 & -0.230 & 1.030 & 0.086 & -0.010 & 0.073 & -0.56 \\ 8 & -0.192 & 1.033 & 0.084 & -0.007 & 0.077 & -0.39 \\ 9 & -0.153 & 1.030 & 0.088 & -0.010 & 0.082 & -0.56 \\ 10 & -0.115 & 1.026 & 0.084 & -0.007 & 0.087 & -0.39 \\ 11 & -0.077 & 1.025 & 0.087 & -0.010 & 0.091 & -0.56 \\ 12 & -0.038 & 1.025 & 0.088 & -0.007 & 0.094 & -0.39 \\ 13 & 0.000 & 1.024 & 0.089 & -0.010 & 0.095 & -0.56 \\ 14 & 0.038 & 1.022 & 0.089 & -0.008 & 0.094 & -0.45 \\ 15 & 0.077 & 1.023 & 0.085 & -0.006 & 0.092 & -0.34 \\ 16 & 0.115 & 1.025 & 0.086 & -0.004 & 0.089 & -0.22 \\ 17 & 0.153 & 1.026 & 0.088 & -0.005 & 0.086 & -0.28 \\ 18 & 0.192 & 1.026 & 0.086 & -0.008 & 0.082 & -0.45 \\ 19 & 0.230 & 1.021 & 0.089 & -0.008 & 0.078 & -0.45 \\ 20 & 0.268 & 1.018 & 0.088 & -0.005 & 0.072 & -0.28 \\ 21 & 0.307 & 1.013 & 0.087 & -0.006 & 0.066 & -0.34 \\ 22 & 0.345 & 1.006 & 0.090 & -0.004 & 0.065 & -0.23 \\ 23 & 0.383 & 0.989 & 0.094 & -0.004 & 0.062 & -0.23 \\ 24 & 0.421 & 0.956 & 0.101 & -0.005 & 0.059 & -0.30 \\ 25 & 0.460 & 0.869 & 0.120 & -0.002 & 0.060 & -0.13\end{array}$




\section{7) Velocity Profile at $Y=0$, and $\mathrm{Z}=21 \mathrm{D}$}

I $\quad X / D \quad W / W_{b} \quad W^{1} / W_{b} \quad V / W_{b} \quad V^{\prime} / W_{b} \quad \phi$, Deg.

$\begin{array}{lllllll}1 & -0.460 & 0.914 & 0.100 & 0.245 & 0.095 & 15.01\end{array}$

$\begin{array}{lllllll}2 & -0.421 & 0.979 & 0.091 & 0.236 & 0.089 & 13.55\end{array}$

$\begin{array}{llllllll}3 & -0.383 & 1.013 & 0.086 & 0.217 & 0.083 & 12.09\end{array}$

$\begin{array}{lllllll}4 & -0.345 & 1.030 & 0.082 & 0.194 & 0.080 & 10.67\end{array}$

$\begin{array}{lllllll}5 & -0.307 & 1.041 & 0.080 & 0.174 & 0.079 & 9.49\end{array}$

$\begin{array}{llllllll}6 & -0.268 & 1.045 & 0.078 & 0.159 & 0.076 & 8.65\end{array}$

$\begin{array}{lllllll}7 & -0.230 & 1.044 & 0.075 & 0.139 & 0.075 & 7.58\end{array}$

$\begin{array}{lllllll}8 & -0.192 & 1.045 & 0.074 & 0.108 & 0.075 & 5.90\end{array}$

$\begin{array}{lllllll}9 & -0.153 & 1.048 & 0.073 & 0.089 & 0.078 & 4.85\end{array}$

$\begin{array}{lllllll}10 & -0.115 & 1.048 & 0.072 & 0.067 & 0.080 & 3.66\end{array}$

$\begin{array}{lllllll}11 & -0.077 & 1.049 & 0.071 & 0.043 & 0.083 & 2.35\end{array}$

$\begin{array}{lllllll}12 & -0.038 & 1.050 & 0.071 & 0.025 & 0.084 & 1.36\end{array}$

$\begin{array}{lllllll}13 & 0.000 & 1.049 & 0.072 & 0.011 & 0.083 & 0.60\end{array}$

$\begin{array}{llllllll}14 & 0.038 & 1.052 & 0.072 & -0.017 & 0.083 & -0.93\end{array}$

$\begin{array}{llllllll}15 & 0.077 & 1.050 & 0.073 & -0.032 & 0.081 & -1.75\end{array}$

$\begin{array}{llllllll}16 & 0.115 & 1.051 & 0.072 & -0.058 & 0.080 & -3.16\end{array}$

$\begin{array}{llllllll}17 & 0.153 & 1.050 & 0.074 & -0.080 & 0.081 & -4.36\end{array}$

$\begin{array}{lllllll}18 & 0.192 & 1.045 & 0.073 & -0.102 & 0.081 & -5.57\end{array}$

$\begin{array}{llllllll}19 & 0.230 & 1.046 & 0.074 & -0.114 & 0.082 & -6.22\end{array}$

$\begin{array}{lllllll}20 & 0.268 & 1.046 & 0.077 & -0.140 & 0.083 & -7.62\end{array}$

$\begin{array}{lllllll}21 & 0.307 & 1.038 & 0.080 & -0.157 & 0.084 & -8.60\end{array}$

$\begin{array}{llllllll}22 & 0.345 & 1.032 & 0.083 & -0.175 & 0.086 & -9.62\end{array}$

$\begin{array}{llllllll}23 & 0.383 & 1.013 & 0.087 & -0.194 & 0.089 & -10.84\end{array}$

$\begin{array}{lllllll}24 & 0.421 & 0.986 & 0.092 & -0.212 & 0.093 & -12.13\end{array}$

$\begin{array}{llllllll}25 & 0.460 & 0.914 & 0.102 & -0.228 & 0.100 & -14.01\end{array}$ 


\section{8) Velocity Profile at $\mathrm{X}=0$, and $\mathrm{Z}=21 \mathrm{D}$}

I $\quad Y / D \quad W / W_{b} \quad W^{\prime} / W_{b} \quad V / W_{b} \quad v^{\prime} / W_{b} \quad \phi, D e g$.

$\begin{array}{rrrrrrr}1 & -0.460 & 0.913 & 0.104 & 0.003 & 0.052 & 0.19 \\ 2 & -0.421 & 0.984 & 0.095 & 0.002 & 0.056 & 0.12 \\ 3 & -0.383 & 1.019 & 0.089 & 0.001 & 0.058 & 0.06 \\ 4 & -0.345 & 1.037 & 0.083 & -0.001 & 0.061 & -0.06 \\ 5 & -0.307 & 1.049 & 0.081 & -0.001 & 0.064 & -0.05 \\ 6 & -0.268 & 1.052 & 0.078 & -0.002 & 0.068 & -0.11 \\ 7 & -0.230 & 1.053 & 0.076 & -0.002 & 0.071 & -0.11 \\ 8 & -0.192 & 1.057 & 0.074 & -0.001 & 0.076 & -0.05 \\ 9 & -0.153 & 1.054 & 0.073 & -0.002 & 0.080 & -0.11 \\ 10 & -0.115 & 1.054 & 0.073 & 0.002 & 0.081 & 0.11 \\ 11 & -0.077 & 1.056 & 0.072 & 0.005 & 0.082 & 0.27 \\ 12 & -0.038 & 1.054 & 0.072 & 0.008 & 0.083 & 0.43 \\ 13 & 0.000 & 1.052 & 0.072 & 0.008 & 0.083 & 0.44 \\ 14 & 0.038 & 1.052 & 0.073 & 0.007 & 0.083 & 0.38 \\ 15 & 0.077 & 1.053 & 0.073 & 0.006 & 0.081 & 0.33 \\ 16 & 0.115 & 1.053 & 0.073 & 0.005 & 0.079 & 0.27 \\ 17 & 0.153 & 1.053 & 0.074 & 0.005 & 0.075 & 0.27 \\ 18 & 0.192 & 1.056 & 0.075 & 0.005 & 0.072 & 0.27 \\ 19 & 0.230 & 1.048 & 0.076 & 0.007 & 0.069 & 0.38 \\ 20 & 0.268 & 1.049 & 0.078 & 0.005 & 0.065 & 0.27 \\ 21 & 0.307 & 1.041 & 0.080 & 0.004 & 0.059 & 0.22 \\ 22 & 0.345 & 1.034 & 0.084 & 0.005 & 0.057 & 0.28 \\ 23 & 0.383 & 1.015 & 0.089 & 0.006 & 0.055 & 0.34 \\ 24 & 0.421 & 0.983 & 0.095 & 0.001 & 0.054 & 0.06 \\ 25 & 0.460 & 0.920 & 0.108 & 0.000 & 0.052 & 0.00\end{array}$




\section{9) Velocity Profile at $\mathrm{Y}=0$, and $\mathrm{Z}=25 \mathrm{D}$}

I $\quad X / D \quad W / W_{b} \quad W^{\prime} / W_{b} \quad V / W_{b} \quad V^{\prime} / W_{b} \quad \phi$, Deg.

$\begin{array}{rrrrrrr}1 & -0.460 & 0.859 & 0.102 & 0.209 & 0.089 & 13.67 \\ 2 & -0.421 & 0.952 & 0.092 & 0.208 & 0.080 & 12.32 \\ 3 & -0.383 & 0.999 & 0.087 & 0.201 & 0.076 & 11.38 \\ 4 & -0.345 & 1.019 & 0.083 & 0.182 & 0.072 & 10.13 \\ 5 & -0.307 & 1.034 & 0.078 & 0.166 & 0.069 & 9.12 \\ 6 & -0.268 & 1.045 & 0.075 & 0.149 & 0.067 & 8.11 \\ 7 & -0.230 & 1.053 & 0.072 & 0.126 & 0.066 & 6.82 \\ 8 & -0.192 & 1.059 & 0.072 & 0.108 & 0.067 & 5.82 \\ 9 & -0.153 & 1.062 & 0.071 & 0.093 & 0.069 & 5.00 \\ 10 & -0.115 & 1.061 & 0.069 & 0.068 & 0.071 & 3.67 \\ 11 & -0.077 & 1.059 & 0.069 & 0.051 & 0.073 & 2.76 \\ 12 & -0.038 & 1.059 & 0.068 & 0.029 & 0.073 & 1.57 \\ 13 & 0.000 & 1.060 & 0.068 & 0.014 & 0.074 & 0.76 \\ 14 & 0.038 & 1.059 & 0.069 & -0.002 & 0.073 & -0.11 \\ 15 & 0.077 & 1.061 & 0.069 & -0.020 & 0.072 & -1.08 \\ 16 & 0.115 & 1.059 & 0.069 & -0.036 & 0.071 & -1.95 \\ 17 & 0.153 & 1.060 & 0.069 & -0.053 & 0.071 & -2.86 \\ 18 & 0.192 & 1.061 & 0.070 & -0.072 & 0.072 & -3.88 \\ 19 & 0.230 & 1.057 & 0.070 & -0.086 & 0.073 & -4.65 \\ 20 & 0.268 & 1.056 & 0.072 & -0.108 & 0.074 & -5.84 \\ 21 & 0.307 & 1.052 & 0.074 & -0.123 & 0.073 & -6.67 \\ 22 & 0.345 & 1.044 & 0.079 & -0.139 & 0.076 & -7.58 \\ 23 & 0.383 & 1.026 & 0.083 & -0.159 & 0.079 & -8.81 \\ 24 & 0.421 & 1.004 & 0.088 & -0.170 & 0.082 & -9.61 \\ 25 & 0.460 & 0.925 & 0.096 & -0.174 & 0.088 & -10.65\end{array}$




\section{0) Velocity Profile at $\mathrm{x}=0$, and $\mathrm{Z}=25 \mathrm{D}$}

$I \quad Y / D \quad W / W_{b} \quad W^{\prime} / W_{b} \quad V / W_{b} \quad v^{\prime} / W_{b} \quad \phi$, Deg.

$\begin{array}{rrrrrrr}1 & -0.460 & 0.907 & 0.101 & 0.004 & 0.051 & 0.25 \\ 2 & -0.421 & 0.973 & 0.092 & 0.003 & 0.052 & 0.18 \\ 3 & -0.383 & 1.012 & 0.087 & 0.004 & 0.054 & 0.23 \\ 4 & -0.345 & 1.030 & 0.082 & 0.003 & 0.056 & 0.17 \\ 5 & -0.307 & 1.042 & 0.079 & 0.005 & 0.058 & 0.27 \\ 6 & -0.268 & 1.054 & 0.076 & 0.006 & 0.060 & 0.33 \\ 7 & -0.230 & 1.059 & 0.072 & 0.005 & 0.063 & 0.27 \\ 8 & -0.192 & 1.061 & 0.071 & 0.005 & 0.065 & 0.27 \\ 9 & -0.153 & 1.064 & 0.070 & 0.007 & 0.068 & 0.38 \\ 10 & -0.115 & 1.064 & 0.069 & 0.009 & 0.071 & 0.48 \\ 11 & -0.077 & 1.067 & 0.068 & 0.009 & 0.073 & 0.48 \\ 12 & -0.038 & 1.065 & 0.068 & 0.009 & 0.074 & 0.48 \\ 13 & 0.000 & 1.064 & 0.068 & 0.006 & 0.074 & 0.32 \\ 14 & 0.038 & 1.064 & 0.069 & 0.007 & 0.073 & 0.38 \\ 15 & 0.077 & 1.065 & 0.069 & 0.007 & 0.072 & 0.38 \\ 16 & 0.115 & 1.061 & 0.069 & 0.007 & 0.070 & 0.38 \\ 17 & 0.153 & 1.060 & 0.070 & 0.008 & 0.067 & 0.43 \\ 18 & 0.192 & 1.054 & 0.071 & 0.010 & 0.065 & 0.54 \\ 19 & 0.230 & 1.053 & 0.073 & 0.012 & 0.061 & 0.65 \\ 20 & 0.268 & 1.045 & 0.076 & 0.010 & 0.058 & 0.55 \\ 21 & 0.307 & 1.045 & 0.078 & 0.010 & 0.056 & 0.55 \\ 22 & 0.345 & 1.034 & 0.082 & 0.010 & 0.053 & 0.55 \\ 23 & 0.383 & 1.012 & 0.086 & 0.009 & 0.052 & 0.51 \\ 24 & 0.421 & 0.974 & 0.090 & 0.008 & 0.051 & 0.47 \\ 25 & 0.460 & 0.914 & 0.098 & 0.002 & 0.050 & 0.13\end{array}$




\section{1) Velocity Profile at $Y=0$, and $Z=30 D$}

I $\quad x / D \quad W / W_{b} \quad W^{\prime} / W_{b} \quad V / W_{b} \quad v^{\prime} / W_{b} \quad \phi$, Deg.

$\begin{array}{rrrrrrr}1 & -0.460 & 0.869 & 0.097 & 0.197 & 0.081 & 12.77 \\ 2 & -0.421 & 0.961 & 0.089 & 0.193 & 0.075 & 11.36 \\ 3 & -0.383 & 1.004 & 0.084 & 0.187 & 0.070 & 10.55 \\ 4 & -0.345 & 1.025 & 0.080 & 0.170 & 0.067 & 9.42 \\ 5 & -0.307 & 1.039 & 0.077 & 0.156 & 0.064 & 8.54 \\ 6 & -0.268 & 1.053 & 0.073 & 0.131 & 0.062 & 7.09 \\ 7 & -0.230 & 1.059 & 0.071 & 0.113 & 0.060 & 6.09 \\ 8 & -0.192 & 1.065 & 0.070 & 0.091 & 0.059 & 4.88 \\ 9 & -0.153 & 1.070 & 0.068 & 0.076 & 0.059 & 4.06 \\ 10 & -0.115 & 1.074 & 0.067 & 0.060 & 0.061 & 3.20 \\ 11 & -0.077 & 1.074 & 0.067 & 0.041 & 0.064 & 2.19 \\ 12 & -0.038 & 1.075 & 0.065 & 0.025 & 0.064 & 1.33 \\ 13 & 0.000 & 1.079 & 0.066 & 0.008 & 0.064 & 0.42 \\ 14 & 0.038 & 1.077 & 0.066 & 0.002 & 0.064 & 0.11 \\ 15 & 0.077 & 1.074 & 0.067 & -0.014 & 0.064 & -0.75 \\ 16 & 0.115 & 1.076 & 0.068 & -0.029 & 0.063 & -1.54 \\ 17 & 0.153 & 1.075 & 0.067 & -0.048 & 0.061 & -2.56 \\ 18 & 0.192 & 1.072 & 0.068 & -0.063 & 0.060 & -3.36 \\ 19 & 0.230 & 1.070 & 0.069 & -0.077 & 0.062 & -4.12 \\ 20 & 0.268 & 1.067 & 0.070 & -0.097 & 0.063 & -5.19 \\ 21 & 0.307 & 1.062 & 0.074 & -0.106 & 0.066 & -5.70 \\ 22 & 0.345 & 1.040 & 0.079 & -0.122 & 0.069 & -6.69 \\ 23 & 0.383 & 1.015 & 0.083 & -0.137 & 0.071 & -7.69 \\ 24 & 0.421 & 0.988 & 0.087 & -0.144 & 0.076 & -8.29 \\ 25 & 0.460 & 0.927 & 0.097 & -0.155 & 0.082 & -9.49\end{array}$


I $\quad Y / D \quad W / W_{b} \quad W^{\prime} / W_{b} \quad V / W_{b} \quad v^{\prime} / W_{b} \quad \phi$, Deg.

$\begin{array}{rrrrrrr}1 & -0.460 & 0.895 & 0.098 & -0.002 & 0.050 & -0.13 \\ 2 & -0.421 & 0.969 & 0.090 & -0.002 & 0.053 & -0.12 \\ 3 & -0.383 & 1.006 & 0.084 & -0.003 & 0.055 & -0.17 \\ 4 & -0.345 & 1.031 & 0.080 & -0.002 & 0.057 & -0.11 \\ 5 & -0.307 & 1.045 & 0.077 & -0.004 & 0.058 & -0.22 \\ 6 & -0.268 & 1.057 & 0.073 & 0.000 & 0.059 & 0.00 \\ 7 & -0.230 & 1.064 & 0.071 & -0.001 & 0.061 & -0.05 \\ 8 & -0.192 & 1.068 & 0.069 & 0.000 & 0.061 & 0.00 \\ 9 & -0.153 & 1.070 & 0.068 & 0.000 & 0.061 & 0.00 \\ 10 & -0.115 & 1.073 & 0.067 & 0.000 & 0.062 & 0.00 \\ 11 & -0.077 & 1.076 & 0.066 & 0.002 & 0.064 & 0.11 \\ 12 & -0.038 & 1.078 & 0.066 & 0.004 & 0.065 & 0.21 \\ 13 & 0.000 & 1.077 & 0.066 & 0.005 & 0.066 & 0.27 \\ 14 & 0.038 & 1.079 & 0.066 & 0.007 & 0.066 & 0.37 \\ 15 & 0.077 & 1.076 & 0.067 & 0.005 & 0.065 & 0.27 \\ 16 & 0.115 & 1.073 & 0.067 & 0.006 & 0.063 & 0.32 \\ 17 & 0.153 & 1.073 & 0.067 & 0.009 & 0.062 & 0.48 \\ 18 & 0.192 & 1.070 & 0.070 & 0.010 & 0.058 & 0.54 \\ 19 & 0.230 & 1.065 & 0.071 & 0.009 & 0.056 & 0.48 \\ 20 & 0.268 & 1.058 & 0.074 & 0.010 & 0.053 & 0.54 \\ 21 & 0.307 & 1.054 & 0.077 & 0.017 & 0.052 & 0.92 \\ 22 & 0.345 & 1.037 & 0.080 & 0.013 & 0.051 & 0.72 \\ 23 & 0.383 & 1.020 & 0.084 & 0.012 & 0.050 & 0.67 \\ 24 & 0.421 & 0.984 & 0.088 & 0.011 & 0.049 & 0.64 \\ 25 & 0.460 & 0.919 & 0.096 & -0.002 & 0.049 & -0.12\end{array}$




\section{APPENDIX B}

Mean and Turbulence Velocity Profiles

for Header H342-100/0-1 and a 19-Tube Tube Bundle.

Velocities in the Outlet Pipe \#1

with Outlet \#1 Fully Opened and Outlet \#2 Fully Closed

19-Tube Tube Bundle in Outlet \#1

Tube Bundle Entrance Location, $Z=4.26 \mathrm{D}$

Tube Bundle Exit Location, $Z=6.2 \mathrm{D}$

Water Temperature $=21.5^{\circ} \mathrm{C}$

Water Kinematic Viscosity $=9.71958^{*} 10^{-7} \mathrm{~m}^{2} / \mathrm{s}$

Pipe Diameter, $\mathrm{D}=5.25 \mathrm{~cm}$ (2.07 in)

Reynolds Number $\operatorname{Re}=100000$ 

1) Velocity Profile at $\mathrm{Y}=0, \mathrm{Z}=8.2 \mathrm{D}$, and $\mathrm{C}=2 \mathrm{D}$

I $\quad x / D \quad W / W_{b} \quad W^{\prime} / W_{b} \quad V / W_{b} \quad v^{\prime} / W_{b} \quad \phi$, Deg.

$\begin{array}{rrrrrrr}1 & -0.460 & 1.052 & 0.105 & 0.019 & 0.070 & 1.03 \\ 2 & -0.421 & 1.054 & 0.108 & 0.011 & 0.065 & 0.60 \\ 3 & -0.383 & 1.047 & 0.101 & 0.010 & 0.063 & 0.55 \\ 4 & -0.345 & 1.030 & 0.088 & 0.012 & 0.060 & 0.67 \\ 5 & -0.307 & 1.014 & 0.076 & 0.016 & 0.055 & 0.90 \\ 6 & -0.268 & 1.009 & 0.067 & 0.020 & 0.057 & 1.14 \\ 7 & -0.230 & 1.045 & 0.078 & 0.016 & 0.065 & 0.88 \\ 8 & -0.192 & 1.092 & 0.091 & 0.008 & 0.062 & 0.42 \\ 9 & -0.153 & 1.088 & 0.096 & 0.003 & 0.054 & 0.16 \\ 10 & -0.115 & 1.060 & 0.087 & 0.009 & 0.055 & 0.49 \\ 11 & -0.077 & 1.014 & 0.073 & 0.014 & 0.058 & 0.79 \\ 12 & -0.038 & 1.043 & 0.081 & 0.015 & 0.066 & 0.82 \\ 13 & 0.000 & 1.098 & 0.092 & 0.004 & 0.062 & 0.21 \\ 14 & 0.038 & 1.099 & 0.090 & 0.007 & 0.055 & 0.36 \\ 15 & 0.077 & 1.065 & 0.083 & 0.010 & 0.060 & 0.54 \\ 16 & 0.115 & 1.017 & 0.072 & 0.013 & 0.060 & 0.73 \\ 17 & 0.153 & 1.011 & 0.081 & 0.005 & 0.061 & 0.28 \\ 18 & 0.192 & 1.070 & 0.091 & -0.001 & 0.056 & -0.05 \\ 19 & 0.230 & 1.083 & 0.087 & -0.001 & 0.058 & -0.05 \\ 20 & 0.268 & 1.047 & 0.078 & 0.005 & 0.063 & 0.27 \\ 21 & 0.307 & 1.016 & 0.072 & 0.004 & 0.065 & 0.23 \\ 22 & 0.345 & 1.041 & 0.085 & 0.002 & 0.067 & 0.11 \\ 23 & 0.383 & 1.064 & 0.093 & 0.001 & 0.067 & 0.05 \\ 24 & 0.421 & 1.059 & 0.097 & -0.006 & 0.069 & -0.32 \\ 25 & 0.460 & 1.046 & 0.094 & -0.006 & 0.068 & -0.33\end{array}$




\section{2) Velocity Profile at $\mathrm{X}=0, \mathrm{Z}=8.2 \mathrm{D}$, and $\mathrm{C}=2 \mathrm{D}$}

I $\quad Y / D \quad W / W_{b} \quad W^{1} / W_{b} \quad V / W_{b} \quad v^{\prime} / W_{b} \quad \phi, D e g$.

$\begin{array}{rrrrrrr}1 & -0.460 & 0.966 & 0.100 & 0.001 & 0.066 & 0.06 \\ 2 & -0.421 & 1.016 & 0.095 & 0.001 & 0.063 & 0.06 \\ 3 & -0.383 & 1.026 & 0.083 & 0.004 & 0.060 & 0.22 \\ 4 & -0.345 & 1.011 & 0.074 & 0.006 & 0.056 & 0.34 \\ 5 & -0.307 & 0.975 & 0.066 & 0.006 & 0.051 & 0.35 \\ 6 & -0.268 & 0.962 & 0.062 & 0.008 & 0.046 & 0.48 \\ 7 & -0.230 & 1.001 & 0.067 & 0.009 & 0.055 & 0.52 \\ 8 & -0.192 & 1.027 & 0.078 & 0.007 & 0.058 & 0.39 \\ 9 & -0.153 & 1.021 & 0.082 & 0.010 & 0.052 & 0.56 \\ 10 & -0.115 & 1.009 & 0.070 & 0.014 & 0.056 & 0.79 \\ 11 & -0.077 & 1.028 & 0.073 & 0.006 & 0.059 & 0.33 \\ 12 & -0.038 & 1.067 & 0.081 & 0.011 & 0.062 & 0.59 \\ 13 & 0.000 & 1.093 & 0.089 & 0.018 & 0.062 & 0.94 \\ 14 & 0.038 & 1.075 & 0.086 & 0.012 & 0.058 & 0.64 \\ 15 & 0.077 & 1.025 & 0.079 & 0.011 & 0.052 & 0.61 \\ 16 & 0.115 & 1.005 & 0.073 & 0.012 & 0.057 & 0.68 \\ 17 & 0.153 & 1.043 & 0.082 & 0.014 & 0.055 & 0.77 \\ 18 & 0.192 & 1.069 & 0.087 & 0.015 & 0.051 & 0.80 \\ 19 & 0.230 & 1.033 & 0.081 & 0.008 & 0.059 & 0.44 \\ 20 & 0.268 & 0.992 & 0.073 & 0.007 & 0.058 & 0.40 \\ 21 & 0.307 & 0.978 & 0.066 & 0.003 & 0.056 & 0.18 \\ 22 & 0.345 & 1.008 & 0.077 & -0.002 & 0.057 & -0.11 \\ 23 & 0.383 & 1.032 & 0.087 & -0.005 & 0.060 & -0.28 \\ 24 & 0.421 & 1.022 & 0.093 & -0.004 & 0.060 & -0.22 \\ 25 & 0.460 & 0.961 & 0.093 & -0.002 & 0.060 & -0.12\end{array}$




\section{3) Velocity Profile at $Y=0, Z=12.2 D$, and $C=6 D$}

I $\quad \boldsymbol{X} / \mathrm{D} \quad \mathrm{W} / W_{b} \quad \mathbf{w}^{\prime} / W_{b} \quad V^{\prime} W_{b} \quad v^{\prime} / W_{b} \quad \phi$, Deg.

$\begin{array}{rrrrrrr}1 & -0.460 & 0.979 & 0.071 & 0.012 & 0.061 & 0.70 \\ 2 & -0.421 & 1.009 & 0.064 & 0.012 & 0.052 & 0.68 \\ 3 & -0.383 & 1.027 & 0.058 & 0.009 & 0.043 & 0.50 \\ 4 & -0.345 & 1.016 & 0.052 & 0.011 & 0.037 & 0.62 \\ 5 & -0.307 & 1.018 & 0.047 & 0.008 & 0.031 & 0.45 \\ 6 & -0.268 & 1.035 & 0.044 & 0.007 & 0.030 & 0.39 \\ 7 & -0.230 & 1.058 & 0.041 & 0.004 & 0.029 & 0.22 \\ 8 & -0.192 & 1.076 & 0.039 & 0.001 & 0.029 & 0.05 \\ 9 & -0.153 & 1.077 & 0.038 & 0.002 & 0.028 & 0.11 \\ 10 & -0.115 & 1.074 & 0.037 & 0.001 & 0.027 & 0.05 \\ 11 & -0.077 & 1.073 & 0.035 & 0.001 & 0.026 & 0.05 \\ 12 & -0.038 & 1.074 & 0.036 & 0.002 & 0.026 & 0.11 \\ 13 & 0.000 & 1.073 & 0.035 & -0.002 & 0.026 & -0.11 \\ 14 & 0.038 & 1.073 & 0.036 & 0.000 & 0.027 & 0.00 \\ 15 & 0.077 & 1.072 & 0.037 & 0.000 & 0.027 & 0.00 \\ 16 & 0.115 & 1.068 & 0.037 & -0.001 & 0.026 & -0.05 \\ 17 & 0.153 & 1.067 & 0.038 & -0.001 & 0.028 & -0.05 \\ 18 & 0.192 & 1.066 & 0.039 & 0.002 & 0.028 & 0.11 \\ 19 & 0.230 & 1.067 & 0.040 & 0.002 & 0.029 & 0.11 \\ 20 & 0.268 & 1.064 & 0.041 & -0.004 & 0.029 & -0.22 \\ 21 & 0.307 & 1.061 & 0.044 & -0.001 & 0.032 & -0.05 \\ 22 & 0.345 & 1.053 & 0.049 & -0.002 & 0.033 & -0.11 \\ 23 & 0.383 & 1.041 & 0.056 & -0.003 & 0.041 & -0.17 \\ 24 & 0.421 & 1.018 & 0.069 & -0.003 & 0.050 & -0.17 \\ 25 & 0.460 & 0.994 & 0.080 & -0.005 & 0.063 & -0.29\end{array}$


I $\quad Y / D \quad W / W_{b} \quad W^{\prime} / W_{b} \quad V / W_{b} \quad v^{\prime} / W_{b} \quad \phi$, Deg.

$\begin{array}{rrrrrrr}1 & -0.460 & 0.968 & 0.067 & -0.001 & 0.055 & -0.06 \\ 2 & -0.421 & 1.011 & 0.056 & -0.002 & 0.041 & -0.11 \\ 3 & -0.383 & 1.028 & 0.051 & 0.002 & 0.032 & 0.11 \\ 4 & -0.345 & 1.043 & 0.046 & 0.003 & 0.030 & 0.16 \\ 5 & -0.307 & 1.061 & 0.043 & 0.000 & 0.029 & 0.00 \\ 6 & -0.268 & 1.065 & 0.041 & 0.003 & 0.028 & 0.16 \\ 7 & -0.230 & 1.070 & 0.038 & -0.001 & 0.027 & -0.05 \\ 8 & -0.192 & 1.072 & 0.037 & -0.002 & 0.027 & -0.11 \\ 9 & -0.153 & 1.074 & 0.037 & -0.001 & 0.027 & -0.05 \\ 10 & -0.115 & 1.075 & 0.036 & 0.000 & 0.026 & 0.00 \\ 11 & -0.077 & 1.075 & 0.035 & 0.002 & 0.026 & 0.11 \\ 12 & -0.038 & 1.076 & 0.035 & 0.001 & 0.026 & 0.05 \\ 13 & 0.000 & 1.075 & 0.035 & 0.001 & 0.025 & 0.05 \\ 14 & 0.038 & 1.070 & 0.035 & 0.003 & 0.025 & 0.16 \\ 15 & 0.077 & 1.069 & 0.035 & 0.001 & 0.026 & 0.05 \\ 16 & 0.115 & 1.070 & 0.035 & 0.002 & 0.026 & 0.11 \\ 17 & 0.153 & 1.065 & 0.036 & 0.001 & 0.026 & 0.05 \\ 18 & 0.192 & 1.063 & 0.037 & -0.001 & 0.026 & -0.05 \\ 19 & 0.230 & 1.058 & 0.038 & -0.001 & 0.026 & -0.05 \\ 20 & 0.268 & 1.053 & 0.040 & 0.001 & 0.028 & 0.05 \\ 21 & 0.307 & 1.043 & 0.043 & 0.001 & 0.029 & 0.05 \\ 22 & 0.345 & 1.039 & 0.049 & 0.001 & 0.032 & 0.06 \\ 23 & 0.383 & 1.028 & 0.059 & 0.003 & 0.035 & 0.17 \\ 24 & 0.421 & 0.993 & 0.071 & 0.004 & 0.041 & 0.23 \\ 25 & 0.460 & 0.936 & 0.077 & 0.001 & 0.055 & 0.06\end{array}$


5) Velocity Profile at $Y=0, Z=16.2 D$, and $C=10 D$

$I \quad x / D \quad W / W_{b} \quad W^{\prime} / W_{b} \quad V^{\prime} W_{b} \quad v^{\prime} / W_{b} \quad \phi$, Deg.

$\begin{array}{rrrrrrr}1 & -0.460 & 0.931 & 0.081 & 0.021 & 0.063 & 1.29 \\ 2 & -0.421 & 0.992 & 0.069 & 0.017 & 0.054 & 0.98 \\ 3 & -0.383 & 1.020 & 0.063 & 0.016 & 0.046 & 0.90 \\ 4 & -0.345 & 1.036 & 0.056 & 0.013 & 0.039 & 0.72 \\ 5 & -0.307 & 1.044 & 0.051 & 0.007 & 0.032 & 0.38 \\ 6 & -0.268 & 1.059 & 0.046 & 0.006 & 0.028 & 0.32 \\ 7 & -0.230 & 1.072 & 0.042 & 0.001 & 0.026 & 0.05 \\ 8 & -0.192 & 1.087 & 0.039 & 0.003 & 0.026 & 0.16 \\ 9 & -0.153 & 1.099 & 0.037 & 0.000 & 0.025 & 0.00 \\ 10 & -0.115 & 1.103 & 0.035 & -0.002 & 0.025 & -0.10 \\ 11 & -0.077 & 1.108 & 0.034 & -0.002 & 0.024 & -0.10 \\ 12 & -0.038 & 1.111 & 0.034 & -0.002 & 0.024 & -0.10 \\ 13 & 0.000 & 1.107 & 0.033 & -0.002 & 0.024 & -0.10 \\ 14 & 0.038 & 1.109 & 0.033 & -0.002 & 0.024 & -0.10 \\ 15 & 0.077 & 1.106 & 0.034 & -0.003 & 0.025 & -0.16 \\ 16 & 0.115 & 1.102 & 0.034 & -0.002 & 0.024 & -0.10 \\ 17 & 0.153 & 1.099 & 0.035 & -0.002 & 0.026 & -0.10 \\ 18 & 0.192 & 1.096 & 0.037 & -0.002 & 0.026 & -0.10 \\ 19 & 0.230 & 1.092 & 0.038 & -0.003 & 0.026 & -0.16 \\ 20 & 0.268 & 1.084 & 0.041 & -0.002 & 0.027 & -0.11 \\ 21 & 0.307 & 1.076 & 0.046 & -0.003 & 0.027 & -0.16 \\ 22 & 0.345 & 1.058 & 0.054 & -0.003 & 0.029 & -0.16 \\ 23 & 0.383 & 1.042 & 0.065 & -0.004 & 0.042 & -0.22 \\ 24 & 0.421 & 1.012 & 0.075 & -0.002 & 0.053 & -0.11 \\ 25 & 0.460 & 0.982 & 0.086 & -0.002 & 0.064 & -0.12\end{array}$




\section{6) Velocity Profile at $\mathrm{X}=0, \mathrm{Z}=16.2 \mathrm{D}$, and $\mathrm{C}=10 \mathrm{D}$}

I $\quad Y / D \quad W / W_{b} \quad W^{\prime} / W_{b} \quad V / W_{b} \quad v^{\prime} / W_{b} \quad \phi$, Deg.

$\begin{array}{rrrrrrr}1 & -0.460 & 0.949 & 0.078 & -0.002 & 0.058 & -0.12 \\ 2 & -0.421 & 1.003 & 0.058 & 0.004 & 0.047 & 0.23 \\ 3 & -0.383 & 1.047 & 0.048 & 0.002 & 0.038 & 0.11 \\ 4 & -0.345 & 1.064 & 0.044 & 0.001 & 0.032 & 0.05 \\ 5 & -0.307 & 1.081 & 0.042 & 0.000 & 0.029 & 0.00 \\ 6 & -0.268 & 1.090 & 0.039 & -0.002 & 0.028 & -0.11 \\ 7 & -0.230 & 1.095 & 0.037 & -0.001 & 0.026 & -0.05 \\ 8 & -0.192 & 1.099 & 0.036 & -0.001 & 0.025 & -0.05 \\ 9 & -0.153 & 1.102 & 0.035 & -0.002 & 0.025 & -0.10 \\ 10 & -0.115 & 1.105 & 0.035 & -0.001 & 0.024 & -0.05 \\ 11 & -0.077 & 1.105 & 0.034 & 0.000 & 0.023 & 0.00 \\ 12 & -0.038 & 1.107 & 0.034 & 0.000 & 0.023 & 0.00 \\ 13 & 0.000 & 1.109 & 0.034 & 0.000 & 0.023 & 0.00 \\ 14 & 0.038 & 1.109 & 0.034 & 0.000 & 0.023 & 0.00 \\ 15 & 0.077 & 1.103 & 0.034 & -0.001 & 0.023 & -0.05 \\ 16 & 0.115 & 1.103 & 0.035 & -0.002 & 0.023 & -0.10 \\ 17 & 0.153 & 1.094 & 0.036 & -0.003 & 0.024 & -0.16 \\ 18 & 0.192 & 1.086 & 0.036 & -0.003 & 0.025 & -0.16 \\ 19 & 0.230 & 1.080 & 0.037 & 0.001 & 0.025 & 0.05 \\ 20 & 0.268 & 1.074 & 0.039 & -0.003 & 0.027 & -0.16 \\ 21 & 0.307 & 1.062 & 0.045 & 0.000 & 0.028 & 0.00 \\ 22 & 0.345 & 1.043 & 0.049 & 0.003 & 0.033 & 0.16 \\ 23 & 0.383 & 1.018 & 0.059 & 0.001 & 0.039 & 0.06 \\ 24 & 0.421 & 0.981 & 0.069 & 0.002 & 0.046 & 0.12 \\ 25 & 0.460 & 0.922 & 0.083 & -0.001 & 0.056 & -0.06\end{array}$


7) Velocity Profile at $Y=0, Z=19.7 D$, and $C=13.5 \mathrm{D}$

I $\quad x / D \quad W / W_{b} \quad W^{\prime} / W_{b} \quad V / W_{b} \quad v^{\prime} / W_{b} \quad \phi$, Deg.

$\begin{array}{rrrrrrr}1 & -0.460 & 0.904 & 0.083 & 0.014 & 0.067 & 0.89 \\ 2 & -0.421 & 0.966 & 0.074 & 0.013 & 0.057 & 0.77 \\ 3 & -0.383 & 1.004 & 0.067 & 0.011 & 0.052 & 0.63 \\ 4 & -0.345 & 1.044 & 0.062 & 0.008 & 0.046 & 0.44 \\ 5 & -0.307 & 1.054 & 0.056 & 0.009 & 0.038 & 0.49 \\ 6 & -0.268 & 1.072 & 0.052 & 0.008 & 0.034 & 0.43 \\ 7 & -0.230 & 1.081 & 0.048 & 0.007 & 0.030 & 0.37 \\ 8 & -0.192 & 1.096 & 0.043 & 0.007 & 0.028 & 0.37 \\ 9 & -0.153 & 1.107 & 0.039 & 0.005 & 0.027 & 0.26 \\ 10 & -0.115 & 1.115 & 0.036 & 0.004 & 0.026 & 0.21 \\ 11 & -0.077 & 1.125 & 0.035 & 0.002 & 0.025 & 0.10 \\ 12 & -0.038 & 1.133 & 0.034 & 0.001 & 0.025 & 0.05 \\ 13 & 0.000 & 1.134 & 0.033 & 0.001 & 0.024 & 0.05 \\ 14 & 0.038 & 1.132 & 0.033 & 0.002 & 0.024 & 0.10 \\ 15 & 0.077 & 1.132 & 0.034 & -0.001 & 0.024 & -0.05 \\ 16 & 0.115 & 1.129 & 0.035 & 0.002 & 0.024 & 0.10 \\ 17 & 0.153 & 1.127 & 0.036 & 0.001 & 0.024 & 0.05 \\ 18 & 0.192 & 1.123 & 0.037 & 0.000 & 0.024 & 0.00 \\ 19 & 0.230 & 1.118 & 0.039 & 0.001 & 0.026 & 0.05 \\ 20 & 0.268 & 1.105 & 0.043 & -0.001 & 0.027 & -0.05 \\ 21 & 0.307 & 1.092 & 0.050 & -0.001 & 0.028 & -0.05 \\ 22 & 0.345 & 1.072 & 0.059 & -0.002 & 0.031 & -0.11 \\ 23 & 0.383 & 1.031 & 0.071 & -0.002 & 0.045 & -0.11 \\ 24 & 0.421 & 0.981 & 0.080 & 0.000 & 0.056 & 0.00 \\ 25 & 0.460 & 0.911 & 0.089 & -0.003 & 0.067 & -0.19\end{array}$


8) Velocity Profile at $\mathrm{X}=0, \mathrm{Z}=19.7 \mathrm{D}$, and $\mathrm{C}=13.5 \mathrm{D}$

I $\quad Y / D \quad W / W_{b} \quad W^{\prime} / W_{b} \quad V / W_{b} \quad v^{\prime} / W_{b} \quad \phi$, Deg.

$\begin{array}{rrrrrrr}1 & -0.460 & 0.925 & 0.084 & 0.000 & 0.052 & 0.00 \\ 2 & -0.421 & 0.971 & 0.067 & -0.004 & 0.048 & -0.24 \\ 3 & -0.383 & 1.015 & 0.060 & -0.001 & 0.044 & -0.06 \\ 4 & -0.345 & 1.049 & 0.054 & 0.000 & 0.039 & 0.00 \\ 5 & -0.307 & 1.073 & 0.045 & 0.002 & 0.034 & 0.11 \\ 6 & -0.268 & 1.096 & 0.042 & 0.004 & 0.031 & 0.21 \\ 7 & -0.230 & 1.112 & 0.039 & 0.005 & 0.029 & 0.26 \\ 8 & -0.192 & 1.121 & 0.036 & 0.004 & 0.029 & 0.20 \\ 9 & -0.153 & 1.128 & 0.034 & 0.003 & 0.028 & 0.15 \\ 10 & -0.115 & 1.132 & 0.034 & 0.002 & 0.028 & 0.10 \\ 11 & -0.077 & 1.135 & 0.034 & 0.004 & 0.027 & 0.20 \\ 12 & -0.038 & 1.134 & 0.033 & 0.005 & 0.026 & 0.25 \\ 13 & 0.000 & 1.136 & 0.033 & 0.004 & 0.026 & 0.20 \\ 14 & 0.038 & 1.135 & 0.033 & 0.002 & 0.027 & 0.10 \\ 15 & 0.077 & 1.135 & 0.033 & 0.002 & 0.027 & 0.10 \\ 16 & 0.115 & 1.130 & 0.032 & 0.005 & 0.027 & 0.25 \\ 17 & 0.153 & 1.128 & 0.033 & 0.006 & 0.027 & 0.30 \\ 18 & 0.192 & 1.122 & 0.032 & 0.004 & 0.028 & 0.20 \\ 19 & 0.230 & 1.114 & 0.034 & 0.004 & 0.029 & 0.21 \\ 20 & 0.268 & 1.107 & 0.037 & 0.004 & 0.030 & 0.21 \\ 21 & 0.307 & 1.091 & 0.047 & 0.005 & 0.032 & 0.26 \\ 22 & 0.345 & 1.064 & 0.057 & 0.005 & 0.036 & 0.27 \\ 23 & 0.383 & 1.012 & 0.067 & 0.004 & 0.043 & 0.23 \\ 24 & 0.421 & 0.972 & 0.076 & -0.001 & 0.050 & -0.06 \\ 25 & 0.460 & 0.907 & 0.086 & -0.002 & 0.054 & -0.13\end{array}$


9) Velocity Profile at $Y=0, Z=23.7 D$, and $C=17.5 \mathrm{D}$

$I \quad x / D \quad W / W_{b} \quad W^{\prime} / W_{b} \quad V / W_{b} \quad v^{\prime} / W_{b} \quad \phi$, Deg.

$\begin{array}{lllllll}1 & -0.460 & 0.888 & 0.086 & 0.010 & 0.069 & 0.65\end{array}$

$\begin{array}{lllllll}2 & -0.421 & 0.955 & 0.079 & 0.014 & 0.060 & 0.84\end{array}$

$\begin{array}{lllllll}3 & -0.383 & 1.001 & 0.071 & 0.013 & 0.054 & 0.74\end{array}$

$\begin{array}{llllllll}4 & -0.345 & 1.027 & 0.067 & 0.011 & 0.048 & 0.61\end{array}$

$\begin{array}{lllllll}5 & -0.307 & 1.056 & 0.062 & 0.009 & 0.044 & 0.49\end{array}$

$\begin{array}{lllllll}6 & -0.268 & 1.076 & 0.057 & 0.008 & 0.040 & 0.43\end{array}$

$\begin{array}{lllllll}7 & -0.230 & 1.096 & 0.053 & 0.008 & 0.036 & 0.42\end{array}$

$\begin{array}{lllllll}8 & -0.192 & 1.108 & 0.049 & 0.008 & 0.032 & 0.41\end{array}$

$\begin{array}{llllllll}9 & -0.153 & 1.127 & 0.043 & 0.007 & 0.029 & 0.36\end{array}$

$\begin{array}{llllllll}10 & -0.115 & 1.137 & 0.038 & 0.007 & 0.027 & 0.35\end{array}$

$\begin{array}{lllllll}11 & -0.077 & 1.153 & 0.036 & 0.005 & 0.026 & 0.25\end{array}$

$\begin{array}{lllllll}12 & -0.038 & 1.163 & 0.035 & 0.002 & 0.025 & 0.10\end{array}$

$\begin{array}{lllllll}13 & 0.000 & 1.167 & 0.035 & 0.001 & 0.025 & 0.05\end{array}$

$\begin{array}{lllllll}14 & 0.038 & 1.168 & 0.035 & 0.001 & 0.025 & 0.05\end{array}$

$\begin{array}{llllllll}15 & 0.077 & 1.168 & 0.036 & 0.001 & 0.025 & 0.05\end{array}$

$\begin{array}{llllllll}16 & 0.115 & 1.159 & 0.037 & -0.001 & 0.025 & -0.05\end{array}$

$\begin{array}{llllllll}17 & 0.153 & 1.156 & 0.039 & 0.001 & 0.024 & 0.05\end{array}$

$\begin{array}{lllllll}18 & 0.192 & 1.144 & 0.042 & 0.002 & 0.026 & 0.10\end{array}$

$\begin{array}{lllllll}19 & 0.230 & 1.131 & 0.045 & 0.003 & 0.026 & 0.15\end{array}$

$\begin{array}{llllllll}20 & 0.268 & 1.116 & 0.048 & 0.002 & 0.027 & 0.10\end{array}$

$\begin{array}{llllllll}21 & 0.307 & 1.099 & 0.055 & 0.002 & 0.027 & 0.10\end{array}$

$\begin{array}{llllllll}22 & 0.345 & 1.071 & 0.064 & 0.002 & 0.034 & 0.11\end{array}$

$\begin{array}{llllllll}23 & 0.383 & 1.040 & 0.075 & 0.003 & 0.045 & 0.17\end{array}$

$\begin{array}{llllllll}24 & 0.421 & 0.993 & 0.082 & -0.001 & 0.058 & -0.06\end{array}$

$\begin{array}{lllllll}25 & 0.460 & 0.882 & 0.091 & -0.002 & 0.065 & -0.13\end{array}$ 
10) Velocity Profile at $X=0, Z=23.7 D$, and $C=17.5 D$

I $\quad Y / D \quad W / W_{b} \quad W^{\prime} / W_{b} \quad V_{/} W_{b} \quad V^{\prime} / W_{b} \quad \phi, D e g$.

$\begin{array}{rrrrrrr}1 & -0.460 & 0.865 & 0.087 & 0.003 & 0.049 & 0.20 \\ 2 & -0.421 & 0.943 & 0.074 & 0.004 & 0.049 & 0.24 \\ 3 & -0.383 & 0.991 & 0.066 & 0.004 & 0.046 & 0.23 \\ 4 & -0.345 & 1.031 & 0.058 & 0.003 & 0.043 & 0.17 \\ 5 & -0.307 & 1.065 & 0.050 & 0.004 & 0.038 & 0.22 \\ 6 & -0.268 & 1.094 & 0.046 & 0.003 & 0.033 & 0.16 \\ 7 & -0.230 & 1.118 & 0.041 & 0.001 & 0.032 & 0.05 \\ 8 & -0.192 & 1.134 & 0.036 & 0.002 & 0.030 & 0.10 \\ 9 & -0.153 & 1.150 & 0.035 & 0.002 & 0.029 & 0.10 \\ 10 & -0.115 & 1.154 & 0.034 & 0.002 & 0.029 & 0.10 \\ 11 & -0.077 & 1.161 & 0.034 & 0.003 & 0.028 & 0.15 \\ 12 & -0.038 & 1.164 & 0.033 & 0.002 & 0.027 & 0.10 \\ 13 & 0.000 & 1.165 & 0.034 & 0.003 & 0.026 & 0.15 \\ 14 & 0.038 & 1.167 & 0.034 & 0.003 & 0.026 & 0.15 \\ 15 & 0.077 & 1.164 & 0.034 & 0.004 & 0.025 & 0.20 \\ 16 & 0.115 & 1.160 & 0.034 & 0.005 & 0.026 & 0.25 \\ 17 & 0.153 & 1.154 & 0.034 & 0.005 & 0.026 & 0.25 \\ 18 & 0.192 & 1.144 & 0.036 & 0.006 & 0.027 & 0.30 \\ 19 & 0.230 & 1.130 & 0.038 & 0.005 & 0.028 & 0.25 \\ 20 & 0.268 & 1.113 & 0.045 & 0.005 & 0.031 & 0.26 \\ 21 & 0.307 & 1.079 & 0.054 & 0.005 & 0.036 & 0.27 \\ 22 & 0.345 & 1.041 & 0.062 & 0.005 & 0.042 & 0.28 \\ 23 & 0.383 & 1.005 & 0.071 & 0.005 & 0.047 & 0.29 \\ 24 & 0.421 & 0.965 & 0.078 & 0.002 & 0.051 & 0.12 \\ 25 & 0.460 & 0.891 & 0.087 & -0.002 & 0.052 & -0.13\end{array}$




\section{1) Velocity Profile at $Y=0, Z=28.2 D$, and $C=22 D$}

I $\quad \boldsymbol{X} / \mathrm{D} \quad W / W_{b} \quad W^{\prime} / W_{b} \quad V / W_{b} \quad W^{\prime} / W_{b} \quad \phi$, Deg.

$\begin{array}{rrrrrrr}1 & -0.460 & 0.878 & 0.090 & 0.014 & 0.065 & 0.91 \\ 2 & -0.421 & 0.943 & 0.081 & 0.014 & 0.061 & 0.85 \\ 3 & -0.383 & 0.996 & 0.075 & 0.011 & 0.056 & 0.63 \\ 4 & -0.345 & 1.032 & 0.070 & 0.008 & 0.052 & 0.44 \\ 5 & -0.307 & 1.064 & 0.064 & 0.003 & 0.048 & 0.16 \\ 6 & -0.268 & 1.087 & 0.060 & 0.005 & 0.045 & 0.26 \\ 7 & -0.230 & 1.104 & 0.055 & 0.003 & 0.042 & 0.16 \\ 8 & -0.192 & 1.119 & 0.052 & 0.005 & 0.038 & 0.26 \\ 9 & -0.153 & 1.137 & 0.047 & 0.004 & 0.033 & 0.20 \\ 10 & -0.115 & 1.157 & 0.042 & 0.003 & 0.029 & 0.15 \\ 11 & -0.077 & 1.168 & 0.038 & 0.003 & 0.027 & 0.15 \\ 12 & -0.038 & 1.182 & 0.036 & 0.000 & 0.026 & 0.00 \\ 13 & 0.000 & 1.189 & 0.036 & 0.000 & 0.025 & 0.00 \\ 14 & 0.038 & 1.193 & 0.036 & -0.002 & 0.025 & -0.10 \\ 15 & 0.077 & 1.192 & 0.037 & -0.001 & 0.026 & -0.05 \\ 16 & 0.115 & 1.190 & 0.038 & -0.001 & 0.025 & -0.05 \\ 17 & 0.153 & 1.184 & 0.041 & -0.002 & 0.026 & -0.10 \\ 18 & 0.192 & 1.163 & 0.044 & 0.000 & 0.027 & 0.00 \\ 19 & 0.230 & 1.144 & 0.048 & -0.001 & 0.029 & -0.05 \\ 20 & 0.268 & 1.124 & 0.054 & 0.001 & 0.033 & 0.05 \\ 21 & 0.307 & 1.093 & 0.060 & 0.003 & 0.038 & 0.16 \\ 22 & 0.345 & 1.065 & 0.069 & -0.001 & 0.046 & -0.05 \\ 23 & 0.383 & 1.033 & 0.076 & -0.001 & 0.054 & -0.06 \\ 24 & 0.421 & 0.972 & 0.082 & -0.003 & 0.061 & -0.18 \\ 25 & 0.460 & 0.886 & 0.090 & 0.000 & 0.065 & 0.00\end{array}$


I $\quad Y / D \quad W / W_{b} \quad W^{\prime} / W_{b} \quad V / W_{b} \quad v^{\prime} / W_{b} \quad \phi, D e g$.

$\begin{array}{rrrrrrr}1 & -0.460 & 0.853 & 0.089 & -0.001 & 0.050 & -0.07 \\ 2 & -0.421 & 0.939 & 0.080 & -0.001 & 0.051 & -0.06 \\ 3 & -0.383 & 0.989 & 0.073 & 0.004 & 0.048 & 0.23 \\ 4 & -0.345 & 1.031 & 0.067 & 0.004 & 0.045 & 0.22 \\ 5 & -0.307 & 1.066 & 0.062 & 0.003 & 0.042 & 0.16 \\ 6 & -0.268 & 1.097 & 0.057 & 0.004 & 0.038 & 0.21 \\ 7 & -0.230 & 1.123 & 0.051 & 0.002 & 0.034 & 0.10 \\ 8 & -0.192 & 1.142 & 0.046 & 0.001 & 0.033 & 0.05 \\ 9 & -0.153 & 1.161 & 0.041 & 0.000 & 0.032 & 0.00 \\ 10 & -0.115 & 1.170 & 0.039 & 0.002 & 0.030 & 0.10 \\ 11 & -0.077 & 1.176 & 0.038 & 0.003 & 0.029 & 0.15 \\ 12 & -0.038 & 1.181 & 0.036 & 0.002 & 0.028 & 0.10 \\ 13 & 0.000 & 1.183 & 0.036 & 0.004 & 0.027 & 0.19 \\ 14 & 0.038 & 1.185 & 0.037 & 0.005 & 0.027 & 0.24 \\ 15 & 0.077 & 1.184 & 0.037 & 0.004 & 0.026 & 0.19 \\ 16 & 0.115 & 1.178 & 0.038 & 0.004 & 0.027 & 0.19 \\ 17 & 0.153 & 1.166 & 0.039 & 0.004 & 0.028 & 0.20 \\ 18 & 0.192 & 1.151 & 0.043 & 0.002 & 0.031 & 0.10 \\ 19 & 0.230 & 1.126 & 0.048 & 0.002 & 0.034 & 0.10 \\ 20 & 0.268 & 1.101 & 0.056 & 0.003 & 0.036 & 0.16 \\ 21 & 0.307 & 1.069 & 0.063 & 0.002 & 0.040 & 0.11 \\ 22 & 0.345 & 1.041 & 0.068 & 0.003 & 0.044 & 0.17 \\ 23 & 0.383 & 1.001 & 0.075 & 0.003 & 0.049 & 0.17 \\ 24 & 0.421 & 0.962 & 0.081 & 0.003 & 0.050 & 0.18 \\ 25 & 0.460 & 0.871 & 0.089 & 0.001 & 0.050 & 0.07\end{array}$






\section{Technical Publications}

\section{Periodical}

Journal of Research of the National Institute of Standards and Technology-Reports NIST research and development in those disciplines of the physical and engineering sciences in which the Institute is active. These include physics, chemistry, engineering, mathematics, and computer sciences. Papers cover a broad range of subjects, with major emphasis on measurement methodology and the basic technology underlying standardization. Also included from time to time are survey articles on topics closely related to the Institute's technical and scientific programs. Issued six times a year.

\section{Nonperiodicals}

Monographs-Major contributions to the technical literature on various subjects related to the Institute's scientific and technical activities.

Handbooks-Recommended codes of engineering and industrial practice (including safety codes) developed in cooperation with interested industries, professional organizations, and regulatory bodies.

Special Publications-Include proceedings of conferences sponsored by NIST, NIST annual reports, and other special publications appropriate to this grouping such as wall charts, pocket cards, and bibliographies.

National Standard Reference Data Series_-Provides quantitative data on the physical and chemical properties of materials, compiled from the world's literature and critically evaluated. Developed under a worldwide program coordinated by NIST under the authority of the National Standard Data Act (Public Law 90-396). NOTE: The Journal of Physical and Chemical Reference Data (JPCRD) is published bi-monthly for NIST by the American Chemical Society (ACS) and the American Institute of Physics (AIP). Subscriptions, reprints, and supplements are available from ACS, 1155 Sixteenth St., NW, Washington, DC 20056.

Building Science Series-Disseminates technical information developed at the Institute on building materials, components, systems, and whole structures. The series presents research results, test methods, and performance criteria related to the structural and environmental functions and the durability and safety characteristics of building elements and systems.

Technical Notes-Studies or reports which are complete in themselves but restrictive in their treatment of a subject. Analogous to monographs but not so comprehensive in scope or definitive in treatment of the subject area. Often serve as a vehicle for final reports of work performed at NIST under the sponsorship of other government agencies.

Voluntary Product Standards-Developed under procedures published by the Department of Commerce in Part 10, Title 15, of the Code of Federal Regulations. The standards establish nationally recognized requirements for products, and provide all concerned interests with a basis for common understanding of the characteristics of the products. NIST administers this program in support of the efforts of private-sector standardizing organizations.

Order the following NIST publications_FIPS and NISTIRs-from the National Technical Information Service, Springfield, VA 22161.

Federal Information Processing Standards Publications (FIPS PUB)-Publications in this series collectively constitute the Federal Information Processing Standards Register. The Register serves as the official source of information in the Federal Government regarding standards issued by NIST pursuant to the Federal Property and Administrative Services Act of 1949 as amended, Public Law 89-306 (79 Stat. 1127), and as implemented by Executive Order 11717 (38 FR 12315, dated May 11, 1973) and Part 6 of Title 15 CFR (Code of Federal Regulations).

NIST Interagency Reports (NISTIR)-A special series of interim or final reports on work performed by NIST for outside sponsors (both government and nongovernment). In general, initial distribution is handled by the sponsor; public distribution is by the National Technical Information Service, Springfield, VA 22161, in paper copy or microfiche form. 


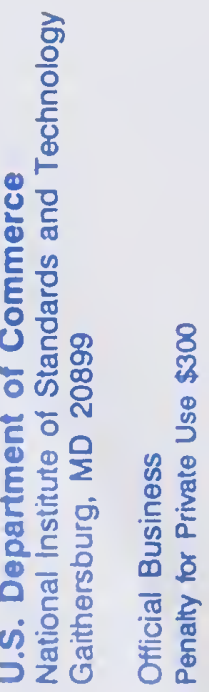

